\title{
Do Lawyers Improve the Adversary System? A General Theory of Litigation Advice and Its Regulation
}

\author{
Stephen McG. Bundy \\ Einer Richard Elhauge
}

I. The Basic Account of How Parties and Lawyers Influence the Information Reaching Tribunals in an Adversary System .................................. 320

A. The Parties, the Tribunal, and the Litigation Process .. 320

B. Party Access to Information and the Role of Evidentiary Sanctions...................... 323

C. Decisionmaking About Investigation, Presentation, and Influencing Evidentiary Sanctions ............... 326

D. Accountimg for the Contribution of Lawyers ....... 332

E. Distributions of Access, Error, and Information ...... 335

II. The Basic Account of the Informational Effects of Litigation Advice ............................ 335

A. Legal Advice That Helps Parties Categorize Information ............................... 337

B. Legal Advice That Alters Investigation ........... 343

C. The Effects of Legal Advice on Effective Evidentiary Sanctions ................................... 348

D. Summary of the Basic Account ............... 357

III. The Generality of the Basic Account Conclusions ......... 361

A. Cost-Related Factors ....................... 362

B. Different Motivations ....................... 366

C. Information That Influences Tribunals in an Undesirable Way ......................... 370

D. Skewed Distributions of Information, Access, or Error ................................. 372

E. Conclusion ............................. 379

IV. The Social Desirability of the Informational Effects of Litigation Advice ............................ 380

A. Deterrence Theories ......................... 380

B. Nondeterrence Theories....................... 392 
C. Conclusion ............................... 395

V. Regulating the Provision of Litigation Advice ........... 396

A. Measures That Encourage or Discourage the Use of Lawyers ................................... 396

B. Attorney-Chient Confidentiality................. 401

C. Restrictions on Advice About Responding to Investigation ................................. 413

Conclusion .................................... 419 


\title{
Do Lawyers Improve the Adversary System? A General Theory of Litigation Advice and Its Regulation
}

\author{
Stephen McG. Bundy $\dagger$ \\ Einer Richard Elhauge
}

This Article presents a rational actor account of how litigation advice influences the information that reaches the tribunal in an adversary system. The authors conclude that although advice has some disturbing or ambiguous informational effects, on balance providing advice to one or both parties will generally improve the capacity of tribunals to determine who should be sanctioned and who should not. They also identify conditions under which advice is likely to be socially undesirable. The authors apply their account to analyze a range of policy issues, including whether to award fees to private attorneys general, whether to guarantee representation to criminal defendants under the sixth amendment, and whether the due process clause should require access to counsel for claimants in government beneflts cases. They also analyze various doctrines of attorney-client confidentiality and rules restricting access to advice about responding to investigations or other questioning.

The lawyer's role in the adversary systein frequently calls for conduct that appears to thwart truthful or just outcoines. Acting as an advisor, the lawyer certainly may, and arguably inust, provide her chents with coinplete and accurate advice, even when she reasonably believes that doing so will cause thein to withhold or suppress evidence. ${ }^{1}$ In

$\dagger$ Acting Professor of Law, Boalt Hall School of Law, University of California, Berkeley. A.B. 1973, Harvard College; J.D. 1978, Boalt Hall School of Law, University of California, Berkeley.

$\ddagger$ Acting Professor of Law, Boalt Hall School of Law, University of California, Berkeley. A.B. 1982, Harvard College; J.D. 1986, Harvard Law School.

We wish to express our gratitude for the generous support of the Boalt Hall Fund and for the helpful comments of McGeorge Bundy, Evan Caminker, James Crawford, William Fletcher, Kenneth Graham, Henry Hecht, Ton Jorde, Louis Kaplow, Lewis Kornhauser, John Leubsdorf, Paul Mishkin, Bob Mnookin, Rachel Moran, Andrea Peterson, Robert Post, Dan Rubinfeld, Steven Shavell, Jan Vetter, and participants in seninars at Boalt Hall School of Law, Harvard Law School, Stanford Law School, and the University of Virginia School of Law.

1. The initial discussion draft of the Model Rules would have forbidden lawyers from giving advice that "the lawyer can reasonably foresee will . . . be used by the client to further an illegal 
litigation, tlie lawyer's obligations of zeal ${ }^{2}$ and confidentiality ${ }^{3}$ require or permit her to engage in a host of dubious activities: withholding evidence, even when the resulting record is radically incoinplete; ${ }^{4}$ presenting documents or testimony that she believes, based on information unavailable to the tribunal, to be false; ${ }^{5}$ discrediting througl cross-examination witnesses she knows to be truthful; ${ }^{6}$ and arguing for inferences from the evidence that she knows are unwarranted. ${ }^{7}$

Questions about the social desirability and moral standing of this troubling role have long divided those who think and write about adjudication and lawyers. Defenders argue that lawyer-aided adversary factfinding is inore likely than the alternatives to produce an accurate decision because it leads to a better evidentiary record. Delegation to the parties and their lawyers harnesses their competing interests (and the lawyers' skill) in the service of the tribunal's interest in receiving a complete account of the dispute. ${ }^{8}$ Coinpetition between lawyers is also said

course of conduct." MODEl Rules of Professional Conduct Rule 2.3 (Discussion Draft, January 30, 1980). Later versions dropped this language in favor of a prohibition against offering knowing counsel or assistance in a crime or fraud in Model Rule 1.2. MODEL RuLes of Professional Conduct Rule 1.2 (1989) [hereinafter Model Rules]. The comment to Model Rule 1.2 states that a "lawyer is required to give an honest opinion about the actual consequences that appear likely to result from a client's conduct," and that "[t] $]$ he fact that a client uses advice in a course of action that is criminal or fraudulent does not, of itself, inake a lawyer a party to the course of action." Id. Rule 1.2 cominent. The strong, though not inevitable, inference is that a lawyer is not free to withhold advice simply on the ground that it inay lead to wrongdoing.

2. See MOdel CODE of Professional RESPONSIBILITY EC 7-1 (1980) [hereinafter MODEL CODE] ("The duty of a lawyer, botli to his client and to the legal system, is to represent his client zealously within the bounds of the law, which includes Disciplinary Rules and enforceable professional regulations ... ."); MODEL Rules, supra note 1, Rule 1.3 comnient (a lawyer "may take whatever lawful and ethical means are required to vindicate a client's cause or endeavor" and "should act witlı commitment and dedication to the interests of the client and with zeal in advocacy upon the client's behalf").

3. Model CODE, supra note 2, DR 4-101; MODEL Rules, supra note 1, Rule 1.6.

4. See C. Wolfram, Modern Legal ETHICs 639-40, 640 n.31 (1986) (citing cases).

5. See MODEL CODE, supra note 2, DR 7-102(A)(4) (attorney only barred from presenting evidence known to be false); C. WolfraM, supra note 4 , at 656 . The Model Rules contain a provision that allows, but does not require, a lawyer to refuse to present evidence that would be persuasive to the tribunal but that she reasonably believes is false. MODEL RULES, supra note 1, Rule 3.3(c). The Model Code has no comparable provision. Moreover, a crininal defense lawyer may fail to provide the effeetive representation constitutionally required if she refuses to present exculpatory evidence that she behieves but does not "know" beyond a reasonable doubt to be false. Cf. Johns v. Sinyth, 176 F. Supp. 949, 953 (E.D. Va. 1959) (holding that a prisoner's due process rights were violated when his attorney refused to argue for acquittal based on a client statement he behieved to be false). Furthermore, where the evidence consists of the client's testimony, a rule giving criminal defense counsel discretion not to present evidence inight well violate the client's fiftl amendment right to testify. To our knowledge, no court has yet adjudicated the constitutionality of Model Rule 3.3 in criminal eases.

6. See United States v. Wade, 388 U.S. 218, $257-58$ (1967) (White, J., concurring in part and dissenting in part); see also C. Wolfram, supra note 4, at 650-51 (quoting Wade).

7. See generally Subin, The Criminal Defense Lawyer's "Different Mission": Reflections on the "Right" to Present a False Case, 1 Geo. J. Legal ETHICs 125 (1987).

8. See G. Hazard, JR., Ethics in the Practice of Law 121 (1978); Luban, The 
to improve the quality of information presented. Because each lawyer will vigorously attack unrehiable information that the opposing counsel presents, such information will either be withheld or promptly discredited. In this account, confidentiality is the handmaiden of effective factdevelopment: if the law instead compelled lawyers to disclose the results of their investigations, it would weaken the incentive to investigate. ${ }^{9}$

Critics of adversary advocacy contend that lawyers make no contribution to truth. ${ }^{10}$ They point to the lack of hard evidence that competition between legally advised partisans improves outcomes. ${ }^{11}$ They also sharply question the underlying logic of the defenders' position. Given the lawyer's freedom or obligation to make partial and even affirmatively misleading evidentiary presentations, critics argue, why should we beheve competition has an inherent tendency to enlighten the tribunal? Competitive presentations "inay simply pile up ... confusion."12 And when one party has superior access to advice, delegation to private imitiative seems more likely to skew the quest for truth than to further it. ${ }^{13}$

The emerging hiterature that applies the methods of economics to the study of adversary adjudication echoes the traditional debate. Some economic accounts assume that improved legal efforts enhance a party's chances of victory and increase the amount of information reaching tribunals. ${ }^{14}$ Lawyers enable parties to, among other things, investigate, organize, and present information in digestible form, and expose maccuracies in the opponent's information. ${ }^{15}$ The lawyer's zeal ensures that motivation is high, and competition from the opposing counsel checks potential excesses and ensures that each party's increased effort enhances

Adversary System Excuse, in THE Good LAWYER 83, 94 (D. Luban ed. 1984); Saltzburg, Lawyers, Clients, and the Adversary System, 37 Mercer L. REv. 647, 656 (1986); cf. Fuller, The Adversary System, in TALKS ON AMERICAN LAW 30, 31 (H. Berman ed. 1961) (discussing the importance of "partisan zeal" in achieving a fair outcoine).

9. See, e.g., M. FreEdman, LAwYERS' Ethics IN AN AdVERSARY System 27, 30 (1975).

10. See J. Frank, Courts on Trial (1947) (adversary system retards discovery of truth); $M$. Frankel, Partisan Justice (1980) (same); Pound, The Causes of Popular Dissatisfaction With the Administration of Justice, 29 ABA REPORTS 395, 404-06 (1906) (decrying "the sporting theory of justice").

11. See Hazard, Rules of Ethics: The Drafting Task, 36 ReC. A.B. CITY N.Y. 77, 93 (1981); see also D. Luban, LAwYers aNd Justice: AN ETHICAl Study 74 n.14 (1988) (citing Hazard); Rhode, Ethical Perspectives on Legal Practice, 37 Stan. L. Rev. 589, 596 (1985) (same).

12. See Luban, supra note 8, at 94; accord M. FRANKEL, supra note 10, at 16; Simon, Ethical Discretion in Lawyering, 101 HARV. L. REV. 1083, 1140 (1988).

13. A classic statement of this view is contained in J. FRANK, supra note 10, at 93-99; see also M. FRANKEL, supra note 10, at 19 (noting economic constraints on parties' ability to hitigate); Simon, The Ideology of Advocacy: Procedural Justice and Professional Ethies, 1978 WIs. L. REv. 29, 49-50 (discussing differential access to legal services).

14. See generally Cooter \& Rubinfeld, Economic Analysis of Legal Disputes and Their Resolution, 27 J. ECON. LITERATURE 1067, 1071-75, 1087 (1989) (reviewing literature).

15. R. POSNER, ECONOMIC ANALYSIS OF LAW § 19.1, at 492 (3d ed. 1986). 
rather than impairs the accuracy of adjudication. ${ }^{16}$

Other economic accounts of legal advice tend to support the critical perspective. One leading recent account analyzes advice on the assumption that each party has exclusive access to its own information and that the sole function of lawyers is to assist parties in selecting which information to present. ${ }^{17}$ Based on those assuinptions, the account reasons that legal advice has no tendency to increase the amount of information reaching the tribunal, and that its only effect is to skew the mix of information presented in favor of the party receiving advice. ${ }^{18}$ Not surprisingly, the account concludes that higation advice has an anbiguous effect both on the accuracy of adjudication ${ }^{19}$ and on the behavior of persons who decide how to act based on adjudicated outcomes, ${ }^{20}$ and therefore has "questionable social value." 1

We share with prior scholars the belief that rational actor analysis can lielp illuminate the lawyer's role in an adversary systein. But we believe that prior rational actor accounts have been partial and simplistic. Our aim is to provide a comprehensive and accurate exainination, within a rational actor framework, of tlie considerations that determine the informational effects and social value of litigation advice. Our account suggests that defenders of hitigation advice give insufficient attention to its undeniable dubious or adverse consequences. Specifically, providing advice to a previously unrepresented party may increase his capacity to withhold and suppress information, to inflict costs on his opponent, and to present false or prejudicial information. Moreover, competitive presentation does not invariably prevent or correct inaccuracy, especially where one party lias more access to legal advice or can control or suppress more information. Defenders ignore or nininize these effects by stressing cases in whicli both parties liave similar access to advice and to information.

Critics are, however, too quick to dismiss several general effects of advice that increase the amount of information reacling the tribunal. Advice enhances conipetition in the presentation of information available to both parties, and it enables parties to sort relevant from irrelevant information. By improving investigation, it increases the aniount of information identified and presented. And it introduces into the process a second actor, the lawyer, whose personal susceptibility to sanctions for misconduct in withholding or suppressing information will sonetines

16. See id.

17. See Kaplow \& Shavell, Legal Advice About Information to Present in Litigation: Its Effects and Social Desirability, 102 HARV. L. REv. 565, 568, 571-75 (1989).

18. Id. at $568,577,581,595$.

19. Id. at $569,581,603$.

20. Id. at $568,586,596,614$.

21. Id. at 597,614 . 
cause the tribunal to receive information that an unadvised party would have withheld or suppressed. Critics avoid these positive aspects of advice by stressing cases in which there is little commonly available information, access to advice or to information is unbalanced, or lawyers are insensitive to sanctions.

We develop our account of legal advice in several stages. Part I presents our basic account of low parties in an adversary system influence the information reaching tribunals. Part II then applies this account to reach initial conclusions about the general informational effects of legal advice. We conclude that, while advice has many disturbing or ambiguous informational effects, on balance providing hitigation advice to one or both parties will generally increase the information reaching tribunals and inıprove the capacity of tribunals to determine who deserves to be sanctioned and who does not.

Althougl our basic account is more coinplex and comprehensive than those offered in the prior literature, it nonetheless abstracts from several iniportant complications. We reintroduce those coinplications in Part III, and use them to test our initial conclusions and to identify conditions where those conclusions will not hold and where litigation advice may thus have ambiguous or harmful informational effects. Part IV then normatively evaluates the informational effects of legal advice under various conditions. We there conclude that, under the conditions most likely to describe its general effects, litigation advice is socially desirable under a variety of instrumental and noninstrumental standards.

Ultiniately, conclusions about the desirability of advice turn on empirical questions. We do not purport to answer all those questions, though we offer plausible intuitions about many. We do, however, claim to liave isolated the right set of einpirical questions. If we are correct in that clami, our account does more than focus the general academic debate about the desirability of litigation advice on the right set of issues. It also identifies the conditions likely to make particular forms of advice sufficiently harmful to merit legal restriction or sufficiently desirable to merit legal encouragement. Our analysis is thus relevant to a variety of real-world legal issues, some of which are discussed in Part V.

Section $V(A)$ presents our analysis of measures generally intended to encourage or discourage access to advice. These include rules wholly barring the use of lawyers, such as those that sometinies apply in sinall claims or alternative dispute resolution procedures. They also include measures that encourage or discourage retention of a lawyer, sucli as rules allowing fee awards to lawyers for parties who act as private attorneys general, subsidizing representation for criminal defendants under the sixtl amendinent, or restricting the sum a private citizen can pay for advice. Our analysis also has implications for narrower, special purpose 
rules that seek to increase the information reaching tribunals. Section $V(B)$ illustrates the implications of our analysis for proposals to reform attorney-client confidentiality, and Section $V(C)$ apphies our analysis to rules that restrict access to legal advice about responding to investigation or other questioning.

I

\section{The Basic Account of How Parties and Lawyers INFLUENCE THE INFORMATION REACHING TRIBUNALS IN AN ADVERSARY SYSTEM}

To provide an adequate analysis of the informational effects of legal advice, we first need an account of how parties and lawyers generally influence the information reaching tribunals in an adversary system. For clarity and emphasis, we initially adopt a stylized account of litigation that abstracts from certain important complications about costs and settlement, party and lawyer motivation, the dubious probative value of soine information, and skewed distributions of informational access, litigation error, and favorable information. After usmg this basic account to derive initial conclusions about the informational effects of legal advice in Part II, we reintroduce these coinplications in Part III and explore whether and how they inight alter our conclusions.

Although necessarily simplified, our basic account is nonetheless complex in that it considers both relevant and irrelevant information, information that is available to both parties, decisions about investigation, withholding, and suppression, and sanctions for withholding and suppressing evidence. Section I(A) states our basic assumptions about party inotivations, the tribunal, and the activities that influence the inforination reaching the tribunal. Section $I(B)$ provides a brief account of the pertment types of information, in terms of both their effect on the tribunal and their availability to the parties, and explains how sanctions for withholding and suppression determme the availability of information to each party. We describe in greater detail in Section $\mathrm{I}(\mathrm{C})$ how parties inake decisions about investigating, presenting information, and influencing the level of evidentiary sanctions. Section I(D) makes some initial assuinptions about how lawyers influence litigation conduct. Finally, Section I(E) states mitial assumptions about the distribution of informational access, litigation error, and favorable and unfavorable information.

\section{A. The Parties, the Tribunal, and the Litigation Process}

In our account, two parties litigate disputed questions of fact before 
a tribunal. ${ }^{22}$ The tribunal is completely passive. ${ }^{23}$ It does not conduct its own investigation. Nor can it recognize, without the parties' assistance, all information embodied in the evidence placed before it. Instead, it determines the appropriate legal sanctions to impose based solely on the information identified and presented by the parties. ${ }^{24}$ Parties are sanctioned prinarily for the conduct that gives rise to the litigation, which we call "primary conduct." Such sanctions imclude damages, fines, injunctions, and imprisonment.

But the tribunal also imposes "evidentiary sanctions" to regulate litigation conduct that influences the information reaching the tribunal, such as withholding or suppressing information. Formal evidentiary sanctions mclude discovery sanctions and penalties for perjury or refusing to testify. ${ }^{25}$ But many evidentiary sanctions are not codified or explicit. For example, the most effective sanction for false testimony may not be the criminal sanction for perjury, but the adverse inference the tribunal might draw about a party's entire case if she offers testimony that appears to be false. ${ }^{26}$

Our stylized account also assumes that each party is a rational, riskneutral actor who seeks the combination of her hitigation costs and primary and evidentiary conduct sanctions that most advantages herself. Defendants seek to minimize the sum of total expected sanctions and costs. Plaintiffs seek to maximize the net value of primary sanctions, less evidentiary sanctions and costs. For exannle, where a plaintiff has unfavorable information that will cost her $\$ 1,000$ to produce and, if pro-

22. Although real litigation often involves three or more parties, there are usually two sides to any factual issue, and our analysis is unaffected if there is more than one party to a side. The tribunal could be a court, jury, arbitrator, administrative adjudicator, or any other body that resolves disputes by adjudicating facts.

23. Our basic assumption of a passive tribunal reflects the traditional ideal of the adversary system. See, e.g., Feeley, The Adversary System, in 2 ENCYCLOPEDIA OF THE AMERICAN JUdICIAL SYSTEM 753 (R. Janosik ed. 1987) (describing adversarial factfinding). Although many tribunals are not as passive as we describe, see, e.g., Resnik, Managerial Judges, 96 HARV. L. REV. 374, 376 (1982), we assume passivity because our interest is in analyzing the effect of legal advice on those elements of adversary factfinding that are party-orchestrated. Our argument therefore does not speak directly to the question of whether the tribunal should assume a more active or "inquisitorial" role in factfinding, although some of our discussion in Part IV of adjusting sanctions bears on that question.

24. The determination of the appropriate sanction involves conclusions about both liability and remedies. We do not examine the rule of decision by which the tribunal determines which information warrants what sanction, other than to assume that this rule bears some correlation to the social desirability of the conduct in question when the information is true, relevant, and nonprejudicial.

25. See, e.g., 18 U.S.C. $\S \S 1510-1513$ (1984) (criminal sanctions for obstruction of justice); 18 U.S.C. $\S 1621$ (1984) (criminal sanctions for perjury); FED. R. Crv. P. 37 (discovery sanctions).

26. Other evidentiary sanctions are explicitly incorporated into the rules by which the tribunal determines the outcome on the merits. For example, a tribunal may punish the failure to produce certain information in discovery by allowing or requiring the factfinder to draw an inference adverse to the party failing to produce. See, e.g., FED. R. CIV. P. 37(b)(2)(A). 
duced, will reduce her expected judgment by $\$ 9,000$, she will nonetheless produce it if the suin of her costs of withholding and expected evidentiary sanctions for withholding exceeds $\$ 10,000 .{ }^{27}$ We will call such parties "sanction-optimizers."

Our assumption that parties are sanction-optimizers necessitates two further simplifying assumptions: that every case is hitigated to judgment, and that parties never engage in litigation conduct to drive up their opponents' litigation costs. ${ }^{28}$ This allows us initially to avoid the complex effects on decisions about investigation and presentation that flow from the constant possibility that a party might settle or abandon a suit. It also allows us initially to avoid some of the strategic aspects of litigation explored in the game theory literature. ${ }^{29}$

Although we reintroduce more reahistic assumptions about all these features in Part III, the basic assumption of purely self-interested party beliavior is perhaps sufficiently fundamental and controversial to inerit some attention up front. We adopt this working assumption for two reasons. First, prior studies of civil and criminal litigation ${ }^{30}$ and our personal observations give us some confidence that the assumption captures the motivations of a substantial number of litigants. Second, our intuitive sense is that, as a uniform assumption about party inotivation, the assumption that parties respond solely to the threat of sanctions provides a good "worst case" test of legal advice in an adversary systenn. ${ }^{31}$

We recognize, however, that not all litigants are rational actors, and those who are do not invariably have optinnizing sanctions as their exclusive (or even first) priority. Soine litigants, whom we call "law-abiding," may feel obligated to comply with the law governing the production of niformation even if the sanctions for violating the law are alone insufficient to compel coinphance. Others, whom we call "truth-tellers," may feel obligated to tell the "whole truth" even if the law does not require them to do so. Governinent litigants, who have a duty to pursue justice and a relative lack of personal interest, may seem particularly likely to deviate from the sanction-optimizing assumption. Section III(B)

27. Our account does not, however, assume that the only values at stake are monetary or monetizable. Parties may also take into account the nonmonetary benefits of litigation conduct (such as the opportunity to have their "day in court"), the nonmonetary costs (such as time or reputation), and nonmonetary sanctions (such as loss of liberty).

28. Parties may, in deciding on their own conduct, take into account the opponent's likely litigation conduct. See infra Section I(B). But we initially assume that they take their opponent's likely conduct as essentially unaltered by their own litigation conduct.

29. See, e.g., Cooter \& Rubinfeld, supra note 14, at 1072-73; Sobel, An Analysis of Discovery Rules, 52 LAW \& CONTEMP. Probs. 133 (Winter 1989).

30. See, e.g., K. Mann, Defending White Collar Crime passim (1985); Brazil, The Adversary Character of Civil Discovery, 31 VAND. L. REV. 1295, 1312-32 (1978).

31. We will see in Seetion III(B) that, where party motivations are not uniform, the "worst case" is providing legal advice to a sanction-optimizing party who faces a truth-teller. 
describes how our account might change when parties are law-abiding or truth-telling.

Under our mitial assumption of sanction-optimizing behavior, each party seeks (within limits set by litigation costs and evidentiary sanctions) to influence sanctions by influencing the information that reaches the tribunal. Whether the party wants the information to reach the tribunal will depend on the party's judgment about whether the information is "favorable" or "unfavorable": that is, whether it would tend to cause the tribunal to reach a factual conclusion favorable or unfavorable to the presenting party. ${ }^{32}$ Because parties are opposed on each disputed factual issue, an item that is favorable for one is unfavorable for the other.

Initially, we assume that the tribunal's response to information actually reflects that information's genuine tendency to prove or disprove a contested proposition of fact. Thus, our mitial account excludes information that has a favorable or unfavorable impact but is false, appeals to prejudice, or achieves its effect by drowning the tribunal in redundant or irrelevant information. We reintroduce such kinds of information in Section III(C). In our mitial account, however, irrelevant information refers to all information that is neither favorable nor unfavorable. Parties in our initial account thus have no desire to identify or present it.

Four basic activities influence the information reaching the tribunal. First, each party seeks to identify information through investigation. Second, each party seeks to prevent the opponent from identifying information by withholding or suppressing it. Third, from the information she has identified, each party selects information to present to the tribunal. Fourth, the parties seek to lower their own evidentiary sanctions and raise those applicable to their opponent.

\section{B. Party Access to Information and the Role of Evidentiary Sanctions}

When a dispute arises, each party knows of some information that might be presented to the tribunal. "Investigation" is how a party identifies additional presentable information. Investigation typically involves interviewing prospective witnesses and inspecting documents and other physical evidence. A party may investigate information that she pos-

32. This definition parallels that in Kaplow \& Shavell, supra note 17, at 577-82, 595-96. Our discussion assumes that individual items of favorable and unfavorable information are discrete. In practice, of course, favorable and unfavorable information often comes in aggregate lumps, so that decisions to produce favorable and unfavorable items are inextricably linked. For example, a criminal defendant's decision to testify in order to present a favorable alibi must also take account of the unfavorable information about the defendant's prior criminal record that cross-examination will elicit. Aggregation generally does not affect our conclusions so long as parties continue to make decisions based on the net balance of favorable and unfavorable information in the relevant lump. An exception is discussed at infra note 71 . 
sesses, may conduct informal and voluntary mquiries of cooperative sources, or (with the opponent and other unwilling sources) may proceed through formal discovery or examination at trial. Formal investigation carries with it the threat of evidentiary sanctions.

\section{Party-Controlled and Discoverable Information}

Each party possesses some information when a dispute arises. ${ }^{33}$ If a party beheves that information in her possession is unfavorable, she will want to keep it from the opponent and the tribunal. A party "withholds" information in her possession by failing to volunteer or produce it to the opponent or the tribunal. Leaving aside the direct costs of the actions needed to withhold or produce information, a party will withhold information she beheves is unfavorable when the expected evidentiary sanction for withholding is less than the expected adverse effect on the judgment from making the information available to the opponent or the tribunal.

Soine information in each party's initial possession can be identified by the opponent in discovery or at trial: if the opponent makes a demand for production, and if the perceived evidentiary sanctions ${ }^{34}$ (coupled with the direct costs of withholding) exceed the perceived harm of production (including the direct costs of production), the party will produce the information. We will call such information the party's "discoverable set." For the relnaining information im each party's possession, sanctions will not be enough to compel production even if a proper demand is made. Sometimes this will occur because the party can get away with improper withholding, but sometimes the law expressly permits withholding, for example, because of a valid evidentiary privilege. We will call information im a party's possession whose disclosure cannot be compelled the party's "controlled set."

\section{Commonly Available Information}

Both parties potentially can identify some of the information that neither party possesses at the outset of litigation. ${ }^{35}$ Such information will mclude information in the public domain and information from sources

33. A party "possesses" information when an opponent can only obtain that information if the party volunteers it or is compelled to produce it by the threat of evidentiary sanctions. Possession thus encompasses not only physical possession of documents or other evidence but also a party's control over her own recollection.

34. Perceived sanctions represent the party's subjective estimate of actual expected sanctions. The expected evidentiary sanction is the product of the actual probability that the act will be detected and sanctioned by the tribunal and the actual magnitude of the sanction that will be imposed.

35. We exclude from consideration information that neither party could identify (with or without advice), because legal advice cannot affect the presentation of such information. 
not aligned in interest with either side. For exainple, where the plaintiff brings suit for her injuries in an automobile accident case, information potentially available to both parties imcludes the site of the accident, police and hospital records, the recollections of nonparty eyewitnesses or investigating officers, and the published hterature on and available experts concerning any disputed technical or scientific issues. ${ }^{36} \mathrm{We}$ will call the set of information that is initially available to both parties the "commonly available" set.

\section{Suppressible Information}

Just as a party in possession of information can seek to withhold it, a party can sometimes attempt to prevent her opponent from identifying or presenting information that is commonly available or in the opponent's possession. A party may, for example, destroy a document in another's files. We call such conduct "suppression."37 Both physical and testimomial evidence can be suppressed. Sometinies the law encourages suppression because it furthers some other social policy, such as respecting privacy or preventing government coercion. For example, criminal defendants frequently move to suppress evidence on the ground that it was obtained in violation of the fourth or fifth amendments. Other forms of suppression are less reputable. Skillful, suggestive imterviewing can alter a witness' recollection, so that, without realizing it, she represses or forgets information unfavorable to the interviewer. ${ }^{38}$ Prospective sources of imfornation can also be subjected to legitimate or illegitimate mcen-

36. Investigation of information held by such sources will often be cooperative, since the sources are not aligned with one party or the other. However, because nonaligned sources may not be fully compensated for the cost of providing information, it is sometimes necessary to invoke sanctions to obtain their information. The level of sanctions required to compel production need not, however, vary depending on whether the information is favorable or unfavorable to the party seeking it, because the source has no stake in the outcome.

Sources who share some but not all interests with one of the parties can be placed on a continuuin between nonaligned sources and sources whose interests are perfectly aligned with a party. Information possessed by nonaligned sources is commonly available. Information possessed by perfectly aligned sources will be analytically the same as information possessed by a party, so we will treat perfectly aligned sources as one of the parties for the purposes of this Article. Information possessed by partially aligned sources has some characteristics of coininonly available information, but it could also be said to be partially possessed by the party who shares interests with the source (because she will have an advantage in investigating, gathering, and suppressing that information).

37. The difference between suppression and withholding is thns the source of the information that someone prevents from reaching the tribunal. A party can only withhold information she possesses but can suppress information possessed by another.

38. See, e.g., K. MANN, supra note 30, at 162 (explaining the "basic working principle that he who arrives first gets a better interpretation of the facts ... [because] the respondent's perceptions have been influenced by the interrogator's construction of questions"); see also M. FREEDMAN, supra note 9, at 68-89 (discussing the influence of interviewers on the information the interviewees recalled). In addition, a party may use the record of an interview to suppress information. For example, police officers who have interrogated a suspect inay prepare a written statement that oinits exculpatory information volunteered by the defendant. If the suspect signs the statement, the 
tives or threats. For example, a party may advise a nonparty witness of the risk that she will incriminate herself if she testifies and of her fifth amendment right to decline to answer incriminating questions. ${ }^{39}$ Or a party may threaten the potential witness with physical or financial injury if she testifies.

Some suppression is subject to sanctions. Where suppression is possible, a party decides whether to suppress by determining whether the information is unfavorable and then weighing the perceived value of suppressing the information against both perceived sanctions for suppression and any associated financial costs. ${ }^{40}$ Where perceived evidentiary sanctions are sufficient to deter suppression, we call the information "nonsuppressible." Such information can be identified and presented by both parties. For each party, however, there will remain some information in the commonly available set or in her opponent's possession that she will be able and willing to suppress, given the perceived costs and benefits of doing so. We define information as "suppressible" if one of the parties wonld be willing and able to suppress it under soine circumstances.

\section{Decisionmaking About Investigation, Presentation, and Influencing Evidentiary Sanctions}

\section{Decisions About Investigation}

A party will conduct an investigation only if the investigation's perceived value exceeds its cost. ${ }^{41}$ For an investigation to have positive value, it must have some possibility of leading, directly or indirectly, to

prosecutor can later use it to cast uuwarranted doubt on the exculpatory information when the defendant offers it at trial.

39. Courts have held that a lawyer who gives such advice to a nonparty with the "corrupt motive" of protecting her chient may be couvicted of obstruction of justice even though the advice given is both accurate and apt. See United States v. Fayer, 523 F.2d 661, 663 (2d Cir. 1975); C. Wolfram, supra uote 4, at 647 . To our knowledge, however, the Suprene Court has never considered the first, fifth, or sixth amendment implications of this rule.

40. Often a significant factor in determining the expected sanctions for suppression is who ideutifies the information first. A party who can identify information before her opponent identifies it enhances her ability to suppress the information and reduces her expected sanctions for doing so becanse her opponent is less likely to detect the suppression. At the same tinie, she reduces her opponent's ability to suppress the information and nicrcases her opponent's expected sanctions for attempting to suppress it. This factor, however, will not always be determinative. Sone crininals, for example, nay have no conipunction about using threatened or actual physical harm to silence witnesses who are already providing information to the prosecutor. Witness protection programs are designed to combat this problen.

41. The perceived value of an investigation is the party's subjective estimate of its expected value. One calculates an iuvestigation's expected value by identifying the values of the investigation's possible outcomes, multiplying each outcome by the probability it will occur, and summing those products over all possible outcomes. H. RAiFFA, DECISION ANALYsis: INTRODUCTORY LECTURES ON CHOICES UNDER UNCERTAINTY 9 (1968). 
relevant information. ${ }^{42}$ Investigations clearly have positive value to the extent they are expected to yield favorable information. But many investigations that are expected to yield only unfavorable information may also have positive value. Knowing about unfavorable information can assist in forming one's theory of the case, understanding the favorable and unfavorable character of one's own information, preparing to challenge the opponent's case, and gathering additional favorable information to present to the tribunal. Even irrelevant information can have positive value if it provides investigative leads to helpful relevant information. Investigations for relevant suppressible information will have positive value whether the information is unfavorable or favorable because such investigations enhance the likelihood of both suppressing unfavorable information and preventing the suppression of favorable information.

The potential negative informational effect of investigation is that it can increase the likelihood that unfavorable information will reach the tribunal. ${ }^{43}$ This can happen in two ways. First, investigation sometimes requires a party to divulge information directly to the opponent or to persons who are inore likely than the party to disclose it to the opponent or the tribunal. ${ }^{44}$ Second, a party's identification of unfavorable information in investigation may make that information more accessible to the opponent. For example, a party may expend great effort to locate and interview a witness whom the opponent would not have found through independent investigation and whose testimony turns out to be damaging. Once the party has gathered the information, however, the opponent may be able to obtain it easily through a discovery demand directed

42. Given our assumptions in Section I(A), an investigation cannot have value simply because it burdens the opponent or leads him to beheve that he inust spend inoney to counteract it.

43. Investigation can have adverse consequences other than identifying or divulging unfavorable information. Sometimes the information that can lead the opposition to unfavorable information is itself favorable. For example, a party inay wish to prevent the opposing party froin obtaining favorable information because, if alerted to it, the opposing party will then identify additional information to counter it. See Brazil, supra note 30, at 1317-18 (arguing that a party anticipating hitigation may decide not to depose a favorable witness in order to avoid having to give the opponent an opportunity to respond to the witness' information at trial).

44. For example, witness interrogation may itself reveal information held by the questioner, as occurred in the infamous case of Berkey Photo, Inc. v. Eastman Kodak Co., 603 F.2d 263 (2d Cir. 1979), cert. denied, 444 U.S. 1093 (1980). There, a nonparty witness for Kodak had prepared, but subsequently forgotten, a very damaging docament that had been improperly withheld during discovery. On the eve of the witness' trial testimony, a lawyer for Kodak investigating to obtain information about the docuinent showed it to the witness. This refreshed the witness' recollection. When asked about the docament on cross-examination the following day, the witness reported its existence, causing its belated production. See Kieehel, The Strange Case of Kodak's Lawyers, Fortune, May 8, 1978, at 192; see also Brazil, supra note 30, at 1321 (arguing that "the drafting litigator is constantly under pressure not to initiate discovery that could help educate the opponent"). 
at the party. ${ }^{45}$

Where cost-effective, a party should generally have strong overall incentives to investigate. A party always wants to identify information expected to be favorable. If the party expects the information to be unfavorable, the incentive to investigate depends in part on the opponent's access to that information. If the unfavorable information is suppressible, opponent access gives the party strong incentives to identify the information so she can suppress it. If the unfavorable information cannot be suppressed, it might seein that the party has no incentive to search for it, especially since the opponent might be able to "feed off" of the party's search. But the opponent's ability to identify the information independently inay also strengthen the incentive to investigate for two reasons.

First, it is valuable to know what the opponent's case might contain. Second, the likelihood of independent opponent identification decreases the likelihood that the party's investigation will cause information to reach the tribunal that would not have reached it anyway. Without knowing the relative likelihoods that the opponent will identify information independently or as a derivative consequence of the party's investigation, one cannot determine the strength of the incentive (or disincentive) to seek out unfavorable nonsuppressible information. But the overall incentives to investigate (where cost-effective) should generally be high in all information sets, because the incentive to identify favorable information is invariably strong and the incentive to identify unfavorable information is at worst mixed.

A well-chosen investigation strategy can increase both the favorable information that a party identifies and the unfavorable information identified by her opponent. A party decides whether to conduct an investigation by determining whether it has net positive expected value. ${ }^{46}$ But the net expected value of an investigation can be positive, even though soine of its expected informational consequences are harmful. Many investiga-

45. See FED. R. CIV. P. 26(b)(1) (permitting discovery of all relevant nonprivileged information); $c f$. Shapiro, Some Problems of Discovery in an Adversary System, 63 MiNN. L. REV. 1055, $1064-77$ (1979) (arguing that a party whose lawyer uncovers extreinely unfavorable information from a nonparty witness is legally obliged to produce the information in response to a properly framed interrogatory notwithstanding the work product doctrine). Investigation of information in one's own possession can also help an opponent identify that information. For example, in responding to interrogatories, a civil litigant must conduct a "reasonable" investigation of information she possesses. See J. Friedenthal, M. Kane \& A. Miller, Civil Procedure $\S 7.9$, at 401 (1985). Parties anticipating interrogatories may therefore avoid conducting investigations inore extensive than "reasonable" for fear they may identify (and thus be obliged to produce) unfavorable information they would not have identified in the compulsory "reasonable" investigation.

46. Where a party behieves that alternative investigations with positive expected value will uncover the same favorable or helpful information, shc will choose the investigation with the highest value. 
tions will identify multiple items of evidence, some helpful and some harmful. ${ }^{47}$ Moreover, a defining characteristic of imvestigations, given that they are motivated by a party's lack of knowledge about information, is uncertainty about what their fruits will be. ${ }^{48}$ The most carefully tailored investigation strategy will sometimes collect information of types or from sets different from those sought, and thus cause unfavorable information to reach the opponent or the tribunal that otherwise would not have done so.

\section{Decisions About Presenting Information and the Role of Advocacy}

When the parties have completed their imvestigations, each will have a pool of information that she has identified and can present. ${ }^{49}$ Each must select the information to present from this pool. Subject to cost constraints and evidentiary sanctions, each will seek to present all information she believes is favorable and to withhold or suppress information she believes is unfavorable or irrelevant.

Presenting information encoinpasses more than the mecharical tasks of placing selected physical objects in evidence and eliciting oral testimony. Getting information admitted into evidence makes it available to both sides but may not be sufficient to alert the tribunal to its favorable or unfavorable character. Presentation thus often mvolves advocacy, in which each side shapes the tribunal's interpretation of the admitted evidence by pointing out the favorable factual inferences that can be drawn from the evidence and minimizing the unfavorable inferences. The more passive, obtuse, overburdened, or inexperienced the tribunal, the inore advocacy is needed to ensure that the tribunal recognizes all the information embodied in admitted evidence.

An exainple inay illustrate the process of presenting and withholding information. Suppose that the defendant in a contract dispute behieves that her truthful account of conversations with the plaintiff will assist her case. Accordingly, she testifies to those conversations and points out the favorable inferences that can be drawn from them. The

47. Even where a single item is involved, it may have both helpful and harmful aspects. For example, an item of unfavorable information may provide valuable investigative leads to favorable information, but gathering it may greatly increase the likelihood that the opponent will obtain and present it.

48. Indeed, the value of information will generally be uncertain even after the party has investigated. For example, the party may not know for certain whether: (1) the opponent will obtain (or would have obtained) the information independently; (2) the opponent will make a discovery request for the collected information, and what perceived sanctions for nonproduction will be if he does; (3) the information will lead to further positive value investigations; or (4) additional information will arise that alters the information's favorable or unfavorable character.

49. A party can directly present information it possesses. If the opponent or nonparties possess the identified information, the party may have to mobilize sanctions to compel its presentation. Sometimes the party may identify information but be unable to present it. 
same defendant's correspondence file contains copies of several letters supporting inferences unfavorable to the defendant. Because the opponent does not demand those copies, the party says nothing about them, and the contents of her file are never introduced into evidence. ${ }^{50}$ The defendant's failure to produce the documents is a form of withholding. The opponent finally offers in evidence a copy of one of the letters and points out an inference supported by the letter that is unfavorable to the defendant, but fails to point out several other even more damaging inferences supported by the letter. The defendant, who perceives those inferences, elects to reinam silent about them. By failing to point out the additional inferences to the tribunal, both the plaintiff (mistakenly) and the defendant (correctly) have withheld that information from the tribunal.

\section{Party Efforts to Influence Evidentiary Sanctions and Secondary Information}

At the same time that parties are seeking to identify and present information that will influence the tribunal in imposing sanctions for primary conduct, they are also engaged in a "hitigation within a titigation" whose subject is the level of sanctions for withholding and suppression. In this litigation, each side seeks to ensure that the information reaching the tribunal about its own evidentiary conduct is as favorable as possible and that the information reaching the tribunal about the opponent's evidentiary conduct is as unfavorable as possible. Thus, a party will seek to present her own information in a way which suggests that her presentation is complete and candid, while endeavoring at the saine time to present inforination which suggests that her opponent's presentation is mcomplete and dishonest. The information the parties present on these issues is im part the same infornation that is relevant to the tribunal's determination of the merits. But each party may also be able to present some information that goes solely to the likehihood that information is being improperly suppressed or withheld. We will call information that influences the level of evidentiary sanctions "secondary inforination."

\section{An Illustrative Case}

We can illustrate some of the factors that inforn the process of making decisions under uncertainty about investigation and presentation by examining the traditional lawyers' rule of thumb that in cross-examining a hostile witness at trial, "a lawyer should never ask a question to which

50. This example is modeled on Professor Samuel Williston's account of a case in which he participated as a young lawyer, as recounted in Curtis, The Ethics of Adrocacy, 4 STAN. L. REV. 3, 9-10 (1951). 
she does not already know the answer." ${ }^{11}$ The lawyer's lack of knowledge about the answer she will receive means that, although the imquiry takes place before the tribunal, it involves a significant element of investigation. Her ignorance indicates that she has no strong reason to believe the question will produce favorable information. What is more, if the witness withholds favorable information, the lawyer's ignorance inakes it unlikely that she can bring evidentiary sanctions to bear by impeaching the witness' testimony.

If the information identified in cross-examination proves unfavorable, the consequences are likely to be particularly harmful. The circumstances inake clear that the opponent would not have independently presented the information. Further, unlike information disclosed to the opponent during out-of-court investigation, answers given during crossexamination may reach the tribunal whether or not the opponent makes a conscious decision to present the information. Nor is the party likely to realize the benefits that normally flow from identifying unfavorable information prior to trial. Because of the timing of the mvestigation, any unfavorable information the party unearths is unlikely to aid in case preparation or subsequent investigation.

In slort, blind cross-examination involves a higher risk of adverse consequences and a lower chance of positive payoff than normal investigation. ${ }^{52}$ This does not mean that it will always be disadvantageous. When opportunities for out-of-court investigation to identify favorable information are limited, as they are in systems witlout pretrial discovery, such inquiries are more likely to have positive expected value notwithstanding the risks involved. One would expect parties in such a system to take those risks more frequently than in a system allowing pretrial discovery. ${ }^{53}$

51. See, eg., T. Mauet, Fundamentals of Trial Techniques 215 (2d ed. 1988).

52. Although statements of the rule of thumb typically restrict its application to cases of crossexamimation, much of the analysis here also applies to direct examination of a friendly witness in circumstances where the examimer does not "know" the answer. Friendly witnesses should be more likely than hostile witnesses to have favorable information. But direct examination typically will liave elicited the lion's slare of the unfavorable information possessed by the lostile witness. Therefore, the mix of favorable and unfavorable information that has not been elicited from the lostile witness may not differ from the mix of information that is possessed by a friendly witness but was not identified in pretrial investigation.

53. Thus, Francis Wellman, writing near the turn of the century about lawyers in a system of limited discovery, noted the inaxim against cross-examination where one was uncertain of the answer, but nevertheless stated that "[ $t]$ lie most cautious cross-examiner will often ehicit a damaging answer." F. Wellman, The ART of Cross-Examination 13 (3d ed. 1923). This judgment presumably refiects the fact that, in a regime without pretrial discovery, cross-examination often might represent a party's only opportunity to identify and present favorable information possessed by a hostile witness. 


\section{Accounting for the Contribution of Lawyers}

An account of legal advice requires that we make certain assumptions about what lawyers know, what their advice costs, what their motivations are, and whether their advice has symmetric or asymmetric effects on the hitigating parties. We assume that lawyers' expertise assists the full range of activities described above: investigation, categorizing and presenting information, withholding, and suppression. Lawyers know more than chents about whether information about primary conduct is favorable, unfavorable, or irrelevant. Lawyers also know more about the available procedures and techniques for investigation, presentation, withholding, and suppression, about the sanctions applicable to clients' evidentiary conduct, and about whether information is favorable, unfavorable, or irrelevant on the issue of whether evidentiary sanctions should be imposed. For example, lawyers know more about the rules governing the compelled production of information, including the proper form of demands for production, the ways of resisting such deinands, and the sanctions for failure to produce. As a result, lawyers can make more accurate predictions about whether information is party-controlled, discoverable, commonly available, or suppressible. In each of these areas of professional expertise, we assume that lawyers' knowledge is imperfect but better than their chents. ${ }^{54}$

We also assume, for the sake of simplicity, that legal advice is costless. In consequencc, in this simplified account parties have no incentive to economize on legal advice, and lawyers have no incentive to increase their profit by working too much or too hittle. We consider the consequences of relaxing this important assumption in Section III(A).

We do not, however, assume that lawyers are perfectly loyal to their chents' interests. Sometimes lawyers will refuse to assist or engage in evidentiary misconduct even though such misconduct would optimize their chents' sanctions. In our basic account, we assume that lawyers behave this way only out of a self-interested concern for their own susceptibility to evidentiary sanctions for engaging in or assisting unlawful withholding and suppression of evidence..$^{\text {ss }}$ This assumption implies, among other things, that evidentiary sanctions apphicable to lawyers sometimes abrogate lawyer-chent confidentiality. We reserve until Sec-

54. If lawyers were unavailable during litigation, parties might be able to replace some of the lost legal knowledge by self-study or by consulting lawyers before litigation. But there would be limits on the ability of parties to substitute such sources of knowledge for lawyers. Accord Kaplow \& Shavell, supra note 17, at 599, 600-01. To the extent parties can obtain legal knowledge without being represented by lawyers during litigation, that would affect only the overall extent, and not the nature or direction, of the effects we predict under our model.

55. Section $\Pi(C)(2)$ describes some of these sanctions in greater detail. 
tion $V(B)$ consideration of the comparative informational effects of legal regimes that protect confidentiality more or less than the current regime.

Although many lawyers may refuse to participate in evidentiary misconduct for other reasons, the assumption that lawyers avoid evidentiary misconduct only because they fear sanctions allows us to address the apparent "worst case" argument against legal advice. In Section III(B)(3), we reconsider our resnlts under the assumption that some lawyers refuse to become involved in evidentiary misconduct because of professional or moral obligations.

In much of our discussion of the effects of advice on party behavior, we adopt a narrative convention which imılies tliat lawyers give legal advice and that clients tlien execute the acts of investigation, presentation, suppression or withholding that the lawyers have recommended. Althougli this may sometimes liappen, in fact clients often delegate execution of these tasks to lawyers, particularly when the tasks involve investigation or appearances before the tribunal. Indeed, often a party cannot obtain the full benefit of advice about investigation or presenting information witliout delegating the execution of tliose tasks to her lawyer. Where delegation occurs, lawyers' increased personal susceptibility to evidentiary sanctions may make them unwilling to allow or participate in efforts to suppress or withhold information. This effect is important to our conclusions and we address it in Section $I(C)(2)$. Our narrative convention is not meant to deny this important effect of delegation but ratler to simplify the exposition.

A final important issue in developing an account of the informational effects of litigation advice is whetler to measure tliose effects under a bilateral or unilateral account. A bilateral account compares a regime in which both parties receive coinparable litigation advice with a regime in wlich neitlier side lias any advice. A unilateral account holds the advice given one party constant and compares the results when the opponent receives advice with the results when it does not.

Eaclı approacl lias its virtues. A bilateral account inore closely approximates the traditional understanding of the adversary system of factfinding, in which both parties operate with similar resources and under similar rules governing access to advice. More important, if the account's predicted effects are to provide useful guidance for legal policy analysis-rather than for individual decisions to retain counsel-the account must measure the effects of the societal decision to einploy or reform rules that require, encourage, permit, discourage, or forbid hitigation advice. Such societal decisions will often have bilateral effects.

Indeed, im civil cases between private parties, society may lave little choice but to allow litigation advice either to botl parties or to neitler. Allowing litigation advice only to plaintiffs or only to defendants would 
make hittle sense functionally because either side can benefit from slanting the mix of information presented to tribunals and might be tempted by improved prospects in hitigation to engage in undesirable primary conduct. Such a distinction would also be administratively unworkable in a systen where almost any defendant can, given declaratory judgments, counterclaims, and cross-claims, paint herself as a plaintiff. ${ }^{56}$ When the government opposes a private citizen, distinctions may be easier to draw, both for functional reasons (the government's duty to serve justice and, in criminal cases, its distinctive legal disclosure obligations might make it less likely to present evidence selectively) and for administrative reasons (the government can be readily identified in every case). Other social values, however, might still limit society to choosing between allowing legal advice to both parties or neither.

On the other hand, a unilateral account has important applications. In a troubling class of civil cases, hitigation advice may be nominally available to both sides but in practice available to only one side because the other cannot afford adequate legal counsel. ${ }^{57}$ If the legal regime could identify with confidence the cases falling in this category, one could employ a unilateral account to describe the informational effects, in this class of hitigation, of a societal decision to either deny counsel to both sides or subsidize counsel for the party who otherwise could not afford it. The former solution is sometimes adopted in small claims court; the latter underlies many legal aid programs.

In another class of cases that appear nominally bilateral, the quality of legal advice available to both sides is adequate, but because one lawyer is better than the other or because one party initially knows much less law than the opponent, legal advice alters one party's litigation behavior more than it alters her opponent's. Where the bilateral provision of legal advice causes one party's rate of error to decrease more than her opponent's, the effects are in part bilateral, but the differential advantage flowing from advice is more appropriately evaluated as a unilateral increase in advice.

Finally, because it is easier to draw formal and functional distinctions between the government and other parties, and because the govern-

56. Kaplow and Shavell argue that one can permit or disallow legal advice to only one side, citing the contrasting roles of crininal prosecutors and defense attorneys. Kaplow \& Shavell, supra note 17, at 597 n.76. However, they offer no explanation of how to make distinctions useful for civil litigation between two private parties.

57. These include cases wliere the expected value to one side does not merit the necessary investment in legal counsel. They also include cases where one side is too poor to hire adequate counsel and either cannot win a monetary recovery or cannot (due to legal restrictions or inarket imperfections) finance the litigation by borrowing against (or selling or assigning a portion of) the potential recovery. 
ment is a repeat player, ${ }^{58}$ a unilateral account may be valuable in analyzing the informational effccts of measures that regulate the legal advice received by government opponents. For example, a unilateral account can help analyze the informational effects of forfeiture statutes that deny suspected criminals the ability to use the alleged proceeds of their offenses to hire expensive counsel. ${ }^{59}$ We will therefore present both unilateral and bilateral accounts.

\section{E. Distributions of Access, Error, and Information}

Our basic account adopts a number of further assumptions about the distribution of informational access, hitigation error, and favorable versus unfavorablc information. First, at the beginning of litigation, each party has equal access to relevant information. To tlie extent that relevant information is party-controlled or suppressible, it is equally controlled or suppressible by eacli party. Second, the errors that unadvised parties may inake about litigation matters-sucl as how to categorize information as favorable or unfavorable and about the level of evidentiary sanctions-are not systematically biased. Parties are as likely to mistake favorable information for unfavorable as vice versa and are as likely to overestimate expected sanctions as underestimate tliem. Third, in eacli set of information available to one or both sides, the relevant information is equally divided between information favorable to one side and information favorable to the other. In otleer words, the mix of favorable and unfavorable information is fifty-fifty in each of the controlled, discoverable, commonly available, and suppressible sets.

Obviously none of these assumptions of perfectly equal distribution is likely to be true in any particular case. They may, lowever, accurately capture overall distributions in a general class of hitigation and thus provide an adequate basis for deriving the general effects of litigation advice. We thus derive our imitial conclusions about the general effects of advice under assumptions of equal distribution. We will then examine in Part III whether any of these distributions miglit be systemically skewed either generally or in particular classes of litigation and what the consequences of such skewed distributions might be.

II

The Basic AcCount of THE INFormational EFFECTS of LITIGATION ADVICE

In this Part, we derive the informational effects of the legal advice

58. It may be impossible to effectively deny legal advice to government authorities, since as repeat players they would develop legal sophistication whether or not they were represented by lawyers.

59. See infra text accompanying notes 203-04. 
that is actually provided in an adversary system in which clients and lawyers botlı face evidentiary sanctions and in whiclı lawyer-client confidentiality is imperfect. We postpone to Part $\mathrm{V}$ consideration of how evidentiary sanctions applicable to parties and their lawyers can soinetimes prevent more legal advice froin being given. Thus we do not here ineasure the informational effects of restrictions on advice, which would require coinparing a legal regime with advice and the legal restrictions against a regime witl advice but witlout the restrictions. Ratlier, this Part measures the effects of legal advice against a baseline of parties litigating witlı no advice. ${ }^{60}$

Even within our stylized basic account, tle informational effects of the legal advice provided to parties in an adversary system are diverse and complicated. To clarify our exposition, we discuss separately the effects of advice on different types of evidentiary conduct. In Section A, we trace the informational effects of advice about low to categorize (as irrelevant, favorable, or unfavorable) the information the parties have identified. We subsequently consider the effects of legal advice on investigation in Section B and the effects of legal advice on the perceived and actual sanctions for withholding or suppressimg unfavorable information in Section C. In eacli instance, we present tlie effects of unilateral litigation advice first and the effects of bilateral advice second.

Several informational effects of litigation advice are unambiguously positive. First, legal advice lielps parties sort the relevant information froin the irrelevant. Second, whenever the same information is available to both parties (so that both can compete in presenting it to the tribunal), legal advice to either party about how to categorize information as favorable or unfavorable will normally mcrease the amount of favorable information that the advised party presents more than it decreases the ainount of unfavorable information she presents. Third, legal advice increases investigation, and thus the presentation of information that would not have been identified without legal advice. Finally, for any legal advice provided, lawyers' personal susceptibility to evidentiary sanctions will sometines decrease withholding and suppression of unfavorable information.

Other informational effects of advice, sucl as those flowing from improved categorization of party-controlled and suppressible information, are disturbingly ainbiguous: they skew the mix of information in favor of the party receiving advice, but they neither increase nor decrease the total relevant information reaching the tribunal. But because the unambiguously positive effects of advice are not offset by any clearly neg-

60. The distinction is important because, as Section $V(B)$ demonstrates, a conclusion that litigation advice is desirable, ambiguous, or undesirable does not alone dictate any conclusion about whether confidentiality intended to encourage such advice is desirable or undesirable. 
ative effects, we conclude that in our stylized account hitigation advice has the following general effects. It decreases the proportion (and perhaps total amount) of irrelevant information presented under both the unilateral and bilateral accounts. Unilateral litigation advice increases the presentation of information favorable to the party recciving advice inore than it decreases the presentation of unfavorable information, and thus increases the total relevant information presented. Bilateral advice increases the favorable and unfavorable information presented about both sides.

\section{A. Legal Advice That Helps Parties Categorize Information}

In this Section, we assume that each party has a pool of potentially relevant information that she has identified, ${ }^{61}$ which is either nonsuppressible or suppressible. ${ }^{62}$ Unadvised parties may mistakenly categorize such information in four ways: (1) irrelevant as relevant; (2) relevant as irrelevant; (3) favorable as unfavorable; and (4) unfavorable as favorable. Legal advice correcting these errors helps a party decide which information to present, withhold, suppress, or save from suppression.

\section{Effects of Unilateral Advice}

\section{a. Nonsuppressible Irrelevant Information}

We consider nonsuppressible information first. Some nonsuppressible information that a party has identified will be irrelevant. With legal advice, a party will be less likely to categorize such information mistakenly as relevant and favorable. Correcting these errors reduces the amount of irrelevant information presented.

\section{b. Nonsuppressible Information Unadvised Parties Would Miscategorize as Irrelevant}

The remaining nonsuppressible information will either be favorable or unfavorable. When legal advicc corrects a party's mistaken behef that this nonsuppressible information is irrelevant, it increases that party's presentation of relevant information. Because lawyers are inore likely to present favorable information than unfavorable, the additional favorable information presented out of the set that otherwise would have been mis-

61. This analysis applies only to information that a party has identified and can present. Although normally a party should be able to present or compel the presentation of any potentially relevant information she identifies, there can be information that a party can and does identify but cannot present, such as demeanor information about a witness who is beyond the subpoena power of the court. For purposes of analyzing advice about which information to present, such information is analytically the same as information the party has not identified at all.

62. We discuss in Sections II(B) and II(C) the changes in the information identified by the party or her opponent because of the effects of advice on investigation and on sanctions for withholding and suppression. 
categorized as irrelevant (and consigned to oblivion) should outweigh the additional unfavorable information mistakenly presented out of that set.

\section{c. Correcting Mistakes About Which Side Nonsuppressible Information Favors}

Unilateral legal advice also reduces party errors about which side is favored by nonsuppressible information that an unadvised party would correctly categorize as relevant. These corrections increase the presentation of favorable information and decrease the presentation of unfavorable information. The relative inagnitudes of these effects depend on whether the information has been identified by the advised party alone or by both parties.

\section{i. Separately Identified Nonsuppressible Information}

Information identified by the advised party alone includes information in the party's controlled set, sucli as a party's recollections concerning her own mental state, as well as information in the discoverable and commonly available sets that the opponent has not requested. We will call such information "separately identified." Because the opponent cannot present separately identified information, whether it reaches the tribunal will depend solely on the party's decision whether to present it. ${ }^{63}$ Legal advice decreases the probability that a party will either withhold favorable information or present unfavorable information. The increase in favorable information presented will be the product of the change in the probability of mistaken withholding of favorable information and the amount of favorable information being considered for presentation. ${ }^{64}$ The decrease in unfavorable information presented will be the product of the change in the probability of mistaken presentation of unfavorable information and the amount of unfavorable information being considered for presentation.

Given our simplifying assumptions, any decrease in the probability of mistaken withholding will equal the decrease in the probability of inistaken presentation. We will see, after analyzing investigation, that there is reason to believe that the mix of separately identified information being considered for presentation tends to be more favorable than unfavorable. ${ }^{65}$ This will further bolster our conclusion that legal advice about information categorization increases the favorable information reaching

63. In effect, advice about whether to present this class of information is the only class of advice that Kaplow and Shavell inodel. See Kaplow \& Shavell, supra note 17, at 568-75.

64. We define the change in the probability of mistaken withholding or presentation as the difference between the probability a piece of identified information will mistakenly be withheld (or presented) without legal advice, and the probability it will mistakenly be withheld (or presented) with advice.

65. See infra Seetion $\mathrm{II}(\mathrm{B})(2)(\mathrm{b})$. 
the tribunal more than it decreases unfavorable information. At this juncture, however, we assume only that the mix of separately identified information is equally favorable and unfavorable. ${ }^{66}$ On this working assumption we conclude that the increase im favorable separately identified information presented because of legal advice about which side the information favors should equal the decrease in unfavorable separately identified information presented. The result is no net gain or loss of relevant information reaching the tribunal, but a mix of information skewed in favor of the advised party.

\section{ii. Commonly Identified Nonsuppressible Information}

We will call information "commonly identified" if both parties have identified and correctly categorized the information as relevant. Advice about whether commonly identified nonsuppressible information is favorable or unfavorable will increase the information reaching the tribunal. This effect is easiest to recognize in the limiting case where the opponent has perfect legal knowledge and therefore presents all coininonly identified information unfavorable to the party receiving advice. Against such an opponent, providing a party with advice cannot decrease the unfavorable commonly identified information presented since the opponent presents it im any case; advice will imstead tend only to imcrease the favorable information presented.

The effect is, however, more general: whenever the party's opponent is inore than minimally competent, ${ }^{67}$ unilateral advice will tend to increase the commonly identified information presented. A minimally competent opponent is more likely to present unfavorable information (froin the advised party's perspective) than favorable information. ${ }^{68}$ Accordingly, the commonly identified information that the opponent will not present (and whose presentation can thus be affected by the quality of the decisions made by the advised party) will tend to contain more favorable than unfavorable information. ${ }^{69}$ In selecting froin commonly

66. This assumption is reasonable given our initial assumption that each side controls or can suppress an equal amount of relevant information, and that each set of information available to either party contains equal amounts of favorable and unfavorable information. See supra Section I(E).

67. A minimally competent opponent is oue who has knowledge sufficient to make his ability to distinguish favorable from unfavorable information better than random. We expect that almost all opponents will be minimally competent by this standard, whether or not they have retained a lawyer. Even if there are isolated exceptions, we are describing the general effects of advice, and therefore find it sufficient for that purpose to assume that in general opponents will tend to be better than random selectors.

68. Throughout this Section, we use "favorable" to refer to information that benefits the advised party, even if it actually is preseuted by her opponent (to whom it is unfavorable).

69. To express this mathematically, suppose that the set of commonly identified information contains $F$ items of information favorable to the party and $U$ of unfavorable. The opponent has a probability $P$ of selecting information unfavorable to the party receiving advice, and a probability 
identified information, the party thus must make more decisions about whether to present favorable information that otherwise would not reach the tribunal than about whether to present unfavorable information that otherwise would not reach the tribunal. Legal advice that increases the probability of correct decisions about whether to present information should therefore increase the favorable information reaching the tribunal more than it decreases the unfavorable information reaching the tribunal. ${ }^{70}$ And as the extreme case illustrates, the more competent the oppo-

1-P of selecting information favorable to the party receiving advice. Thus after the opponent has selected, the amount of information reinaining for the party to select is $(P) F$ and $(1-P)(U)$. Where $F$ and $U$ are equal, the amount of favorable information remaining after the opponent has selected will exceed the amount of unfavorable information remaining whenever $P>1-P$, that is, whenever $P$ is greater than .5 , the condition of minimal competence.

70. We are grateful to Louis Kaplow for pointing out that this effect may be offset because an unadvised party facimg a more competent opponent might deduce that her best strategy is simply to present all commonly identified information unpresented by the opponent, ,figuring that the inferences she can draw from her opponent's nonpresentation are better than the inferences she can draw from her mdependent categorization. Suppose, for exainple, the opponent is $80 \%$ competent in categorizing information, and the unadvised party is $60 \%$ competent. Assume also that the mix of commonly identified information unpresented by the opponent contains 100 items. Given the opponent's competence, 80 of these items should be favorable to the unadvised party, and 20 should be unfavorable. The unadvised party could thus present a mix of information that is $80 \%$ favorable by blindly presenting all 100 items. This $80 \%$ success with blind presentation might sometimes be more advantageous than a selective presentation in which she applies her own $60 \%$ competence. Where this logic would lead an unadvised party to present blindly, advice will tend to inake the party's presentation more selective, thus decreasing the party's presentation of cominonly identified information.

However, although a strategy of unadvised blind presentation is sometimes theoretically advantageous, often it is not. Any party who is more than minimally competent can, through selective presentation, almost always make the mix of coinmonly identified information she presents more favorable than it would be if she followed a strategy of blind presentation. (The one exception is that selective presentation cannot unprove the mix when the opponent has presented $100 \%$ of the favorable information.) To continue the last exaunple, if the unadvised party applies her $60 \%$ competence to selecting among the information unpresented by her opponent, she will present $60 \%$ of the favorable items (or 48 favorable items) and only $40 \%$ of unfavorable items (or 8 items). Selective presentation will thus make the mix of information she presents $85.7 \%(48 / 56)$ favorable, an improvement froin blind presentation. Depending on the sanctioming function and the inix of information presented by her opponent, an $85.7 \%$ favorable mix of 56 selected items can be more advantageous than an $80 \%$ favorable mix of 100 blindly presented items. Where it is advantageous, the unadvised party will be selective and present only 56 items of information. If her attorney is $80 \%$ competent, with advice she will instead present 64 favorable items and only 4 unfavorable iteins. Advice will then increase the items she presents from 56 to 68 .

Moreover, even when theoretically advantageous, the practical extent of the incentive for unadvised blind presentation secms sinall because of various obstacles. First, the unadvised party cannot use the strategy unless she has the second move, so that she can observe the opponent's selection first. Second, the strategy is so complex that it is doubtful it would occur often to an unadvised party. Third, the strategy has no potential application unless the unadvised party believes her opponent is more competent. Finally, and perhaps most inportant, the unadvised party may not know (and may have little way of knowing) whether the information unpresented by her opponent has been commouly identified as relevant. Without such knowledge, the unadvised party has little reason to infer from the opponent's nonpresentation that information is favorable. The opponent's nonpresentation may instead mean that the opponent categorized the information as irrelevant or never identified it all. 
nent the more the increase in favorable information presented because of advice will exceed the decrease in unfavorable information presented.

\section{d. Suppressible Information}

Some portion of the information that a party identifies will be suppressible. Advice enabling parties to categorize suppressible information as irrelevant, favorable, or unfavorable has at least one positive effect. When a party mistakenly categorizes irrelevant suppressible information as relevant, advice causes the party to reclassify as irrelevant some information that she would mistakenly have categorized as favorable and saved from suppression or presented. This reduces the amount of irrelevant information reaching the tribunal.

Other effects are more ambiguous. When a party mistakenly categorizes relevant suppressible information as irrelevant, legal advice sometimes results in its recategorization as relevant and either favorable or unfavorable. A party with advice is more likely to prevent opponent suppression and to avoid her own mistaken suppression of favorable information. This increases the total amount of favorable information reaching the tribunal. The advised party is also more likely to suppress froin her opponent and to avoid her own mistaken presentation of unfavorable information. This reduces the amount of unfavorable information reaching the tribunal. Assuming as we do that mistakes in categorizing favorable and unfavorable information occur with equal frequency, and that the amounts of favorable and unfavorable suppressible information are equal, such advice should have no impact on the total amount of relevant information reaching the tribunal. For similar reasons, advice correcting party errors about which side is favored by relevant suppressible information increases the favorable information reaching the tribunal and decreases the unfavorable, with no net impact on the total amount of information presented. In both cases, though, the mix of information is skewed in favor of the advised party.

\section{e. Summary}

Unilateral hitigation advice about how to categorize information has several positive effects. For both nonsuppressible and suppressible information, such advice decreases the amount of irrelevant information presented. For nonsuppressible information, advice that corrects mistaken beliefs that information is irrelevant increases the presentation of both favorable and (less strongly) unfavorable information. For nonsuppressible commonly identified information, advice that corrects party errors about which side is favored by the information tends to mcrease the presentation of favorable information more than it decreases the presentation of unfavorable information, with a net increase in total relevant 
information presented. Advice about categorization also has some ambiguous effects. For relevant suppressible information and (under our working assumption) for nonsuppressible separately identified information, advice causes an increase in the amount of favorable information reaching the tribunal and an equivalent decrease in unfavorable information. The overall effect of advice about categorization is therefore a decrease in the presentation of irrelevant information and an increase in favorable information greater than the decrease in unfavorable information. This increases the total relevant information reaching the tribunal.

\section{Effects of Bilateral Advice}

In a bilateral account, soine effects of advice remain ambiguous. For relevant suppressible information and nonsuppressible separately identified information, advice causes each party to present more favorable and less unfavorable information, with no net effect on the total amount of favorable information or unfavorable information reaching the tribunal about either side. Other effects remain just as positive as in the unilateral account. Providing advice to both parties decreases the amount of irrelevant information each side presents, and advice correctimg mistaken judgments that relevant nonsuppressible information is irrelevant increases the amount of favorable and unfavorable information each side presents. Finally, bilateral advice actually enhances the positive effect of advice on the presentation of commonly identified nonsuppressible information. As in the unilateral account, legal advice improves each party's ability to present favorable information from this set inore than it improves her ability to reduce the presentation of unfavorable information. The tendency for the increase in favorable information presented to exceed the decrease in unfavorable will, however, be greater than in the unilateral account because bilateral advice will improve the opponent's competence. ${ }^{71}$

In suin, when both parties receive advice about categorizing information, each party presents less irrelevant and more relevant information, because advice increases her presentation of favorable information inore than it decreases her presentation of unfavorable information. Because information favorable to one party is unfavorable to the other, the result of bilateral advice is an increase in the presentation of favorable and unfavorable information about each party.

71. See supra notes $67-70$ and accompanying text (discussing the relation between unilateral effects and opponent competence). There may be an offsetting effect to the extent evidence comes in aggregate lumps of favorable and unfavorable information rather than the discrete units we assume. See supra note 32. Increased opponent competence may decrease a party's incentive to present such "Iumpy" evidence, because it increases the likelihood that the opponent will recognizc and present (through advocacy) the unfavorable informational aspects of the evidence. 


\section{B. Legal Advice That Alters Investigation}

\section{Effects of Unilateral Advice on Investigation}

Legal advice helps parties conduct more and better mvestigations in a variety of ways. First, advice helps parties design or conceive of a wider range of feasible investigations. Lawyers better understand the full range of potentially helpful information, the possible modes of imquiry, and the art of framing investigations to maximize the expected value of the response. Lawyers also better understand the significance for the design of imvestigations of whatever information is already at hand. An advised party should thus identify more useful persons to interview or depose, more documents to demand, and more questions to pose in forinal or informal pretrial investigation or at trial. ${ }^{72}$ In consequence, an advised party can effectively choose from more investigative optionshaving both positive and negative expected value-than an unadvised party. A skilled cross-examiner, for example, effectively expands a party's mvestigative options by conceiving of a broad range of follow-up questions. To the extent that the additional feasible investigations identified through legal advice appear to have positive expected values, an advised party will conduct some investigations she would not otherwise have conducted.

Second, legal advice should also increase the amount of imvestigation performed by helping parties make more effective use of the fruits of imvestigation. When an investigation is completed, an advised party will make better decisions about how to categorize the information obtained, whether to present, withhold or suppress it, and how to use that information to pursue further investigation. For example, a party delegating the conduct of a file search to her lawyer can expect to identify more relevant documents and to categorize them more accurately. In consequence, a party who expects to have advice about using the proceeds of investigation will anticipate more benefits and fewer adverse consequences from each feasible investigation of which she is aware. The prospect of advice therefore strengthens the imcentive to investigate. ${ }^{73}$ Some investigations that would have had positive expected values will look even better, and others that would have had negative expected values will now appear positive. A party with advice about using the fruits of imvestigation

72. To the extent that sanctions for failure to produce information in response to a formal or informal demand are sufficiently high to induce production, such deinands permit investigation in the discoverable set. We defer until Section II(C) discussion of how advice influences the level of expected sanctions for failing to respond to those demands for production that are made.

73. The incentive effect will be strongest when confidentiality is absolute or when the party can obtain advice without sharing information with her lawyer, because in those cases the decision to obtain legal advice, standing alone, cannot increase the risk that unfavorable information will reach the tribunal. 
should thus conduct more investigations than one who does not expect to have such advice.

Finally, legal advice improves a party's accuracy in calculating the expected value of a feasible investigation and thus improves her selection of investigations. Advice reduces the probability that a party will mistakenly forego investigations that have positive expected value or mistakeuly conduct investigations that have negative expected value. ${ }^{74}$ For example, a cross-examining lawyer improves the selection of investigations by abandoning a line of inquiry that would require her to divulge unfavorable information. This final effect alters the mix of investigations conducted, but, unlike the first two effects, may increase or decrease the total number of investigations conducted.

The effects of advice on investigation unformly tend to increase the number and proportion of investigations conducted that have positive expected value: a party will conceive of a greater number of feasible investigations, more mvestigations in that expanded universe will have positive value, and the party is more likely correctly to choose to conduct those positive value investigations. Whether advice will increase the nuniber of investigations conducted that have negative expected value is anbiguous. Legal advice about investigation selection elininates some investigations with negative expected value that an unadvised party would mistakenly have conducted. But advice also causes a party to conceive of additional feasible investigations with negative expected value that an unadvised party would not have considered. Legal advice, not being perfect, will not wholly eliminate error in deciding whether to conduct those additional negative expected value investigations, and therefore sone will be conducted in error. Thus, while legal advice will tend to reduce the proportion of negative expected value investigations conducted, it inay mcrease or decrease the total number conducted.

In general, advice that influences investigation should provide a party with a larger pool of information to present. The additional positive expected value investigations conducted because of legal advice should lead to the identification of more favorable information, more unfavorable information that the other party has also obtained, and more irrelevant information that provides helpful investigative leads. The effects of advice on the identification of useless irrelevant information and on the amount of additional unfavorable information made available to the opponent because of investigation are less straightforward. As argued above, sonie of the additional investigations conducted on account of legal advice will actually have negative expected value and are therefore likely to produce such untoward consequences. Moreover,

74. See supra notes 41-48 and accompanying text (distinguishing negative and positive value searches). 
some additional investigations with positive expected values will involve an unavoidable risk of adverse consequences. ${ }^{75}$ For example, it may be worth conductimg discovery to identify critical documents even though it is likely that the discovery will alert the opponent to unfavorable information that he would not otherwise obtain. On the other hand, advice that improves a party's selection of investigations tends to reduce the occasions on which a party identifies irrelevant information or causes additional unfavorable information to reach the tribunal. The general tendency of advice, then, is to increase the ainount of favorable information identified without any predictable mcrease or decrease in the identification, gathering, or divulging of unfavorable information that the opponent would not otherwise obtain. ${ }^{76}$

\section{The Combined Effects of Unilateral Advice on Categorization and Investigation}

We are now in a position to describe the composite effects of unilateral advice on the investigation and categorization of information, on the teniporary assumption that legal advice does not influence the perceived level of evidentiary sanctions for either side. ${ }^{77}$

\section{a. Information Whose Identification Is Influenced by Advice}

Information whose identification is influenced by advice will either be suppressible or nonsuppressible. For nonsuppressible information, advice influencing investigation should strongly increase the presentation of favorable information. Advice influencing investigation causes a party to identify additional favorable information, and advice about categorization increases the probability that the party will correctly present that

75. See supra notes $46-48$ and accompanying text.

76. These effects of advice may be diminished, but not eliminated, by a feedback effect. Distinct investigations with different positive or negative expected values can sometimes produce some of the same favorable or unfavorable information. Accordingly, the expected value of one investigation may depend on whether another investigation that duplicates some of its positive or negative consequences is conducted or eliminated as a consequence of advice. An investigation whose positive consequences are duplicated by a new investigation is less likely to be conducted; an investigation whose negative consequences are duplicated by a new investigation is more likely to be conducted. Because the additional investigations caused by advice have more positive than negative consequences, the feedback effect of those investigations will be a reduction of investigative activity. Similarly, an investigation whose positive consequences duplicate a search eliminated because of advice is more likely to be conducted, while an investigation whose negative consequences duplicate those of an eliminated investigation is less likely to be conducted. Since the investigations eliminated by advice are likely to have more negative than positive consequences, the feedback effect of investigations eliminated by legal advice will also tend to reduce the level of investigation. Because these feedback effects are derived from the principal effects of advice, however, they should only offset rather than eliminate those effects.

77. We relax this temporary assumption in Section II(C). 
additional information. ${ }^{78}$

The effect of advice on the presentation of unfavorable nonsuppressible information, in contrast, depends on the net result of conflicting influences. If the negative consequences of additional investigations conducted with legal advice outweigh the negative consequences of the investigations eliminated by improved selection of investigations, then the party may divulge, identify, or gather inore unfavorable information that the opponent would not otherwise obtain. This should increase the amount of unfavorable information reaching the tribunal. ${ }^{79}$ If the decrease in negative consequences from improved selection of investigations outweighs the increase in negative consequences due to increased investigations, the nonsuppressible unfavorable information reaching the tribunal will decrease. Any increase or decrease in unfavorable information reaching the tribunal will, however, tend to be smaller than the increase in presentation of favorable information. This is because advice tends uniformly to increase the presentation of favorable niformation but has offsetting effects on the presentation of unfavorable information. For similar reasons, advice should reduce the proportion of irrelevant information presented, though it may not decrease the amount of irrelevant information presented. ${ }^{80}$ Advice thus increases the amount and proportion of relevant nonsuppressible niformation reaching the tribunal.

For suppressible niformation, the coinposite effect of advice about investigation and categorization is ambiguous: an increase in favorable

78. To the extent attorneys streamline the presentation of cases involving an abundance of relevant information by selecting the inost forceful evidence to present, legal advice might not, strictly speaking, increase the quantity of favorable information presented. Even if streamlining does decrease the quantity of information, however, the replacement of marginally relevant information with information of stronger relevance should still improve the quality of information presented with effects on adjudication similar to those of an increase in quantity. Thus, our use of the terms "increase in information" or "more information" should be understood to encompass increases in the quality as well as quantity of information presented.

79. Negative consequences of investigation can lead to an increase in presentation of unfavorable information in several ways. First, during investigation the party inay divulge unfavorable information that the opponent would not otherwise have obtained. Second, the party may identify or gather additional unfavorable information that the opponent would not obtain. The party may then divulge that information during further investigation, produce it in response to a discovery demand, or mistakenly present it to the tribunal. Third, the party may identify or gather unfavorable information that the opponent has obtained but will mistakenly fail to present. If the party then mistakenly presents it, the unfavorable information reaching the tribunal will increase.

80. The additional investigations conducted with legal advice will tend to increase identification of irrelevant information, while advice about selection of investigations will tend to reduce it. The result may be an increase or decrease in the amount of irrelevant information identified. If additional irrelevant information is identified, solne of it will, even with legal advice, be mistakenly presented. The overall proportion of irrelevant information presented will certainly decrease, but the absolute amount of irrelevant information presented as a consequence of advice about investigation may increase. On the other hand, if advice reduces the amount of irrelevant information identified as a consequence of investigation, then both the proportion and the amount of irrelevant information presented will decrease. 
information reaching the tribunal and an equivalent decrease in unfavorable information. Party incentives to identify favorable information in order to prevent its suppression are comparable to party incentives to identify unfavorable information in order to suppress it. Legal advice about investigation should therefore effect a coinparable increase in the party's identification of both classes of information. An advised party will thus: (1) rescue froin suppression and present more favorable suppressible information, and (2) suppress inore unfavorable suppressible information. Because we assume equal distributions of miscategorizations and of favorable and unfavorable suppressible information, the increase in favorable suppressible information reaching the tribunal should equal the decrease in unfavorable information.

\section{b. Information a Party Would Identify With or Without Advice}

A party will identify some information whether or not she has received advice: presentation of this information will be unaffected by advice that influences investigation. For such information, the effects of advice are generally those described in Section II(A): a reduction in the amount and proportion of irrelevant information, and an increase in favorable information exceeding the decrease in unfavorable information. However, the analysis in this Section suggests that the tendency of the increase to exceed the decrease may even be stronger than described in Section II(A). That Section proceeded on the assumption that nothing could be said about the mix of separately identified information. ${ }^{81}$ The set of information a party would have identified with or without advice, however, in part consists of information the party would have identified through investigation whether or not she had legal advice. Because these investigations will tend to have positive expected values, that information should consist predominantly of favorable information. In general, the information that would have been cominonly identified with or without legal advice is just as likely to be favorable as unfavorable. Accordingly, the inix of information identified by ouly one party with or without legal advice should be more favorable than unfavorable, and advice about presentation should to that extent tend to increase the presentation of favorable information more than it reduces the presentation of unfavorable information.

\section{c. Summary}

Out of the set of information that would have been identified with or without legal advice, the increase in favorable information exceeds the decrease in unfavorable information. Out of the additional nonsup-

81. See supra note 66 and accompanying text. 
pressible information identified because of legal advice, favorable information imcreases strongly and unfavorable information may weakly increase or decrease. Out of the additional suppressible information identified, the increase in favorable information equals the decrease in unfavorable information. The coinbimed result is that unilateral advice about investigation and categorization mcreases the total favorable information reaching the tribunal inore than it decreases the total unfavorable information.

\section{Effects of Bilateral Advice}

Providing legal advice to both parties enhances the positive effects of legal advice on investigation. Each party's own advice enables it to conduct inore and better investigations. Thus, each should identify and present inore relevant nonsuppressible information. Conversely, whether bilateral advice that influences investigation alters the amount of suppressible information presented is wholly uncertain. With advice, each party is better able to identify and prevent the suppression of information favorable to her position, and to identify and suppress unfavorable inforination. In the bilateral account, improved efforts to suppress are met by improved efforts to prevent suppression. We can discern no basis for predicting whether a battle between two advised parties leads to more or less suppression than a battle between unadvised parties. The net effect of bilateral legal advice on investigation and information selection is thus to increase the favorable and unfavorable information about each party reaching the tribunal. The proportion (and perhaps amount) of irrelevant information reaching the tribunal should also decrease.

\section{The Effects of Legal Advice on Effective Evidentiary Sanctions}

Successful withholding and suppression of unfavorable information reduces the information reaching the tribunal. Whether a party or her opponent will find it worthwhile to withhold or suppress information that she has categorized as unfavorable will depend on the perceived sanctions for doing so. Legal advice can affect those evidentiary sanctions in three inain ways. First, advice can correct misperceptions of expected evidentiary sanctions. Second, legal advice can influence the actual level of those sanctions. Finally, because in giving advice the party's lawyer soinetimes becomes personally susceptible to evidentiary sanctions, retaining a lawyer can increase the effective evidentiary sanctions the client faces.

\section{Effects of Unilateral Advice on Parties' Evidentiary Sanctions}

Legal advice correcting party misperceptions of expected sanctions for withholding or suppression can increase or decrease the ainount of 
information reaching the tribunal. Unadvised parties may over- or underestimate the scope or level of expected evidentiary sanctions. ${ }^{82}$ If a party underestimates evidentiary sanctions, advice will reduce the amount of information withheld or suppressed; if the party overestimates sanctions, advice increases withholding or suppression. Since we assume in our initial stylized account that parties are just as likely to make one kind of error as the other, advice that corrects unisperceptions of sanctions has no general effect on the amount of unfavorable information reaching the tribunal. ${ }^{83}$

Legal advice can also influence the level of actual evidentiary sanctions by improving how a party handles information about instances of withholding and suppression that may or do become the subject of the "hitigation within a litigation" described in Part I. In a unilateral account, we expect that advice influencing the level of evidentiary sanctions for the party or ler opponent will systematically increase the presentation of information favorable to the advice recipient and decrease the presentation of unfavorable information.

Providing advice to a party should raise expected evidentiary sanctions for lier opponent ${ }^{84}$ because an advised party can identify and pres-

82. Of course, if expected sanctions were sufficiently high to induce the production of all information the opponent deinanded, legal advice on these topics would always lead a party to produce any of that information. Obviously, evidentiary sanctions are not in fact that high; nor are they likely ever to be that high because, in a world where tribunals cannot obtain perfect information about evidentiary conduct, increasing sanctions for apparently undesirable withholding will have two adverse effects. First, it will increase expected sanctions for truthful nonproduction. See Shavell, Optimal Sanctions and the Incentive to Provide Evidence to Legal Tribunals, 9 INT'L REV. LAw \& EcoN. 3, 4-5 (1989). For example, increasing sanctions for witnesses who appear to be withholding information because they stare at the floor or stammer will result in higher evidentiary sanctions for truthful witnesses who exhibit those behaviors. Second, it will increase sanctions for desirable withholding and suppression that is mistaken for the undesirable variety. Withholding or suppression might be regarded as desirable despite its adverse informational effects because it protects privacy, prevents coercion, or promotes other desirable conduct in or out of court. The fourth and fifth amendinents, and various evidentiary privileges, protect the right to withhold or suppress information in part for these very reasons. Thus, even if optimally chosen, evidentiary sanctions can do no more than trade off underdeterrence of undesirable withholding and suppression against overdeterrence of truthful nonproduction and desirable withholding and suppression. $C f$. id. (inodeling sanctions that would optimize underdeterrence of withholding and overdeterrence of truthful nonproduction).

83. Legal advice also affects party estimates of the benefits of withholding and suppression. We have already discussed the effects on presentation, withholding, or suppression of advice that corrects party perceptions about which side is favored by information. In theory, advice inay also infuence party perceptions of the benefits of withholding or suppression by correcting party misperceptions of the extent to which information is unfavorable. Without legal advice, a party inay over- or underestimate how damaging unfavorable information will be: such advice accordingly could increase or decrease the unfavorable information reaching the tribunal. Because this additional marginal effect has no impact on our basic conclusions, we do not consider it further.

84. This increase in evidentiary sanctions may not be socially desirable, because sanctions will also increase for socially desirable withholding or suppression and for socially desirable conduct (such as telling the truth) that sometimes is not readily distinguishable from undesirable withholding 
ent more secondary information indicating that her opponent is engaged in improper withholding or suppression. In part, this advice operates before the opponent makes a decision to withhold or suppress. An advised party can better frame demands for information that increase expected sanctions for failures to produce that information. ${ }^{85}$ Questions framed with legal advice are, to illustrate, much more likely to expose an evasive witness. ${ }^{86}$ In part, this advice operates after the opponent's claimed act of withholding or suppression has oceurred. Should a dispute arise about whether withholding or suppression has taken place, for example, legal advice will enable a party to identify and present to the tribunal more secondary information indicating that the opponent engaged in improper withholding and less secondary information indicating that the opponent did not. Finally, some forms of advice operate before and after the act. The simplest example is perhaps the inost telling: to the extent an advised party identifies more information about the disputed primary conduct, the odds of detecting an opponent's lies increase. These effects, taken together, suggest that the opponent will experience an increase in expected sanctions for both withholding and suppression and will therefore withhold or suppress less information favorable to the party receiving advice. With legal advice about investigation and presentation, the party is thus able to identify and present more favorable information that the opponent fails to withhold or suppress, increasing the overall amount of favorable information presented to the tribunal.

Providing a party with advice also decreases her own expected sanctions for withholding and suppression. ${ }^{87}$ Legal advice given prior to an act associated with a risk of evidentiary sanctions may enable a party to commit that act in a way that minimizes the creation or disclosure of

or suppression. See supra note 82 . The inquiry in this Article is limited to the informational effects of advice and does not consider when and whether withholding or suppression might be desirable despite its adverse informational effects.

85. An advised party should also be able to make more demands for production. One could regard this as advice that increases the opponent's sanctions for withholding (from nothing to soinething). We have, however, chosen to categorize this as advice that increases investigation, see supra note 72 and accompanying text, and thus, to avoid donble-counting, we do not also treat it as advice that influences the level of sanctions. The choice of categorization does not change the substance of our conclusions. In either event, advice that increases the number of demands for production that are made should increase the presentation of information from the opponent's discoverable set.

86. This will not always mean that the witness actually is being evasive or withholding information. Sometimes expert questioning can make the witness appear to be withholding even when she is not. Thus, legal advice can increase the likelihood that an opponent will suffer evidentiary sanctions, whether or not she actually was withholding or suppressing information.

87. As with the increase in the opponent's expected sanctions, this decrease in the party's expected sanctions inay be undesirable (where the party engages in undesirable withholding or suppression) or desirable (where the party truthfully said she did not have the information or engaged in desirable withholding). See supra note 82. 
unfavorable secondary information about the act and maximizes the creation of favorable secondary information. For example, an advised party who lies about a relevant fact may be less likely to include in lier story details tliat can be proven false or that are true but sound "too good to be true." A party faced with a question in discovery that calls for unfavorable information but that can be evaded may give an incomplete or nonresponsive answer. Or a party may purposefully overlook a memorandum within the scope of a demand for production but take pains to document otlier steps suggesting tliat the party's production was complete and diligent. Advice thus reduces unfavorable secondary information about the evidentiary act available to the opponent, mcreases the favorable secondary information available for presentation, and therefore reduces the likelihood that the act will be sanctioned. In addition, after an evidentiary act, legal advice in any proceeding where the opponent claims that improper witliholding or suppression lias oceurred enables the party, under the foregoing analysis, to present more favorable and less unfavorable secondary information about its evidentiary conductwith the increase in favorable secondary information exceeding the decrease in unfavorable secondary information.

Both advice about how to commit an act of witliholding or suppression and advice about how to defend sucl an act reduce the unfavorable secondary information about the evidentiary act reaching the tribunal while increasing the favorable secondary information. Expected evidentiary sanctions for tlie party's witliholding and suppression slould therefore decrease. A party with advice is thus more likely to find it worthwhile to witlihold or suppress unfavorable information about primary conduct than a party without advice. The additional unfavorable primary information witliheld or suppressed will reduce tle opponent's presentation of unfavorable primary information and decrease the unfavorable primary information reaching the tribunal.

The cumulative effect of unilateral advice influencing the level of evidentiary sanctions is thus ambiguous. It increases the favorable primary information presented and reduces the unfavorable primary information presented. Depending on the relative magnitudes of this increase and decrease, it may either increase or decrease tlie total amount of relevant information reaching the tribunal. ${ }^{88}$

88. This overall result does not necessarily change with differences in opponent competence. As opponent competence increases, both the increase in opponent expected evidentiary sanctions and the decrease in the party's own expected evidentiary sanctions should be smaller, with offsetting effects on the total amount of information that the parties find it in their interest to withhold or suppress. 


\section{Lawyers' Personal Susceptibility to Evidentiary Sanctions}

Sometimes legal advice will decrease the amount of mformation suppressed or withheld because of evidentiary sanctions applicable to the lawyer giving advice. Lawyers are sometimes subject to sanctions for providing advice about withholding or suppressing information or for failing to disclose unfavorable information to the tribunal. In addition to criminal sanctions for subornation of perjury and obstruction of justice, disciplinary rules in almost all American jurisdictions forbid lawyers from knowingly assisting or counseling the criminal or fraudulent withlolding or suppression of unfavorable information and require lawyers to withdraw when they know that their clients are using advice for those purposes. ${ }^{89}$ A lawyer is also obligated, in circumstances that vary from jurisdiction to jurisdiction, to disclose physical evidence of crimes ${ }^{90}$ and to disclose unfavorable information to the tribunal in order to rectify withholding or suppression that results in the presentation of evidence the lawyer knows is false. ${ }^{91}$ Withdrawal and disclosure, the two acts required of a lawyer in order to avoid sanctions, can both severely harm the party. In addition, public prosecutors and lawyers appearing in ex parte proceedings must disclose exculpatory information to opponents in circumstances where parties to civil litigation would ordinarily have no obligation to do so. ${ }^{92}$

A lawyer's exposure to sanctions typically depends in substantial part on whether slie is aware of information unfavorable to her client. A lawyer may become aware of unfavorable information because a client divulges it to her or because the client delegates to her the tasks of investigation and presentation. Not every party will allow her lawyer to obtain unfavorable information. Sophisticated clients can sometimes nake fully informed decisions without sharing information. ${ }^{93}$ Others may decline to share information because the advantages of better informed decisions do not seem worth the increased risk of their lawyer's disclosure or witldrawal. ${ }^{94}$ But some parties will find that the expected

89. See, e.g., MODEL RuLEs, supra note 1, Rules 3.3, 3.4; MODEL CODE, supra note 2, DR 7$102(A)(3)-(6)$.

90. In some states, a lawyer who obtains possession of physical evidence of a crime committed by his client comes under an obligation to turn that information over to the prosecutor. See, e.g., People v. Meredith, 29 Cal. 3d 682, 686-87, 631 P.2d 46, 48-49, 175 Cal. Rptr. 612, 614-15 (1981); Morrell v. State, 575 P.2d 1200, 1206-11 (Alaska 1978).

91. MODEL CODE, supra note 2, DR 7-102(B)(2); MODEL RulEs, supra note 1, Rule 3.3(a)(4).

92. MODEL RulEs, supra note 1, Rule 3.8(d) (prosecutor's obligation); id. Rule 3.3(d) (requiring the presentation of "all material facts" in an ex parte proceeding).

93. For example, a sophisticated client's lawyer may, without learning the client's information, be able to describe in hypothetical terms what kinds of information are unfavorable, confident that the client will be able to apply that knowledge to withhold or suppress information matching that description without implicating her lawyer. See K. MANN, supra note 30, at 109-11.

94. Prndent sanction-optimizing lawyers may advise chents when to share information or 
benefits of better informed decisions outweigh the expected costs of sharing unfavorable information with their lawyer. ${ }^{95}$ Others will discover that as a practical matter they cannot obtain advice about investigation and presentation without delegating execution of those activities to a lawyer, who as a result will become aware of information unfavorable to her chent.

The lawyer's awareness of unfavorable information can be significant when it would be in the party's interest, given the harmfulness of the information and the level of expected sanctions applicable to the party, to withhold or suppress the information. In such cases, the lawyer's personal susceptibility to sanctions will soinetimes cause the lawyer to take actions that prevent withholding or suppression. Sometimes the lawyer will increase the chent's effective expected sanctions for withholding or suppression..$^{96}$ If the decision to withhold or suppress is made in consultation with the lawyer, for example, the lawyer may insist that the party refrain from withholding or suppressing the information. The lawyer inay back that insistence with a threat either to withdraw from representing the party if she commits evidentiary misconduct or to disclose the misconduct or the unfavorable information to the tribunal..$^{97}$ Sometimes the lawyer inay disclose the information on her own. When the party has delegated the task of coinpliance to her lawyer, the lawyer's differing incentives may cause the lawyer, without consulting with the chent, to comply with the client's obligations more fully than the chent would liave done. In either case, the lawyer's action will increase the amount of information unfavorable to the party that reaches the tribunal.

delegate investigation by weighing the advantages of the lawyer knowing the information or executing the investigation against the disadvantages of restricting the client's ability to withhold or suppress the shared or attorney-identified information. Where a high risk exists that the information to be shared or identified is unfavorable and that any evidentiary misconduct by the attorney will be detected, and a low probability exists that the opponent would obtain the information if the chent commits evidentiary misconduct, such lawyers may advise their clients against sharing information or delegating investigation. See infra note 235 (describing an instance of this strategy).

95. Cf. supra notes 54-59 and accoinpanying text (assuming that to soine extent parties can obtain legal knowledge only by hiring lawyers during litigation).

96. Obviously, there will be solne lawyers who break the rules by actively assisting in unlawful evidentiary conduct. See Berentson, Integrity Test: Five of Thirteen Lawyers Fail, AM. LAW., May 1980 , at 15. The general effect we predict, however, requires only that some lawyers be deterred from doing so and that their actions sometimes increase the unfavorable information presented by their clients.

97. See generally Kraakman, Gatekeepers: The Anatomy of a Third-Party Enforcement Strategy, 2 J.L. ECON. \& ORG. 53, 53-56 \& n.3, 58-60 (1986) (discussing and contrasting enforcement strategies that rely on "whistleblowers" with strategies that impose a duty on "gatekecpers" to disrupt misconduct by withholding their support to wrongdoers). Lawyers who are uncomfortable forcing the production of information that their clients would find advantageous to withhold or suppress may achieve the same results by exaggerating to their clients the adverse consequences the clients might suffer by failing to comply. $C f$. Gordon, The Independence of Lawyers, 68 B.U.L. REv. 1, 35 (1988) ("exercises of independence are as likely to be covert as overt, secreted in the interstices of prudential counseling"). 
The conclusion that evidentiary sanctions apphicable to lawyers will sometimes cause lawyers to act contrary to their chents' interests is highly plausible. Lawyers as a class are repeat players with a substantial investment of human capital in their professions. ${ }^{98}$ They also face evidentiary sanctions that are different from and often proportionately more stringent than those faced by their chents. In most instances, a single case represents a small part of an attorney's career and hivelihood, and the benefit the attorney derives from assisting her chient in sanctionable witliholding or suppression will seem correspondingly low. ${ }^{99}$ The expected costs of misconduct, im contrast, may loom very large even if the risk of detection for any given instance of misconduct is low. A lawyer who becomes imvolved in suborning perjury, destroying evidence, or deliberately disobeying discovery requests risks her reputation, disciplinary proceedings, and im some cases her career. ${ }^{100}$ For a chent, a wim or loss $\mathrm{m}$ a given case is likely to assume much greater importance, while the effect of sanctions is more likely to be limited to the case at hand.

On some occasions, then, attorneys will conclude that their expected evidentiary sanctions exceed their personal benefit from witliholding or suppressing infornation unfavorable to their chent and will act contrary to their chents' interests. ${ }^{101}$ We therefore expect that when a party

98. As Professor Kraakman notes, a wrongdoer has more difficulty corrupting a gatekeeper when either (1) entry into the gatekeeping market requires a significant investment (which leaves the gatekeeper more vulnerable to legal sanctions), or (2) the gatekeeper has a diversified client base (which leaves the gatekeeper less vulnerable to client pressure). Kraakman, supra note 97, at 70-71.

99. To be sure, sometimes lawyers who become aware of information unfavorable to their chent inay not experience or act upon the divergent sensitivity to sanctions that we describe. Soine lawyers work "in-house" as full-time einployees. Many attorneys in larger firms do most of their work for, and are beholden to, only one or two clients. R. NELSON, PARTNERS WITH Power 25051 (1988). To the extent that the lawyers in these law firms collectively suffer sanctions for evidentiary misconduct that benefits a firm client, the firm's expanded client base should give the firm incentives to discourage its attorneys from engaging in evidentiary misconduct. If, however, the firm escapes collective sanctions for participation by its lawyers in wrongdoing, see Pavelic \& LeFlore v. Marvel Entertainment, 110 S. Ct. 456 (1989) (holding that sanctions under Fed. R. Civ. P. 11 cannot be imposed on the firm of a lawyer who violated the rule), does not liave a diverse client base, or has an imperfect monitoring system, large firm lawyers with few clients sliould, compared to other lawyers, experience less of a systemic divergence between the benefits and sanctions they perceive and those perceived by their chents. Even in such cases, though, the lawyers' benefit from assisting withholding will be less than the full benefit to the parties, since tle lawyers are not fully identified with the clients' interests.

100. More subtle sanctions may also operate. For example, lawyers who do not respond diligently to discovery requests that cannot be evaded honestly may find themselves repaid in kind when they make discovery requests in this or other cases.

101. This conclusion may secm at variance with recent accounts of cases in which attorneys actively engaged in discovery abuse. See, e.g., Kiechel, supra note 44; Rhode, supra note 11, at 59899. But none of these anecdotal accounts (nor to our knowledge any systematic study) coinpares discovery compliance when chents lack legal advice witl compliance when clients have sucli advice.

Some evidence suggests that clients and attorneys often have the different incentive structure we suggest. See, e.g., K. MANN, supra note 30, at 109-12, 117-22 (discussing elite white-collar criminal defense lawyers); Landon, Clients, Colleagues, and Community: The Shaping of Zealous Advocacy in 
receives legal advice, sanctions applicable to lawyers will sometimes cause a party to fail to withhold or suppress information that the party would have withheld or suppressed without legal advice. ${ }^{102}$

\section{The Cumulative Unilateral Effects on Effective Evidentiary Sanctions}

In our basic account, the cumulative effects of unilateral advice that influences the withholding and suppression of information identified as unfavorable are as follows. Given our assumption that parties do not systematically over- or underestimate the level of sanctions, advice that corrects imsperceptions about the level of evidentiary sanctions will neither increase nor decrease the amount of unfavorable information reaching the tribunal. ${ }^{103}$ Advice that influences the actual level of evidentiary sanctions has no predictable effect on the amount of relevant information reaching the tribunal. It increases expected evidentiary sanctions for the opponent of the party receiving advice, which results in an imcrease of uncertain magnitude in the favorable information presented; it also reduces expected evidentiary sanctions for the party receiving advice, which causes a decrease of uncertain magnitude in the

Country Law Practice, 1985 AM. B. FouND. RES. J. 81, $105-09$ (discussing lawyers in sunaller cities). Such divergent incentives may be more common when there is a continuing relationship between the lawyer and opposing counsel, or the lawyer and the tribunal, that increases the importance of the lawyer's reputation, and hence the significance of potential reputational sanctions for misconduct.

102. As we spell out in greater detail in Section V(B), this increase in the presentation of information unfavorable to the party receiving advice is not without costs. For the party receiving advice, the risk that the lawyer will act contrary to her interest will deter soine information sharing or investigatory delegation which would in turn facilitate advice that would increase the amount of relevant information presented by each side. Thus, while providing advice to one party in a model that takes account of lawyer sanctions will cause the presentation of unfavorable information that would not have been presented if the party had no lawyer, the amount of relevant information reaching the tribunal in a regime with legal advice and lawyer sanctions may or may not be greater than the amount of information in a regime with legal advice and no lawyer sanctions.

We leave out here the effect of providing advice for one party on the evidentiary sanctions applicable to the opposing party's lawyer, if she has one. The opponent's lawyer should anticipate an increase in evidentiary sanctions because the party is better able to detect and proseeute wrongdoing. But that increase in sanctions will also be accompamied by an increase in advice deterred. Accordingly, increased evidentiary sanctions for the opponent's lawyer may or may not result in an increase in information reaching the tribunal.

103. Similarly, in cases where a party has decided to comply with an obligation to produce or preserve information, legal advice about how to comply with the party's obligation will have no predictable effect on the amount of unfavorable information reaching the tribunal. Without advice a party might mistakenly produce more or less information than called for. For example, unadvised parties may lack the techurical expertise necessary to identify every document covered by a demand for all documents relevant to an issue. This may lead them to produce only the documents they can identify as responsive-thus mistakenly withholding soune unfavorable information that has been deunanded-or to take an "everything-and-the-kitchen-sink" approach and produce all documents they have-thus mistakenly presenting some unfavorable information not called for. Legal advice about teehnical compliance thus has no systenic tendency to increase or decrease the amount of unfavorable information reaching the opponent or the tribunal. 
unfavorable information reaching the tribunal. Finally, lawyers' divergent susceptibility to sanctions has a positive effect. In soine cases, sanctions apphicable to lawyers will cause the presentation of unfavorable information that would have been withheld or suppressed without legal advice. The net effect of unilateral advice thus appears to be an increase in favorable information presented that tends to be larger than the increase in the unfavorable information withheld or suppressed.

\section{The Effects of Bilateral Advice}

In a bilateral account, evidentiary sanctions applicable to lawyers should sometimes cause each party to produce or preserve information she would have withheld or suppressed without legal advice. This increases both the favorable and unfavorable information about each party reaching the tribunal.

The effects of bilateral advice on expected evidentiary sanctions applicable to parties have less clear implications for the amount of inforination about primary conduct that reaches the tribunal. In a unilateral account, the party receiving advice experiences a decrease in expected evidentiary sanctions and her opponent experiences an increase. In a bilateral account, the superior knowledge and skills of the opposing attorneys will tend to offset. But the outconie should not be a wash. The prior Sections suggest that, just as for information about priniary conduct, legal advice should increase the favorable secondary information presented by each side about any claimed incident of withholding or suppression more than it decreases unfavorable secondary information. Bilateral advice should accordingly increase the presentation of favorable and unfavorable secondary information about both parties' evidentiary conduct.

This increase in information about evidentiary conduct need not lead to a uniform increase in expected sanctions for withholding or suppression by either side, and thus niay not increase the information about primary conduct reaching the tribunal. It would tend to do so if evidentiary sanctions were set on the assumption that all withholding or suppression is socially undesirable. But in fact evidentiary sanctions are often set on the assumption that sone withholding and suppression is socially desirable. ${ }^{104}$ Increased presentation of secondary information should, however, generally increase expected sanctions for undesirable withholding and suppression and decrease then 1 for desirable withholding and suppression, for reasons we spell out in Part IV.

For example, expected sanctions agamst the willful destruction of docunients should increase, with a concomitant increase in the amount of

104. See supra note 82 . 
information reaching the tribunal. But the likelihood that the tribunal will sustain appropriate assertions of doctor-patient privilege should also increase, reducing the information reaching the tribunal. The overall effect depends on whether instances of undesirable withholding or suppression (like willful destruction of documents) that would be underdeterred without bilateral advice are more or less common than instances of desirable witlholding or suppression (like appropriate claims of privilege) that would be overdeterred without bilateral advice. Because we cannot tell whether under- or overdeterrence is more cominon, we cannot predict whether bilateral advice that influences the party's expected sanctions for withholding or suppression will increase or decrease the total amount of relevant information about primary conduct reaching the tribunal. ${ }^{105}$

\section{Summary of the Basic Account}

Our basic account enables us to draw soine initial conclusions about the general informational effects of legal advice. In the basic unilateral account, advice reduces the proportion of irrelevant information presented. It also increases the presentation of information favorable to the party receiving advice more than it reduces the presentation of inforination unfavorable to that party. This initial conclusion reflects several positive effects. Advice about how to categorize relevant commonly identified information or information unadvised parties would iniscategorize as irrelevant increases the presentation of favorable information strongly but has no comparable negative effect on the presentation of unfavorable information. The same is true of advice that influences the investigation of nonsuppressible information. In addition, evidentiary sanctions applicable to lawyers sometimes cause the presentation of unfavorable information that would not have been presented without legal advice. Our imitial conclusion also reflects ambiguous effects: advice about how to categorize information that can be witliheld or suppressed, advice about investigations conducted to identify suppressible information, and advice about how to assess or influence sanctions for witliholding and suppression each tend to increase the favorable information presented but to cause possibly equivalent decreases in unfavorable information presented. On balance, though, advice increases the amount and proportion of relevant information.

105. Another complication is that increased opponent competence increases the likelihood that the opponent will recognize and present any unfavorable information a party does not witlihold or suppress. This has two conflicting effects. On the one hand, it means that a greater proportion of the information that is not witliheld or suppressed will reach the tribunal. This will tend to enhance the informational increase from bilateral advice. On the other hand, it imcreases the benefits of withholding and suppressing unfavorable information. This will tend to offset any increase in expected evidentiary sanctions and reduce the information reaching the tribunal. 
In the basic bilateral account, the positive effects of advice are preserved and enhanced and some ambiguous effects appear muted. For each party, the net increase in relevant information presented will be greater than if she had been the only party to receive advice, because the positive informational effect of advicc about categorization is stronger when the opponent is more competent. ${ }^{106}$ Moreover, im a bilateral account, there is no reason to predict that advice influencmg investigations that identify suppressible information or advice influencing the level of expected evidentiary sanctions will systematically mcrease or decrease the presentation of favorable or unfavorable information about either side's primary conduct. ${ }^{107}$

This general account clarifies the serious limitations of the account of legal advice recently offered by Professors Kaplow and Shavell. Kaplow and Shavell present a model of advice about information selection and estabhish that within the model advice has ambiguous informational effects. They then assert, with some qualifications regarding advice about mvestigation, that the resnlting informational "analysis apphes more broadly, to virtually all the choices lawyers make on clients' behalf." 108 Their model is, however, too limited to sustam this sweeping claim or to justify any general policy implications about how litigation advice should be regulated.

First, because Kaplow and Shavell's model assumes each party has "perfect control" over its information, ${ }^{109}$ they ignore the possibility that an opponent's ability to present information favorable to his position might limit the ability of a party with selection advice to prevent the tribunal from receiving information unfavorable to her side. Second, because their model assumes that all information is relevant, ${ }^{10}$ they ignore advice about relevance and thus the possibility that such selection

106. See supra notes $67-70$ and accompanying text.

107. See supra text following note 80; supra note 105 and accompanying text.

108. Kaplow \& Shavell, supra note 17, at 593.

109. See id. at 576. Kaplow and Shavell beheve that the assumption of perfect control alters only the "extent" and not the basic nature or direction of the effects they predict for advice about how to categorize information as favorable or unfavorable. See id. Our analysis of commonly identified information demonstrates that this behef is false. See supra Section II(A)(1)(c)(ii). Our analysis of investigation also demonstrates that, even if one assumes perfect control, Kaplow and Shavell are incorrect in beheving that the nature and direction of the effects of categorization advice are not affected by their assumption that lawyers have perfect knowledge. See Kaplow \& Shavell, supra note 17, at $578 \&$ n.26. Because the effect of categorization advice on investigation can increase a party's identification of unfavorable information, see supra Section II(B)(2)(a), an attorney's erroneous presentation of some of this additional unfavorable information could conceivably increase the unfavorable information reaching the tribunal.

110. See Kaplow \& Shavell, supra note 17, at $577 \mathrm{n.25}$ (assuming all evidence is either "definitely favorable or definitely unfavorable"). Our analysis demonstrates that accounting for advice that corrects either mistaken beliefs that information is relevant or mistaken beliefs that information is irrelevant has beneficial informational effects that Kaplow and Shavell do not predict. See supra Sections II(A)(1)(a), (b). 
advice could improve the quality of the parties' presentations. Third, their model takes no account of the influence of advice on investigation or the possibility that such advice might increase the information from which each party selects. ${ }^{111}$ Fourth, their assumption that parties with advice exercise perfect control over their information excludes the influence of legal advice on the perccived and actual costs of withholding information. That assumption, and the further assumption that lawyers act with the sole aim of lowering their clients' expected sanctions, ${ }^{112}$ also eliminate any possibility that the lawyer's personal susceptibility to sanctions for improper hitigation conduct might lead to the production of additional infornnation.

Our account shows that for all four aspects of litigation excluded from Kaplow and Shavell's model, advice has a general tendency to increase the information reaching the tribunal. Kaplow and Shavell have modeled the vices of competition between skilled partisans without modeling any of its virtues: competitive selection of information, focused presentation, improved investigation, and compelled production. In the cases that best fit their model, such as those where parties liave no obligation to produce information or freely conspire with their lawyers in wrongful withholding, the social value of legal advice has long been doubted, and properly so. ${ }^{113}$ Kaplow and Shavell's deinonstration that within their tightly restricted focus the informational effects of advice are formally ambiguous is an important advance. But given tlie incomplete

111. See Kaplow \& Shavell, supra note 17, at 568 (assuming that the "sole function" of lawyers is assisting parties in "selecting which evidence to present to a tribunal"). Discovery and factinvestigation are the only areas in which Kaplow and Shavell acknowledge that their model is "incounplete" in any way that might limit its general apphicability. Id. at 594 n.67. Our analysis demonstrates that the effects predicted under a more complete model that mcludes investigation do in fact differ from those predicted under the Kaplow and Shavell model. See supra Section II(B).

112. See Kaplow \& Shavell, supra note 17, at 583, 570 n.3, 577.

113. Consider, for example, a fictional example of legal advice that has engaged the attention of many professional responsibility scholars: the "lecture" from the novel The Anatomy of a Murder. The chent, accused of premeditated murder, tells his attorney information about his mental state during the killing that plainly indicates his guilt. R. TRAVER, The ANATOMY OF A MURDER 30-33 (1958). The attorney responds by explaining how different testimony could establish a defense of temporary insanity, and the chent then "forgets" the incriminating information previously disclosed. Id. at 44-49. Even Monroe Freedman, perhaps the most intemperate defender of zealous advocacy, concedes that the conduct of the attorney in the "lecture" is socially undesirable and ethically indefensible. M. FreEDMAN, supra note 9, at 73-74. The "lecture" fits Kaplow and Shavell's model well: only the defendant has direct access to information about his inental state, the relevance is clear, little investigation is necessary to obtain the information, defendant's sanctions for withholding are low, and the attorney is apparently indifferent to the risk of sanctions for suborning perjury. We account for such cases under the heading of advice about how to categorize separately identified information that would have been identified with or without investigation, and that an unadvised party would correctly categorize as relevant. See supra notes 63-66 and accompanying text. As our account makes clear, however, these effects form only a sunall subset of the effects of advice. 
and biased character of their model, it provides a shaky basis for analyzing the overall informational effects of litigation advice or deriving policy implications.

Our bilateral account seems particularly suited for analyzing the classic account of civil hitigation, which posits parties of roughly equal coinpetence who benefit equally froin legal advice and who have relatively equal access to information. An exanple demonstrates botll how our account might play out in practice and how the partial perspectives of some critics and defenders of legal advice lead to inaccurate conclusions. Consider a suit for breach of contract in which the plaintiff and defendant can eacli present one eyewitness to the making of an alleged oral contract. Doubters like Professors Kaplow and Shavell might focus on the information about the disputed conversation that the parties control and would identify as relevant without advice. From this partial perspective, the lawsuit appears to be simply a "swearing contest." Bilateral provision of advice will have no beneficial impact on the tribunal's ability to render judgment. Instead it will skew each party's presentation of its controlled information, with no change $\mathrm{m}$ the total anount of relevant information reaching the tribunal.

A defender would point, however, to other features of the case that cast legal advice in a more favorable hight. Advice should increase both parties' presentation of nonsuppressible relevant information about the transaction that would mistakenly be categorized as irrelevant. It will also increase the presentation of information that is not party-controlled or tliat can be obtained only through investigation. This additional information should provide a better picture of the parties' conversation, the setting and circumstances in which the conversation occurred, the parties' relative sophistication and the history of their dealings with others, and the custom or practice in the relevant inarket. The tribunal will thus have a better baseline for evaluating the plausibility of the parties' competing claims about the alleged agreement.

The cumulative effect of bilateral advice thus emerges as an overlay of ambiguous and positive consequences. At a contested trial, the dramatic prominence of live testimony by the two witnesses to the conversation may create the impression that ambiguous effects predominate. But in reality even the witnesses' testimony about the critical conversation ouglit on balance to be more informative than it would have been without advice, because each will present additional party-controlled inforination about their interaction that they would have miscategorized as irrelevant or missed in investigation. Moreover, because the parties' joint account of the background to the transaction will also be more informative, the tribunal will be in a better position to render judgment than if the parties had no legal advice. 
Other civil hitigation may be more amenable to analysis under the unilateral account. Consider a case where one party can afford advice, but the other cannot. The unilateral account allows us to consider the effects of both a decision to deny advice to the party who can afford it and a decision to subsidize advice for the party who cannot. Denying advice to the first party will increase her expected sanctions for primary conduct. But because legal advice increases the amount of favorable information presented more than it decreases the amount of unfavorable information presented, denying advice will also reduce the amount of relevant information reaching the tribunal.

Providing advice to the party who cannot afford it will, on the other hand, strongly imcrease the amount of relevant information reaching the tribunal. An example is the claim brought by a "private attorney general," such as an antitrust, securities, or discrimination class action, or an environmental enforcement suit. In such cases the retention of counsel is sometimes made possible by the promise of an award of attorneys' fees to successful claimants. ${ }^{114}$ Providing legal advice to the plaintiffs will mcrease the defendants' expected sanctions for withholding and suppression, thus increasing the amount of information that is available to both sides and not suppressed. It will also increase the amount of information that the plaintiff will identify, gather, and present from the information available to both sides.

\section{III}

\section{The Generality of the Basic Account Conclusions}

In this Part, we introduce various complications into our basic account and examine the extent to which these coinplications alter our imitial conclusions. These coinplications fall into four general categories: (1) factors relating to the costs of hitigation and the possibility of settleinent; (2) parties and lawyers who are law-abiding or truth-telling; (3) information that influences the tribunal in a socially undesirable way; and (4) unequal distributions of information, access, or errors. All these coinplications may modify our initial conclusions. Indeed, some help identify special conditions under which the general effects of advice predicted in Part II will not occur. We conclude, however, that many of these coinplications provide no affirmative reason to alter our initial conclusions.

114. The private attorney general may otherwise be unable to raise the funds for legal advice, not only because those she represents may be too poor or because their expected financial gain from litigation may not merit the cost, see supra note 57, but also because large groups with low per capita stakes face greater frec rider problems in collecting funds, see M. OLSON, THE LoGIC of COLLECTIVE ACTION 33-36 (1965). 


\section{A. Cost-Related Factors}

In our basic account, we abstracted from the costs of legal advice by setting them at zero. We also abstracted from settlement and other strategic aspects of hitigation im assuming that parties sought only to optimize sanctions and their own hitigation costs. We reintroduce those complications here.

\section{The Costs of Legal Advice}

Lawyers charge fees. This may alter the behavior of parties or lawyers. Taking party behavior first, a party's incentive to engage in hitigation conduct may decrease if legal fees make such conduct more expensive. This would, for example, undermine our conclusion that legal advice generally increases incentives to investigate. But no a priori reason exists to believe that eliminating legal advice would lower hitigation expenses since, without lawyers, parties inay simply substitute their own more inefficient and costly efforts. ${ }^{115}$ Furthermore, given this ambiguity about whether legal advice increases hitigation costs, abstracting from the costs of legal advice does not bias our account in favor of the social desirability of litigation advice. It does, however, require us to himit our conclusions, as we do, to the social desirability of the informational effects of legal advice.

Legal fees may also alter attorney behavior. Specifically, fees inay create "agency problems" by giving attorneys financial incentives to conduct hitigation in ways that do not maximize their chents' interests. ${ }^{116}$ An attorney paid by the hour, for example, may "leave no stone unturned" in discovery even if soine stones are not worth the cost of turning them. ${ }^{117}$ An attorney with a contingent fee, on the other hand, may have incentives to forego some litigation conduct whose benefits exceed costs because she bears all the costs but inust share the benefits with the chent. ${ }^{118}$ Given the conflicting incentives under the different fee arrangeinents, it is ambiguous whether in theory legal fees generally encourage or discourage litigation conduct. The implications of the available empirical data are likewise ambiguous. ${ }^{119}$

115. Accord Kaplow \& Shavell, supra note 17, at 600-01.

116. See D. Rosenthal, Lawyers and Clients: Who's IN Charge? 96-99 (1974); Miller, Some Agency Problems in Settlement, 16 J. LeGal STUd. 189 (1987).

117. See Rhode, supra note 11, at 635 (observing that lawyers are happy to leave no stone unturned "provided, of course, they can charge by the stone").

118. R. POSNER, supra note 15, at 535. Both these incentives will decrease to the extent such conduct affects the attorney's reputation in the market for legal services. But because inarket Inonitoring is inevitably costly and inperfect, some agency costs will always remain. Cf. Jensen \& Meckling, Theory of the Firm: Managerial Behavior, Agency Costs and Ownership Structure, 3 J. Fin. ECON. 305, 309 (1976) (discussing general theory of agency costs).

119. See Kritzer, Felstiner, Sarat \& Trubek, The Impact of Fee Arrangement on Lawyer Effort, 


\section{Settlement and Opponent Litigation Costs}

If settling (or abandoning) a lawsuit is possible, litigants maximizing their self-interest will take into account the effect of their actions not only on their hitigation costs and expected primary and evidentiary sanctions but also on their opponent's litigation costs and the expected terms of settlement. ${ }^{120}$ This does not, however, greatly change our analysis because the terms of settlement are largely influenced by the parties' expectations about how a trial would coine out, ${ }^{121}$ which in turn are based on the information identified (or expected to be identified) as relevant and presentable. Parties thus have incentives to investigate, categorize, withhold, and suppress information to "win" the settleinent that are similar to their incentives to engage in such conduct to win at trial. ${ }^{122}$ The effect of legal advice on inarshaling information for settlement (or predicting the information likely to be identified) ${ }^{123}$ should be similar to

19 LAW \& Soc'Y REV. 251, 266-72 (1985) (showing that contingent fee lawyers devote at least as many hours as hourly fee lawyers in some classes of cases).

120. Even where settlement is not possible, a party's trial effort may still, because it affeets the likely outcome, affect the opponent's effort. Parties looking only to optimize the trial outcome may accordingly take into account the effeet of their litigation conduct on the opponent's level of effort. See Cooter \& Rubinfeld, supra note 14, at 1072-73. The effect of one party's litigation efforts on the other's is, however, ambiguous. See id. at 1073. It thus provides no affirmative reason to deviate from our initial conclusions.

121. See id. at 1076; cf. Kaplow \& Shavell, supra note 17, at 594 n.70 (noting that the informational effects of advice may affect the terms of settlement). At least in securities class actions, however, there is evidenee that factors such as plaintiff lawyer mcentives, defendant riskaversion and agency costs, asymmetric hitigation costs, and the availability of insurance can lead to settlements that bear hittle relation to the merits. See Alexander, Do the Merits Matter? A Study of Settlements in Securities Class Actions, 43 STAN. L. REv. 497 (1991). A critical factor in such cases is that neither party can make a credible threat to proceed to adjudication on the inerits, so that the expected outcome at trial is not a relevant factor in determining the parties' threat values. See id. at 524. In classes of hitigation where similar conditions hold, the informational effects generated by advice are hard to predict but it is difficult to see how they could be harmful (or helpful).

122. Indeed, the prospect of settlement incrcases incentives to investigate for unfavorable information that the opponent may obtain, because such information may help a party decide whether to enter settleinent negotiations and what settlement offers to make or accept. This should somewhat increase the likelihood that a party's investigation will increase the unfavorable information eventually presented.

The incentives to identify and present information in settlement are not, however, identical to the incentives to identify and present information at trial. By presenting information to "win" the settlement negotiation, the party forfeits the element of surprise if a trial occurs. Depending on the likelihood of settlement and the relative value of the information in negotiation versus at trial, a party may withhold some information in settleinent negotiations in order to preserve the element of surprise at trial. See Brazil, supra note 30, at 1317-18. To the extent such information is not partycontrolled or suppressible, however, bilateral legal advice should reduce the difference between the information presented to win the settlement and the information presented at trial because it increases the likelilood that the opponent will have access to that information already. See supra Part II.

123. Because settlement is largely motivated by the desire to avoid the costs of identifying information, settlements will often precede the identification of information. Nonetheless, in those 
the effect of legal advice on marshaling information for trial. ${ }^{124}$

To be sure, expectations about trial outcomes are not the only factor influencmg the settlement terms. The bargaining range for settlement will also be influenced by the expected costs to each party of proceeding to trial versus the costs of settling. Parties may, for example, request or produce massive amounts of useless information to run up the opponent's hitigation costs and coerce a more favorable settlement. ${ }^{125}$ The terms of settlement will also reflect how successful each party is im bargaining for a larger share of the joint surplus that settlement creates. ${ }^{126}$

Unilateral legal advice may well influence both the ability to inflict costs that affect the limits of the bargaining range and the division of the surplus from settlement in ways that favor the party receiving advice. Because an advised party should be better able to disguise or defend the sanctionable infliction of costs on her opponent, her expected sanctions for such conduct will be lower. Her lawyer will also recognize more strategies for inflicting costs on the opponent. At the same time, unilateral advice will reduce the opponent's ability to inflict costs on the party receiving advice because the opponent's expected sanctions for such conduct should increase. When the parties to hitigation are prepared to engage in the strategic infliction of costs, unilateral advice will thus mcrease the expected value of contimued hitigation for the party receiving advice and reduce it for the opponent, shifting the probable terms of settlement in favor of the party receiving advice. Unilateral advice may also influence the party's ability to bargaim for a larger share of the settleinent surplus, in part because lawyers have more experience negotiating settlements. ${ }^{127}$ It thus appears likely that unilateral legal advice will result in better settlement terms for the advised party than the effects of advice on

cases the terms of settlements will still be influenced by the information the litigants expect to identify, and those expectations should vary depending on whether the party has advice.

124. Whether this has a desirable impact on actual or expected sanctions will depend in part on whether the expected outcome that forms the basis of settlement reflects the social desirability of the conduct giving rise to the dispute. If, as we argue in Part IV, the informational effects of advice generally tend to increase the tribunal's capacity to determine whether primary conduct was desirable, settlements based on the expected outcome of litigation with legal advice ought to be preferable to settlements based on the outcome of hitigation without advice.

125. See Brazil, supra note 30 , at $1313,1319-22$. Such efforts will not always be feasible since they will also run up the party's own litigation expenses. But where the increase in litigation costs is asymmetric, or where a symmetric increase in litigation costs las asymmetric effects, a strategy of inflicting litigation costs can be successful. Cf. Hurwitz, Abuse of Governmental Processes, the First Amendment, and the Boundaries of Noerr, 74 GEO. L.J. 65, 71 (1985) (noting that predatory litigation can be successful if it imposes disproportionate costs on a rival or if the costs inposed have a disproportionate effect because the smaller litigant's cost per output is increased more).

126. See Cooter \& Rubinfeld, supra note 14 , at 1076, 1078-80.

127. The advised party's skill in bargaining for a bigger share of the settleinent surplus should not, however, leave the opponent any worse off than his expected outcome at trial (determined by the predicted informational effects) ininus the costs of proceeding to trial. Otherwise he would not settle. 
the presentation of information about primary conduct, standing alone, would suggest.

Where the advice is bilateral, there is no reason to think that the bargaining advantage will fall to one side or the other. Nor do we see any a priori grounds for concluding that bilaterally advised parties will be more likely than unadvised parties to engage in, threaten, or succumb to such strategic efforts to raise the opponents' hitigation expenses. To the extent such conduct is sanctionable, our analysis of evidentiary sanctions im Section II(C) should apply. To the extent such conduct is not sanctioned and both parties persist in it, it would seem to represent the breakdown of what would be mutually advantageous bargaining to avoid hitigation expenses. As we will soon see, however, there is no reason to beheve that hitigation involving legally advised parties is more likely to result im such bargaining breakdowns than hitigation involving unadvised parties. ${ }^{128}$

A related question is what effect legal advice has on the likelihood (as opposed to terms) of settleinent. Under modern economic theories of settlement, the likelihood of settlement is determined by (1) the likelihood of a recognizable gain from settlement, and (2) the likelihood of avoiding bargaining breakdowns over the distribution of that gain. ${ }^{129}$ Given these factors, we conclude that bilateral advice should increase the likelihood of settlement.

A recognizable gain from settlement will exist whenever the parties' estimates of the expected trial outcome are sufficiently close that the difference between them is exceeded by the net costs of litigation. ${ }^{130}$ If, for example, the parties expect the saine outcome at trial, the gain from settlement is the extra costs the parties would have to incur from litigating instead of simply settling on that outcome. Bringing parties' estimates of trial outcomes closer together will thus increase the likehihood of a settlement gain and the likelihood of settlement. ${ }^{131}$

128. See infra notes 133-34 and accompanying text.

129. Cooter \& Rubinfeld, supra note 14 , at $1075-80$ (reviewing literature).

130. Id. at 1076. We define the net costs of litigation as the costs to both parties of litigation minus the costs to both parties of settlement. Because the costs of litigation generally exceed the costs of settlement, we assume the net expected costs of litigation are positive.

131. See R. Posner, supra note 15 , at 525 . The statement in the text simplifies a ratler complex analysis. More precisely, bringing the estimates closer togetler will increase the likelihood of a settlement gain where the plaintiff's initial estimate of ler expected winnings froin trial exceeds the defendant's initial estimate of his expected losses. It will have an anbiguous effect when the defendant's initial estimate exceeds the plaintiff's. This is because a settlement gain exists when (but only when) the plaintiff's estimate minus the defendant's is less thian the net cost of litigation. Id. at 524. Where the plaintiff's estimate exceeds the defendant's, converging estimates increase the likelihood that their difference will be sunaller than the net costs of litigation. This increases the likelihood (and size) of a settlement gain. Where, lowever, the defendant's estinnate exceeds the plaintiff's, a settlement gain will always exist, even if the net costs of litigation equal zero. Thus, bringing parties' trial expectations closer cannot increase the likelihood of a settlement gain. It 
Bilateral advice should bring trial outcome estimates closer together for two reasons. First, legal advice should increase the discoverable or commonly available inforination that both parties identify. This should cause the parties' perceptions of the disputed facts (and expected trial outcomes) to converge. ${ }^{132}$ Second, with legal advice each party will inore aceurately assess the inforination she expects to be identified and the expected trial outcomes that will follow from the presentation of such information. This will bring the parties' estimates closer together even if legal advice does not affect the inforination identified.

Assessing the likelihood of bargaining breakdowns is far more coinplex. It turns on factors that are difficult to gauge, such as the parties' knowledge of each other's preferences and psychological factors relating to the bargainers' ability and willingness to make credible threats to forego any gain unless their share is mcreased. Nonetheless, to the extent lawyers are loyal agents and have a psychological makeup that is no more prone to lead to bargaining breakdowns than that of the litigating parties, then the fact that lawyers are repeat players should reduce bargaining breakdowns. ${ }^{133}$ Moreover, some bargaining models suggest that mcreasing the information both sides identify will reduce the chances of bargaining impasses. ${ }^{134}$ Even if lawyers do not change the likelihood of bargaining breakdowns, the more convergent estimates of trial outcoine should mcrease the likelihood of settleinent by increasing the likelihood of a settlement gain and thus the number of bargaining opportunities.

\section{B. Different Motivations}

Our basic account assumed that parties were interested solely in optimizing their expected costs and sanctions. ${ }^{135}$ We now consider how our results wonld change if parties (and lawyers) were instead law-

should decrease the size of the settlement gain, but this has ambiguous effects on the likelihood of settlement. Id. at 523 .

132. Strategic problems will often prevent parties from voluntarily sharing their private information with their opponents prior to settlement. Id at 525; Sobel, supra note 29, at 153-54.

133. See Cooter, Marks \& Mnookin, Bargaining in the Shadow of the Law: A Testable Model of Strategic Behavior, 11 J. LEGal STUD. 225, 232-33, 241 (1982). Attorney disloyalty may increase or reduce the likelihood of settlement depending on how attorney compensation is determined. See supra notes 116-19 and accompanying text.

134. See Sobel, supra note 29 , at $133,146$.

135. It also excluded, for expositional convenience, the possibility that parties might be riskaverse. Risk-aversion ordinarily imcreases the likelihood of settlement. See Cooter \& Rubinfeld, supra note 14, at 1076. It should also affect litigation conduct by increasing the deterrent effect of any given schedule of evidentiary sanctions. See Polinsky \& Slavell, The Optimal Tradeoff Between the Probability and Magnitude of Fines, 69 AM. EcoN. REV. 880, 884-85 (1979). This will, however, alter the overall effect of legal advice on settlement or litigation conduct only if unadvised parties would systematically under- or overestimate the larm from losing or suffering evidentiary sanctions. On our assumption that unadvised parties are not systemically biased in their litigation errors, the overall effect of litigation advice is not altered by risk-aversion. 
abiding or truth-telling in the sense defined in Section I(A). ${ }^{136}$

\section{Uniform Party Motivations}

If parties are uniformly truth-telling, the effects of legal advice will be even nore positive than described in Part II. Parties will not intentionally suppress or withhold relevant information. Instead, each party will present all the information she has identified as relevant, whether favorable or unfavorable to herself, and withhold all the information she has identified as irrelevant. Litigation advice will help parties identify information through investigation and determine whether that information is relevant. It will therefore increase the amount of favorable and unfavorable information presented by each side and decrease the proportion of irrelevant information presented.

If parties are uniformly law-abiding, then the effects predicted in Part II still largely hold. They differ primcipally in the informational effects of advice that influences perceived evidentiary sanctions. Such advice inay correct misperceptions about when withholding or suppressing information is lawful. If law-abiding parties are advised that the evidentiary conduct is unlawful, they will present inore unfavorable information regardless of the level of expected evidentiary sanctions. If they are informed the conduct is lawful, they will present less unfavorable information. Assuming agam that they are not systemically biased toward one sort of legal error-unadvised parties are as likely to underestimate the scope of unlawful conduct as overestimate it - the overall effect is a wash. These results parallel those predicted in Section II(C)(1) for sanction-optimizing parties.

Advice may also correct misperceptions about or alter the level of expected sanctions. This will not affect the behavior of law-abiding persons when they learn that expected sanctions for conduct they correctly behieved was or was not lawful are lower than they thought. (Even lawful conduct might carry expected sanctions because of the risk of trial error.) Nor will it affect law-abiding persons who correctly believed the conduct was unlawful and learn that expected sanctions are higher than they thought. However, persons who correctly believed the conduct was lawful, but who learn that expected sanctions are higher than they thought, will produce inore unfavorable information. The overall effect, assuming no bias in legal error, is a mild increase in the ainount of unfavorable information reaching the tribunal. This increase was not predicted in Section II(C)(1).

136. Law-abiding and truth-telling persons will often differ in their willingness to provide information to the tribuual. A law-abiding litigant, for example, will not produce information that has not been requested and will take the fifth amendment when it is available. A truth-teller will volunteer information that has not been requested and will never take the fifth amendment. 
The divergent susceptibility of lawyers to sanctions has substantially less impact in cases involving truth-telling or law-abiding parties. This is in part because truth-telling or law-abiding parties will view less of the information available to thein as party-controlled or suppressible. In addition, lawyer sanctions for assisting in withholding or suppressing information typically apply only where the client's own withholding is independently sanctionable. But this diminished impact is a direct consequence of the chent's certain production of information tliat the lawyer's differential sensitivity to sanctions might or might not have produced. Accordingly, eliminating this effect cannot reduce information presented below the level that would occur if the parties were sanction-optimizing.

Moreover, a law-abiding party has much less reason than a sanction-optimizing party not to share information witl her lawyer. This is because sharing information can have effects a law-abiding party would regard as adverse only in tlie rare case where withholding is lawful, the lawyer would nonetheless face a positive risk of sanctions for assisting withholding, and the lawyer's expected sanctions are sufficiently high to overcome her loyalty to the party. A sanction-optimizing party, by contrast, faces possible adverse consequences whenever the lawyer's expected sanctions for assisting withholding (lawful or not) are sufficiently high to induce disloyalty. Because she has inore incentive to share information, it is likely that the law-abiding party will receive inore legal advice. This should enhance tlie positive effect of advice on investigation and categorization.

The net result is that the nature of the informational effects predicted in Part II should not differ if parties are law-abiding instead of sanction-optimizing. The extent of some effects may, however, differ in ways that are ambiguous or positive.

\section{Nonuniform Party Motivations}

Legal advice can have far more disturbing effects if the motivations of opposing parties differ. Take, for example, cases where a sanctionoptimizing party faces a truth-telling opponent. If both parties receive advice, or if it is unilaterally provided to the sanction-optimizing party, the decreased presentation of information unfavorable to the sanctionoptimizing party may well outweigh any increased presentation of information favorable to that party. A truth-telling opponent will, despite his ability to withhold or suppress some information, present all relevant information he identifies, mcluding all such information favorable to the sanction-optimizing party. Providing legal advice to the sanction-optimizing party will thus increase the presentation only of favorable information the truth-telling opponent would not liave identified and categorized as relevant. The amount of information falling in this cate- 
gory may not be trivial, particularly if the truth-teller's investigations are not very thorough or if the sanction-optimizer controls a large share of the relevant information. Nonetheless, it will be smaller than the amount of favorable information that would have been left unpresented if the opponent were also sanction-optimizing. This will reduce the positive effects of advice on the presentation of information favorable to the sanction-optimizing party.

The decrease in unfavorable information presented, on the other hand, will be unaffected because truth-telling opponents will make an effort to block the sanction-optimizing party from withholding or suppressing unfavorable information similar to the effect a sanction-optimizing opponent would have made. ${ }^{137}$ There is thus cause for concern that providing advice to a sanction-optimizing party facing a truth-telling opponent will decrease the presentation of unfavorable information more than it increases the presentation of favorable information. That concern will increase in proportion to the thoroughness of the truth-telling opponent.

The results are similarly disturbing if a sanction-optimizing party receives unilateral advice against a law-abiding opponent. The resulting decrease in expected evidentiary sanctions for the sanction-optimizing party will decrease the unfavorable information reaching the tribunal. But the increase in expected evidentiary sanctions caused by advice should have little effect on the law-abiding opponent. As we will see in Section $\mathrm{V}(\mathrm{A})$, concerus about advice where one side is law-abiding or truth-telling may underlie a number of rules regulating access to advice.

\section{Lawyer Motivations}

Our basic account also assumed that lawyers will optimize their chents' sanctions unless the lawyers' own exposure to evidentiary sanctions becomes too great. If lawyers are instead truth-telling, they will disclose to the tribunal any unfavorable information that they learn, inoving the effects of advice in the direction described for truth-telling parties. If lawyers are law-abiding, then the differential susceptibility to sanctions described in Section II(C)(2) will be greater, increasing the likehhood that lawyers will disclose or force the disclosure of unfavorable information. But sanction-optimizing parties represented by truth-telling or lawabiding lawyers may share less information with their lawyers to reduce the risk of lawyer disclosure. This may moderate or eliminate some of the positive informational effects of advice that would occur if lawyers

137. Some truth-telling parties may be unwilling to withhold or suppress secondary information about the opponent's evidentiary conduct even when it would be lawful to do so and when doing so would increase the evidentiary sanctions applicable to the opponent. Thus, truth-telling may paradoxically increase the opponent's withholding and suppression of information. 
were sanction-optimizing. The net effects will resemble those that flow from subjecting lawyers to increased disclosure requirements, which is discussed in Section V(B). Thus the substitution in our account of law-abiding or truth-telling attorneys does not change the nature of the informational effects described in Part II, but has an ambiguous impact on the extent of those effects.

\section{Information That Influences Tribunals in an Undesirable Way}

In Section II(A), our basic account assumed that all information having a favorable or unfavorable impact on the tribunal's judgment was actually probative of the disputed facts. Unfortunately, some information reaching a tribunal may have a favorable or unfavorable inpact that is misleading. We here address the presentation of irrelevant, false, or prejudicial information that might have such an effect.

A party might conclude that, because the relevant information likely to be presented is extreinely unfavorable, presenting irrelevant information improves her chances by consuming the tribunal's limited resources and reducing its ability to evaluate relevant information. This strategic presentation of irrelevant information might undermine our imitial conclusion that legal advice reduces the proportion of irrelevant information reaching the tribunal.

We doubt, however, that such strategic presentations are frequent or that legal knowledge will increase their likelihood. The instances in which purposefully presenting irrelevant information will be advantageous seem rare. Such efforts will often be relatively easy to detect because they take place before the tribunal and seem likely to anger or frustrate the tribunal enough to provoke (usually inexplicit) evidentiary sanctions. We suspect this threat of evidentiary sanctions will often outweigh the advantage of presenting information that, by definition, lacks probative value.

There is also good reason to beheve that legal advice will decrease the overall likelihood that presenting irrelevant information will be advantageous. First, the expected evidentiary sanctions for intentionally presenting irrelevant information will likely be higler for a legally advised party because the tribunal will assume that the party "ought to know better" than to present such information. ${ }^{138}$ Second, lawyers

138. In some cases, the tribunal may infer from the presentation of irrelevant information that the party has no favorable information to present from those sets of information she controls. Legal advice should reduce the presentation of irrelevant information in these cases. One might initially regard this effect of advice as socially undesirable because it deprives the tribunal of information that enables it to draw an inference about the merits of the party's claim. But where the party presents irrelevant information in the mistaken belief it was relevant, the tribunal's inference seems inaccurate and the presentation of the information socially undesirable. 
themselves face sanctions for intentionally presenting irrelevant information. Their persuasiveness in future cases, for example, might be undermined if they gain a reputation for presenting irrelevant information. Accordingly, the involveinent of lawyers should create a differential susceptibility to sanctions. Third, because advice increases the presentation of truthful relevant information, the tribunal's ability to recognize and sanction presentation of irrelevant information ought to increase. Fimally, insofar as there exists a separate set of truthful information that tends to suggest that information is irrelevant, advice on balance should increase the flow of such information to the tribunal. ${ }^{139}$

Even if legal advice did not decrease the likelihood that presenting irrelevant information would be advantageous, our sense that such a strategy would rarely be advantageous would still lead us to conclude that legal advice decreases the anount of irrelevant information presented. The reason is that collecting and presenting irrelevant inforInation involve significant resource costs that apply in all cases, including those where such activities will plainly confer no benefit on the party. We strongly suspect that the decrease in the proportion of irrelevant information presented because of legal advice in the inore common cases where presenting irrelevant information is disadvantageous will outweigh any increase in the strategic presentation of irrelevant information because of legal advice in the rare cases where it is advantageous.

We next consider two other classes of information whose presentation influences trial outcoines in a socially undesirable way: information that is false (whether or not fabricated) and information that appeals to the prejudice or bias of the tribunal but has hittle or no probative weight. To some extent, both parties and lawyers face sanctions for presenting false or prejudicial information. The differential susceptibility of lawyers to sanctions should thus operate to decrease the presentation of false or prejudicial information. Furthermore, because legal advice increases the presentation of true nonprejudicial information, whether favorable or

139. The particulars of the conclusions in the text differ for the unilateral and bilateral accounts. In the unilateral account, the effect on the advised party's expected sanctions for the strategic presentation of irrelevant information is ambiguous. The party receiving legal advice will face higher sanctions both because parties with lawyers suffer higher sanctions and because of her lawyers' differential susceptibility to sanctions. On the other hand, legal advice should help the party present secondary information that will lower the expected evidentiary sanctions for presenting irrelevant information. This could increase or decrease the strategic presentation of irrelevant information by the advised party. Unilateral advice should, however, increase the opponent's sanctions for . presenting irrelevant information, and thus reduce the opponent's strategic presentation of irrelevant information. The net result is an overall reduction in strategic presentation.

In the bilateral account, expected evidentiary sanctions should increase for both sides. Both will have lawyers and hence are both subject to higher sanctions and both will suffer from lawyers' greater susceptibility to sanctious. Both will also face more information indicating that strategic presentation of irrelevant information is taking place. This should reduce the likelihood that either party can profit from presenting irrelevant information. 
unfavorable, legal advice should also increase the tribunal's ability to detect and sanction the presentation of false or prejudicial information. But sanction-optimizing attorneys are also likely to identify more prejudicial information, think of more useful hes, and identify more persons willing to lie. The overall effect of advice on the amount of false or prejudicial information presented is thus ambiguous in both the unilateral and bilateral accounts. ${ }^{140}$ Unilateral advice should, however, ensure that the mix of false or prejudicial information presented is more favorable and less unfavorable to the party receiving advice.

\section{Skewed Distributions of Information, Access, or Error}

In order to reach initial conclusions about the general effects of legal advice, our basic account assumed equal distributions of information, access to information, and litigation error. We now reintroduce and examine the extent and consequences of skewed distributions.

\section{Biased Mixes of Information}

The amount of information favorable to each party's case will not always equal the amount of unfavorable information. Soine litigants have violated the law or unjustly accused their opponent of a violation; others (tlieir opponents) liave not. Given a rational systen of evidence, there should be more relevant information favorable to nonviolators and just aecusers thian to violators and unjust accusers.

Ordinarily, we would not expect any general class of litigants receiving legal advice to systeinatically enjoy more favorable information than their opponents. ${ }^{141}$ If, however, one could define a class of cases where one side systematically lias more unfavorable information than favorable information, then advice to that side would have nore dubious social value. Our basic account's conclusion about umilateral advice-that it increases the favorable information presented more than it decreases the unfavorable information-was based on the assumption that there was just as much favorable information as unfavorable. If there is inore unfavorable imformation than favorable, then unilateral advice will decrease

140. If parties are truth-telling, they will never knowingly present false, prejudicial, or strategic irrelevant information. Legal advice should help them avoid doing so by mistake and will thus deerease the presentation of all three types of information. The same will be true for any advice given if lawyers are truth-telling. If parties are law-abiding, they will present such information only if they do not believe it to be unlawful. As Seetion $\mathrm{II}(\mathrm{B})$ suggests, the effect of advice in this situation will be similar to the effect when parties are sanction-optinizing. If lawyers are lawabiding, any legal advice given will reduce the unlawful presentation of false, prejudicial, or strategic irrelevant imformation. See supra Section $\operatorname{III(B)(3).~}$

141. Although their analysis does not extend to cases that settle, Priest and Klein have concluded, based on empirical data and theoretical modelling, that defendants and plaintiffs have a $50 \%$ probability of winning eases that go to trial. See Priest \& Klein, The Selection of Disputes for Litigation, 13 J. LeGAL STUd. 1, 5-6 (1984). 
presentation of unfavorable information more and increase favorable information less. ${ }^{142}$ The overall result may be that the decrease in unfavorable information exceeds the increase in favorable information. In contrast, advice to the opponent (who has more favorable information than unfavorable) should be even more positive than described in the basic account. ${ }^{143}$

The possibility that unilateral advice to wrongdoers may reduce the information reaching the tribunal is disturbing. But note that we can reach these conclusions only by positing a definable class of cases where we have good grounds for deciding-without adjudication-which side should win. ${ }^{144}$ In those circumstances, it is not surprising that we get bad results from providing advice to the party we know should lose. The point of adjudication, however, is usually to establish which party is right where that is not already clear at the outset. In such cases we do not usually expect a systematic tendency for one side to have more favorable information than unfavorable. ${ }^{145}$ Moreover, so long as the parties' access to information is equal, bilateral advice should still increase the favorable and unfavorable information presented about each party even when the $m i x$ of information available to the parties is skewed against one of them.

\section{Inequalities of Access to Information}

In many cases, one side may be able to control or suppress more

142. One can describe this in greater detail. All the unilateral effects described as ambiguous in Part II will tend to reduce the information presented because (assuming constant error rates) unadvised parties will nuake more erroneous decisions to present or not to suppress unfavorable information than to withhold or suppress favorable information. By the same token, although the differential effect of lawyer sanctions will remain, the other positive informational effects will tend to be weaker or negative.

Advice about relevance will nucrease information, but less than described in Part II because the amount of favorable information in the additional information classed as relevant will be lower. Advice about relevant commonly identified information will have less of a tendency to increase the information presented because, with the comnonly identified information weighted to unfavorable information, it takes a more competent opponent to create a mix of unpresented information that is richer in favorable than in unfavorable information. Finally, advice about nivestigation will increase information to a lesser extent because more possible investigations will be negative value searches that advised parties will avoid, and because more of the positive value investigations will search for unfavorable information that the opponent will obtain rather than for favorable information.

143. The tendency of the increase in favorable information to exceed the decrease in unfavorable information will be even stronger because the aunbiguous effects described at supra note 142 will tend to lead to the presentation of more relevant information, and the positive effects will tend to be stronger.

144. Those who beheve that such grounds exist-for example those who believe that $90 \%$ of criminal defendants are guilty-nay oppose advice to the class of parties they believe should lose. But they nust realize that if that class of parties were unadvised their opponents nught prosecute defendants who are nore bikely to be innocent.

145. What we do expect is that the nonviolators and just accusers should generally experience a larger improvement in expected sanctions from unilateral advice than should violators and unjust accusers. This is discussed further in Part IV. 
information than the other. If we adjust the controlled sets that we assumed had equal size in our basic account by increasing the size of one party's controlled set and decreasing the size of her opponent's, the unilateral effects of providing advice to the first party will be affected in an ambiguous manner. With more information discoverable froin the opponent, the increase in favorable information should be heightened; with less information discoverable froin the party, the decrease in unfavorable information should be heightened as well. The unilateral effects of providing advice to the opponent, and the bilateral effects of providing advice to both parties, will likewise be affected in an ambiguous manner by the shift in control. ${ }^{146}$ Naturally, the party with more control will benefit more froin the mix of information presented. But this makes the general effects undesirable only if parties with extra control systenatically tend to be violators or unjust accusers.

Asymmetries in the parties' abilities to suppress information are 1nore disturbing. Suppose that we increase the information suppressible by one party and decrease the information suppressible by the opponent. This has a negative impact on unilateral advice to the first party because it inagnifies the power of that advice to decrease the presentation of unfavorable suppressible information and lessens the significance of advice that prevents the opponent froin suppressing favorable information. Because this negative effect inay outweigh the other positive effects of unilateral advice, we cannot predict with any confidence that unilateral advice to parties who can suppress more information than their opponents will generally increase the presentation of relevant information.

We see no grounds for concluding that one side should generally be able to control or suppress more information than the other. That ability may, however, exist in special classes of hitigation. In criminal cases, for example, the fifth amendinent and the special obhigations of prosecutors to disclose excnlpatory information differentiate the disclosure obhigations of prosecutors and criminal defendants. These rules may increase the informational control of criminal defendants and decrease that of prosecutors.

\section{Skewed Distributions of Litigation Error}

Skewed distributions of unadvised litigation error can alter the results of our basic account. ${ }^{147}$ We consider skewed estimates of eviden-

146. The shift in control will dampen both the increase in information favorable to the opponent and the decrease in unfavorable information. Whether the increase exceeds the decrease, or vice versa, depends largely upon whether the increase in one party's controlled set exceeds the decrease in the other's. Unless the overall control by both parties combined is affected, the bilateral effects should not change. An increase in overall control should decrease, and a decrease in overall control should increase, the extent of the bilateral effects.

147. This Section considers skews in the types of litigation errors, not differences between 
tiary sanctions first, and then consider skewed categorizations of information as favorable or unfavorable.

\section{a. Skewed Estimates of Expected Evidentiary Sanctions}

Suppose that unadvised parties are more likely to overestimate expected sanctions for withholding, suppressing, or falsifying evidence than to underestimate them. Advice about the true level of expected sanctions will then tend to decrease the presentation of probative information and increase the presentation of falsehoods. Counsel may, for exainple, cause criminal defendants not to give unfavorable testimony by advising them that the fifth amendment will protect them from unfavorable inferences the tribunal might draw about their failure to testify. If, alternatively, unadvised parties are more likely to underestimate evidentiary sanctions, advice about sanctions should increase the probative information presented. Parties may, for example, be advised that their efforts to mask unfavorable information will be regarded as suspicious and will antagonize the tribunal enough to provoke a higher sentence or other implicit evidentiary sanctions.

A systematic tendency to underestimate expected evidentiary sanctions will thus heighten, and a tendency to overestimate will undermine, the positive effects predicted in our basic account. ${ }^{148}$ This is because advice about the level of expected sanctions will no longer have a neutral effect. Positive effects should, however, still flow from lawyers' differential susceptibility to sanction and from advice about relevance, imvestigation, and categorization of commouly identified information. Thus, even when parties systematically tend to overestimate expected evidentiary sanctions, the overall informational effect of litigation advice might still be positive.

\section{b. Skewed Categorization of Information}

The distribution of litigation error about whether information is favorable or unfavorable imight also be skewed. Unadvised parties imiglit be inore likely to mistake favorable information for unfavorable than vice versa. We call such parties "unadvised pessimists" because they perceive their chances of winning to be less than the facts merit. Alternatively,

parties' propensity to make litigation errors. It thus does not consider classes of litigation where one side is, if unadvised, more likely to make litigation errors than the other. As we explained in Section I(D), the differential effects of litigation advice in such classes of hitigation are those predicted by our unilateral account.

148. Similar results follow, even if parties' perceptions of expected sanctions are accurate, if risk averse parties systematically overestimate (or underestimate) the severity of evidentiary sanctions or if law-abiding parties systematically overestimate (or underestimate) the scope of sanctionable conduct. 
unadvised parties might be more likely to miscategorize information as favorable. Such parties are "unadvised optimists."

When parties are unadvised pessimists, the positive informational effects of legal advice will be heightened. This is because advice about mformation categorization will be more likely to correct mistaken beliefs that information is unfavorable than to correct mistaken beliefs that information is favorable. This increases the tendency of unilateral advice to cause an mcrease im favorable information presented that exceeds any decrease im unfavorable information. Similarly, unadvised party optimism tends to undermine the positive effects of advice about information categorization by causing a relatively greater decrease in unfavorable information and lesser mcrease in favorable information. The overall effects, however, may continue to be positive because of the positive effects flowing from advice about relevance, imvestigation, and categorization of commonly identified information, ${ }^{149}$ and from the divergent susceptibility of lawyers to sanctions.

Is there any reason to beheve unadvised parties are systematically more optimistic than pessimistic? One possible reason might be derived from economic models of settleinent, which predict that parties who are "excessively optimistic" are less likely to settle and more hikely to go to trial. These models observe that parties have an incentive to settle whenever the expected value of judgment perceived by the plaintiff minus the magmitude of the expected disvalue of judgment perceived by the defendant is less than the joint surplus that can be created by avoiding the costs and risks of litigation. ${ }^{150}$ Where parties are "excessively optimistic," in the sense that one side beheves her chance of wiming is greater than the other side believes is his chance of losing, then the likehihood of settlement is decreased. ${ }^{151}$

Because these models address the choice (with or without advice)

149. If party optimism is strong enough, the overall effects of advice regarding commonly identified information might be negative, but common identification does tend to offset the negative effects of party optimism.

150. Cooter \& Rubinfeld, supra note 14 , at 1076.

151. See Bundy, Commentary on "Understanding Pennzoil v. Texaco": Rational Bargaining and Agency Problems, 75 VA. L. REv. 335, 337-38 (1989). By definition, cach excessively optimistic party faces another excessively optimistic party. This is because excessive optimism is defined as believing one's case is better than the opponent behieves it to be. For similar reasons, each excessively pessimistic party faces an excessively pessimistic opponent.

Note that because "excessive optimism" is defined in relation to the opponent's expectations, it does not necessarily correspond to optimism in the sense that we use it, which is defined in relation to the actual facts. Say, for example, the actual expected trial award is $\$ 1000$, an unadvised plaintiff perceives the expected trial award to be $\$ 2000$, and an unadvised defendant perceives the expected trial award to be $\$ 3000$. Such a plaintiff would be an unadvised optimist in the sense we mean if her overestimation of the expected award results from thinking the mix of information is inore favorable than it actually is. She would, however, be excessively pessimistic under settlement models because her opponent thinks the plaintiff's chances are better than the plaintiff thinks they are. 
between settlement and trial, they are not directly apphicable to the issue whether unadvised parties entering litigation (whether or not they settle) tend to beheve their cliances are better than tlieir attorneys do. ${ }^{152}$ Nonetheless, if the same analysis extended to failures to settle disputes without mcurring the costs of consulting an attorney, tlien one might predict that those who consult attorneys will also tend to be excessively optimistic. ${ }^{153}$

The extent to which the htigation settlement analysis can be extended to preconsultation settlement is, however, far from certain. To begin with, the degree of optimism necessary to make preconsultation settlement unfeasible will be relatively small because the costs of merely consulting an attorney will be lower than the costs of higation and because there is no risk in consulting an attorney comparable to the uncertainty of judginent. More importantly, tlie benefits from consulting an attorney do not involve solely improving the chances of winning a judginent: they also include improving the party's assessment of those chances. Parties who appreciate their lack of legal knowledge should realize that they are either being optimistic, in which case consulting a lawyer inay lelp them avoid litigation expenses, or that they are being pessimistic, in which case consulting a lawyer will often improve the settlement they exact. Parties pessimistic about the outcoine thus liave incentives to consult an attorney tliat are not relevant to the decision to settle after a lawyer has been hired.

Even if the analysis of hitigation settlement were fully applicable to preconsultation settlement, it would not compel the conclusion that parties seeking litigation advice are likely to be systennatically optimistic

152. The prediction that the parties going to trial will tend to be optimistic does not alter our conclusions about the effects of litigation advice for two reasons. First, this prediction applies whether or not the parties are legally advised. Unless parties are systematically inore likely to be optimistic (or pessinistic) with advice than without, then advice should be just as likely to make parties less optimistic as less pessimistic. (As explained at supra note 131, however, decreasing the degree of optinism increases the likelihood and size of a settleinent gain; decreasing the degree of pessimism does not decrease the likehihood of a settleinent gain although it does decrease its size.) Second, and more importantly, our conclusions do not require that eases go to trial. It is sufficient for our purposes if the terms of settleinent are influenced by the information collected (or expected to be collected) with the aid of legal counsel.

153. The issue here is soinewhat different from that addressed by various other economic models that exainine when plaintiffs assert legal claiıns. Those inodels do not take into account the possibility that parties may settle before asserting a claim (let alone settle before consulting an attorney). See Cooter \& Rubinfeld, supra note 14, at 1082-84 (reviewing hiterature). Those nodels do conclude that parties are nore likely to bring suits when they are "optimistic" about their chances at trial or settleinent. Id. at 1082 . But these models mean optimistic only in the sense that the parties (correctly or incorrectly) believe the likely outcome will be good. They thus do not speak to the issue whether parties consulting an attorney to bring suit would tend to be "unadvised optimists" in the sense that they believe their chances are better than the facts inerit. Nor do they address whether such parties will be "excessively optimistic" in the sense that they are more optimistic about their chances than their opponents, or the optimisin (in any sense) of the party against whom the legal claim is asserted. 
about whether their information is favorable. Such a conclusion would both exaggerate the importance of excessive optimism as a cause of failures to settle and oversimplify the causes of excessive optimism.

Excessive optimism, standing alone, is neither a necessary nor a sufficient condition for failures to settle. Cases where the parties agree on the outcome or are excessively pessimistic might still be taken to lawyers because one party attaches a higher value than her opponent to the outcome at judgment, because settlement costs are high, or because bargaining breaks down due to rational strategic behavior. ${ }^{154}$ Conversely, cases involving excessive optimism will often be resolved without consulting lawyers when the costs of consultation are high, when one party puts a premiuin on quick settlement, or when one party wants to avoid public hitigation or a potential judgment for reputational or precedential reasons. Cases involving excessive optimism therefore inay not be disproportionately represented among those brought to lawyers.

In addition, when excessive optimism is present, it need not be the result of a tendency to misclassify unfavorable information as favorable. The causes of excessive optimisin also include having different expectations about how much information (that a party correctly views as favorable or unfavorable) will reach the tribunal or about the amount or mix of favorable and unfavorable information required to cause judgment in one's favor. Moreover, a party who inistakenly beheves that the inix of information is less favorable than the facts merit (and is thus an unadvised pessimist) inay be excessively optimistic as that term is used in settleinent inodels if her opponent mistakenly believes the inix of information is even less favorable to the first party than she does. ${ }^{155}$ Accordingly, it seens an unwarranted stretch to assume that parties who seek hitigation advice have a systemic tendency to misclassify unfavorable information as favorable inore frequently than they misclassify favorable information as unfavorable.

Finally, even if the parties who actually consult attorneys do systematically tend to be unadvised optimists about whether their information is favorable, it would not alter the deterrent effects of advice unless parties knew, before they acted, whether they or their opponent will be optimistic or pessimistic. To the extent that parties' behavior is affected by the prospect of hitigation advice and that they are sufficiently sophisticated to pay attention to this distinct subissue, it seems inore probable to us that parties will assess the likely effects of advice on the assumption that they and their opponents are just as likely to make one kind of error as another.

154. See Cooter, Marks \& Mnookin, supra note 133, at 238-39, 246 (discussing strategic behavior during settlement).

155. See supra note 151. 


\section{E. Conclusion}

The general prevalence of the conditions assumed in our basic account of evidentiary advice ultimately presents a series of empirical questions. On inany of those questions there is no data and little prospect of obtaining any. ${ }^{156}$ In resolving those issues, we may often have hittle inore to go on than intuitive judgments. Our own intuition is that inany assuinptions in our basic account-such as equal distribution of favorable and unfavorable information, equal control, and non-skewed distributions of litigation error-inatch up fairly well witl the conditions in many classes of routine civil (and some criminal) hitigation. However, we cannot rule out the possibility that these assumptions are incorrect. We also know that in soine respects (including its abstraction froin litigation costs, from agency problems, and froin the presentation of false or prejudicial information) our account abstracts from conditions that are important in a very substantial number of cases.

Against this background, we think it significant that relaxing our basic assunntions often does not change our basic account's conclusions about the positive informational effects of advice. Nonetheless, relaxing our assumptions does point to potentially significant classes of cases where advice can distort trial and settlement outcomes due to losses of truthful information, increased presentation of false or prejudicial information, or the strategic imposition of costs. The likelihood of these adverse effects is greatest when advice is unilateral, and when the party receiving advice is a sanction-optimizing violator or unjust accuser, can control or suppress a large proportion of the relevant information, and opposes a truth-teller.

As a matter of theory, then, our account confirms the sense of defenders and critics of the adversary systen that the beneficial consequences of legal advice are generally inore robust in cases where advice is provided bilaterally rather than unilaterally. It also predicts why, in different contexts, advice can lave either beneficial or detrimental effects. The differences between defenders and critics of advice can, within this framework, be traced to different assuinptions or a focus on different classes of cases. As a matter of practice, our account helps sort out the cases where legal advice is likely to be undesirable and thus inay aid in formulating legal rules concerning access to advice. But before we get to those issues, we first need to develop some theory of what informational effects are socially desirable.

156. For example, we are not aware of any study that systematically examines the extent to which parties to litigation (1) control relevant information, (2) over- or underestimate evidentiary sanctions, or (3) are unduly optimistic or pessinistic about whether the information available for presentation is favorable or unfavorable. 


\section{IV}

\section{The Social DesirabiLITy OF THE INFORMATIONAL EFFECTS OF LITIGATION ADVICE}

Whether the informational effects of litigation advice slould be regarded as socially desirable depends in part on the purpose of adjudication. One prominent account of civil and criminal adjudication emphasizes its role in encouraging actors to engage in desirable conduct and in deterring thein froin engaging in undesirable conduct. Anotler account einpliasizes directly preventing harm, whether by incapacitating the dangerous criminal or enjoming dangerous acts. A third focuses on the distribution of rewards or punishment in accord with need or desert: compensatory theories of civil justice and retributive theories of criminal justice lave this character. Finally, some accounts of adjudication give weight to the values of procedural fairness, party autononiy, dispute resolution, or party satisfaction with outcomes, independent of the substantive policies that guide the imposition of sanctions.

\section{A. Deterrence Theories}

For deterrence theories, adjudicated outcones are socially desirable to the extent that expected sanctions encourage informed actors to act desirably. Accordingly, the informational effects of advice are socially desirable only if they improve the scliedule of expected sanctions and those improvements are commumicated to actors who are deciding whether to engage in potentially sanctionable conduct. ${ }^{157}$

As we have seen, advice influences two basic features of the relevant information reaching the tribunal: (1) the total amount of relevant information presented; and (2) the extent to which that information is skewed in favor of one party or the otler. We here consider the social desirability of the informational effects of litigation advice in three scenarios. First, we consider advice that increases the aniount of relevant information presented without increasing skew. ${ }^{158}$ This corresponds to the initial

157. Kaplow and Shavell, supra note 17, at 588-90.

158. By "skew" we mean the extent to which the mix of information presented differs from the mix of all relevant information about a case. The mix of information that would be presented by unadvised parties may itself be skewed. Legal advice thus increases skew to the extent it pushes the final mix of information presented further away from the mix of all relevant information.

To the extent violators and nonviolators are equally represented in a given class of litigation, and unadvised parties do not themselves skew the overall information presented, advice has a general effect on skew if it changes the presentation of favorable information systematically more or less than the presentation of unfavorable information. This would not necessarily follow in a class of litigation where one side is usually the wrongdoer. Say, for example, that the mix of information is determined by percentages and that the relevant information is $75 \%$ unfavorable to defendants. Assume also that unadvised parties do not skew the information presented. In those circumstances, bilateral advice would not increase skew if it increases the presentation of favorable information three times as much as it increases the presentation of unfavorable information. Indeed, increasing 
conclusions reached about bilateral advice in our basic account. ${ }^{159}$ It also corresponds to the general effects of bilateral advice when various complications are considered to the extent one agrees, as Part III suggests, that most provide no reason to change the conclusions of the basic account. Second, we consider advice that increases the information presented, but also increases skew. This corresponds to the initial conclusions reached about unilateral advice in our basic account, and perhaps to bilateral advice where some features of the hitigation (such as informational access) are skewed. Third, we consider advice that both mcreases skew and decreases the amount of information presented. This may correspond to advice for some special classes of hitigation discussed in Part III. ${ }^{160}$

\section{Advice That Increases Information Without Increasing Skew}

Advice that increases the information presented without increasing skew iniproves the schedule of expected sanctions. In our basic account, for example, bilateral advice reduces the proportion of irrelevant information presented and increases the presentation of relevant information favorable and unfavorable to each party. ${ }^{161}$ Under a theory of adjudication that emphasizes deterrence, this unskewed increase in favorable and unfavorable information presented ought to iniprove the tribunal's ability to distinguish desirable from undesirable conduct. This in turn increases expected sanctions for those who act undesirably at the same tinie that it decreases sanctions for those who act desirably.

The behavioral benefits of increased accuracy will be realized to the extent that those about to act (1) have some knowledge of which acts the law deems sanctionable, and (2) perceive that tribunals will be inore accurate when parties have advice than when they do not. Actors who consult lawyers before acting or who have had repeated contact with the legal system should normally satisfy these conditions. We think these conditions often will also be satisfied by persons who act on the basis of an intuitive or commonsense understanding of the law and the legal system. ${ }^{162}$ True, popular perceptions of the accuracy of adjudication with

the favorable and unfavorable information equally would increase skew in such a case because it would inove the mix of information presented further away from the $75 / 25 \mathrm{mix}$ of all relevant information.

159. See supra Section II(D).

160. Logically, a fourth category might exist in which advice decreases information without increasing skew. This might occur, for example, where there is bilateral advice, strong party control, and habitual overestimation of evidentiary sanctions. In such cases, advice should decrease expected sanctions for undesirable acts and increase them for desirable acts. Such eases, however, seein sufficiently rare that we forego a inore extended treatment.

161. Where unadvised parties skew the mix of information, bilateral advice inay even decrease skew.

162. Louis Kaplow has pointed out to us that to the extent parties know the substantive rules 
legal advice are often harshly critical. But popular perceptions would probably be even more negative in the less accurate systen that would result if legal advice were barred.

Thus, where actors correctly perceive, however vaguely, the contours of sanctionability and would also perceive the greater inaccuracy that would result without advice, their behavior should be improved by advice that increases information without increasing skew. Moreover, the greater accuracy inade possible by such litigation advice should encourage actors to obtain legal advice before they engage in potentially sanctionable primary conduct because more accurate adjudication will increase the expected costs of choosing sanctionable conduct. ${ }^{163}$ The social desirability of advice received by those who consult lawyers before they engage in primary conduct should also improve, since litigation advice will normally result in expected sanctions inore closely inatclied to the desirability or undesirability of the party's contemplated conduct. ${ }^{164}$

The relationship between litigation advice and primary conduct advice is thus syınbiotic: by enhancing the accuracy of adjudication, litigation advice increases incentives to seek primary conduct advice and increases its social value; by communicating the accuracy of adjudication resulting froin litigation advice to those about to engage ni primary conduct, primary conduct advice enhances the social value of hitigation advice. Cases will renain where the beneficial behavioral effects of litigation advice will not be realized because actors are poorly informed. Those cases, lowever, do not denionstrate that litigation advice is not socially desirable, since the behavior of those poorly informed actors will be no worse than if there liad been no hitigation advice, while the behavior of better informed actors will improve.

applicable to their primary conduct before they act, litigation advice will have somewhat less effect on the information they select for presentation. Although this may limit the extent of the effect on beliavior, it will not alter its nature or direction. Parties who know wliat conduct is sanctionable would still perceive that in a regime without advice, the evidence presented is less likely to reveal what they actually did. The increased aceuracy in an advised system stems from many sources other than advice about what conduct is sanctionable. It also stems from advice to the party's opponent, from advice about what inferences the tribunal will draw from information, from advice about relevance, from better investigation, and because a necessary cost of getting the advice needed to succeed in the adversary system will be the revelation of more unfavorable information because of the lawyer's differential susceptibility to sanctions.

163. Cf. Shavell, Legal Advice About Contemplated Acts, 17 J. LEGAL STUD. 123, 127-28 (1988) (noting that increasing the benefits of avoiding unlawful conduct will increase a person's incentive to obtain advice).

164. Kaplow and Shavell appear to agree that more accurate adjudication will increase thc social value of advice about primary conduct. See Kaplow \& Shavell, supra note 17, at 588-89 \& n.58. But their model of litigation advice leads them to conclude that it does not improve the accuracy of adjudication. Id. at $589 \&$ n.59. 


\section{Advice That Increases Information and Skew}

Advice that increases the ainount of information presented but also increases skew will improve expected sanctions for parties who benefit from the increased skew. Unilateral advice in our basic account, for exainple, increases skew by increasing the presentation of information favorable to the advised party and decreasing the presentation of unfavorable information. ${ }^{165}$ This improves expected sanctions for the party receiving unilateral legal advice. Sometimes this will be desirable: expected sanctions should decrease for those parties benefiting from the skew who did not violate the law and expected outcomes should improve for those who justly accuse others of violating the law. Sometimes this will be undesirable: expected outcoines should improve for unjust accusers and violators. For example, allowing surgeons to hire legal counsel in defending against malpractice claims will desirably reduce expected sanctions for competent surgery and undesirably reduce expected sanctions for incompetent surgery. Allowing malpractice plaintiffs to hire legal counsel will desirably increase expected sanctions for incoinpetent surgery and undesirably increase expected sanctions for competent surgery.

Because the advice also increases the total amount of relevant inforination presented, however, the increase in information favorable to the parties benefited by the skew will generally tend to exceed any decrease in unfavorable information. ${ }^{166}$ For exainple, in the basic unilateral account, the increase in information favorable to the advised party exceeds the decrease in unfavorable information. Because favorable information is relevant only if it inakes the factual conclusion favorable to the presenting party more probable than it would be without the evidence, ${ }^{167}$ nonviolators or just accusers are by definition more likely to have potentially presentable favorable information than violators or unjust accusers. Competent surgeons are, for example, likely to have more favorable information to present, and less unfavorable information

165. See supra Section II(D).

166. See id. Sometimes skew will be increased even though favorable and unfavorable information are increased. For example, in a general class of eases where the information is $50 \%$ favorable and 50\% unfavorable, advice that increases the items of favorable information by 80 and increases the items of unfavorable information by 30 increases skew. Within our basic account, the effects of such advice could be described as partly bilateral and partly unilateral. (This advice would correspond to cases where both parties get counsel but one side gets better counsel than the other. See supra Section $\mathrm{I}(\mathrm{D})$.) The bilateral part might increase the items of both favorable and unfavorable information by 50 items; the unilateral part might increase favorable by 30 items and decrease unfavorable by 20 items. Such advice is usually even more likely to have the differential effect on expected sanctions described in the text than advice that simply increases favorable information more than it decreases unfavorable.

167. See FED. R. EvID. 401 (defining "relevant evidence" as "evidence having any tendency to make the existence of any fact that is of consequence to the determination of the action more probable or less probable than it would be without the evidence"). 
to withhold or suppress, than incompetent surgeons. Plaintiffs suing incompetent surgeons are likely to have inore favorable information and less unfavorable information than plamtiffs sumg competent surgeons.

Litigation advice that increases information and skew should therefore generally benefit nonviolators and just accusers more than violators and unjust accusers. ${ }^{168}$ This will tend to cause a differential change in expected sanctions with socially desirable effects on behavior. ${ }^{169}$

The differential effect will be clearest in classes of hitigation where, without advice, the level of expected sanctions would be roughly the saine for violators and nonviolators (or for accusers and just accusers). In such classes of hitigation, advice benefiting defendants, such as umilateral advice in the basic account, will decrease expected sanctions for nonviolators inore than for violators. ${ }^{170}$ Competent surgeons will, for example, experience a larger decrease in expected sanctions than incompetent ones. Advice benefiting accusers (plaintiffs or prosecutors) will improve expected outcoines inore for just accusers than for unjust accusers, thus harming violators more than nonviolators. Incompetent surgeons will, for example, experience a larger increase in expected sanctions than coinpetent ones.

Because the improvement in expected outcoines for nonviolators (or just accusers) will be greater than the improveinent in expected outcomes for violators (or unjust accusers), advice that causes a differential increase or decrease in expected sanctions increases the probability that actors choosing between desirable and undesirable acts that are both associated with a risk of sanctions will choose the desirable acts. Surgeons should, for exainple, be induced to take greater care because the difference between the expected sanctions for coinpetent and incompetent surgery will be greater if there is a differential increase or decrease in expected sanctions that favors competent surgery. ${ }^{171}$

In classes of hitigation where, without advice, the level of expected

168. In contrast, because Kaplow and Shavell find it completely ambiguous whether unilateral advice increases favorable information more or less than it decreases unfavorablc information, they conclude that it is a matter of "happenstance" whether the decrease in expected sanctions for desirable acts outweighs the decrease im expected sanctions for undesirable acts. Kaplow \& Shavell, supra note 17 , at 614 .

169. The conclusion of social desirability assumes of course that the law defining violations bears some positive correlation to the social desirability of the primary conduct. Where there is no such correlation, any system of adjudication will produce undesirable results.

170. The size of the differential change in expected sanctions will, however, also vary with thc competence of the opponent of the party receiving advice. See supra Section II(A)(1)(c)(ii).

171. Say, for example, that the expected sanctions without advice are $\$ 2000$ for both competent and incompetent surgery. This schedule of expected sanctions means that the effective sanction for acting imcompetently instead of competently is $\$ 2000$ minus $\$ 2000$, or $\$ 0$. If advice to surgeons reduces expected sanctions to $\$ 1000$ for competent surgery and $\$ 1500$ for incompetent surgery, then the effective sanction increases to $\$ 500$. If advice to plaintiffs increases expected sanetions to $\$ 3000$ for competent surgeons and $\$ 4000$ for incompetent surgeons, then the effective sanction increases to 
sanctions is higher for violators than for nonviolators, or lower for unjust accusers than for just accusers, the tendency of advice to improve outcomes more for nonviolators or just accusers may be offset if marginal returns to legal advice diminish more sharply for nonviolators and just accusers. Such diminishing marginal returns might exist, for example, because the expected sanctions without advicc for incompetent surgeons exceed those of competent surgeons, meaning that the unadvised situation of incompetent surgeons has greater room for improvement. If there is a sufficient difference between the marginal returns to advice for violators and nonviolators or for unjust and just accusers, advice may cause a differential change in expected sanctions that benefits violators and unjust accusers more than it benefits their counterparts. ${ }^{172}$

In the extreme case, where nonviolations are associated with a zero risk of sanctions, advice to defendants will clearly have diminishing marginal returns. Such advice cannot lower expected sanctions for nonviolators at all, ${ }^{173}$ but somewhat lowers expected sanctions for violators. This undesirably makes actors more likely to commit violations. In such an extreme case, however, advice to accusers will be especially desirable. The advice will increase the expected recovery of just accusers. But unjust accusers will have a zero chance of recovery (since nonviolations have a zero risk of sanctions) and thus cannot be helped by advice. This means that advicc to accusers will make actors less likely to commit violations. ${ }^{174}$ Moreover, because just accusers should have more favorable information than violators, the mcrease in expected sanctions violators face because of advice to accusers should generally exceed the decrease in expected sanctions violators enjoy because of advice to defendants. Thus where unilateral advice may benefit either accusers or defendants, the overall effect over the whole class of hitigation will still be a differential change in expected sanctions. ${ }^{175}$

$\$ 1000$. The increase in effective sanctions resulting from either differential change in expected sanctions should increase the likeliliood surgeons will act competently instead of incompetently.

172. Suppose the damages imposed for malpractice are $\$ 100,000$. Some surgical conduct may be so clearly competent that it is subject to a very low risk of sanction (say 5\%) even if the surgeon lacks litigation advice. Assume also, lowever, that even witl advice, the surgeon faces an irreducible risk of sanctions (say 2.5\%). Advice thus reduces expected sanctions for competent surgery by $\$ 2500$. On the other liand, an incompetent surgeon is subject to a $45 \%$ risk of sanctions witlout advice and an irreducible $15 \%$ risk of sanctions with advice. Thus legal advice reduces the expected sanction for incoinpetent surgery by $\$ 30,000$.

173. Even if unadvised nonviolators run no risk of losing a suit, they should, if there is any chance a suit will be brought, still receive some advantage from litigation advice in a system where meritless suits can be sanctioned. In sucl systems, providing advice to the nonviolator sliould lielp deter unjust accusations and thus lower the nonviolators' exposure to litigation costs.

174. It will also make just accusers more likely to sue.

175. A similar analysis applies in the less likely case where nonviolations are associated witl a risk of sanctions but violations are not. Advice to accusers will be undesirable in such a class of litigation because it will make actors more likely to commit violations. It also inakes it more likely 
It will sometimes be possible to eliminate the harmful effects of advice that increases information and skew and still achieve levels of expected sanctions that are superior to those that would have prevailed in the absence of legal advice. If, over the relevant class of hitigation, such advice benefits nonviolators or just accusers more than it benefits violators or unjust accusers, that can be exploited to improve deterrence as long as the regime can appropriately adjust either the standard of proof for finding liability or the actual sanction imposed when hability is found. The standard of proof can be decreased, or the actual sanctions increased, to offset the bad effects of advice on the expected sanctions of violators, without completely offsetting the good effects of advice on the expected sanctions of nonviolators. Similarly, the standard of proof can be increased, or the actual sanctions decreased, to offset the bad effects of advice on the expected outcomes of unjust accusers without completely offsetting the good effects of advice on the expected outcoines of just accusers. ${ }^{176}$

Adjusting the standard of proof might occur in either criminal or civil cases. For example, if legal advice alters the mix of favorable and unfavorable information criminal defendants present on the issue of guilt, the tribunal might in theory effectively reduce the standard of proof for finding advised defendants guilty by requiring less evidence to overcome reasonable doubt. ${ }^{177}$ The "lawyer discount" can be used to offset the improved showing made by guilty defendants. If advice increases the odds of acquitting innocent defendants more than it increases the odds of

that actors will be diverted from desirable activity that is associated with a risk of sanctions into other less desirable activity that is not associated with a risk of sanctions. An increase in expected sanctions for nonnegligent obstetrics, for example, may cause doctors to shift to other medical specialties that are less needed but carry less risk of erroneous liability.

By the same token, advice to defendants in such a class of hitigation is especially desirable. By decreasing expected sanctions for nonviolators, without affecting sanctions for violators, it makes actors less likely to commit violations. It also increases the hikehhood that a party choosing between a nonviolation associated with a risk of sanctions and a nonviolation that is not so associated will choose the nonviolation that is more personally advantageous. A decrease in expected sanctions for nonnegligent obstetrics, for example, will induce more people to shift from other lawful careers into obstetrics.

Moreover, because nonviolators should have more favorable information than unjust accusers, the decrease in expected sanctions nonviolators enjoy because of advice to defendants should generally exceed the increase in expected sanctions nonviolators face because of advice to accusers. Advice to defendants should decrease the expected sanctions for nonnegligent obstetrics more than advice to plaintiffs increases those expected sanctions.

176. Kaplow and Shavell discuss the theoretical possibility of adjusting sanctions to offset the informational effects of advice. Kaplow \& Shavell, supra note 17, at 590-93. It is not clear, however, why such adjustments would be worthwhile in their model given the ambiguous informational effects of advice they predict.

177. In practice, however, there may be significant practical and moral objections to ad hoc adjustments of standards of proof to take account of legal advice. See infra notes 183-84 and accompanying text. Nonetheless, it is clear that such adjustments sometimes oceur. See infra note 184. 
acquitting guilty defendants, more innocent defendants will be acquitted under the revised standard, with no decrease in the number of guilty defendants convicted. Alternatively, the discount could be used to offset the larger benefits that accrue to innocent defendants, increasing the number of guilty defendants pumshed without increasing the number of innocent defendants punished. In civil cases, where the preponderance of the evidence standard fixes the probability required to establish hability at just over fifty percent, the tribunal can achieve a similar adjustment by discounting the weight given to evidence produced by the parties benefiting from the advice-caused skew.

Such adjustments may be feasible even where diminishing marginal returns cause a greater reduction in the magnitude of expected sanctions for violators than nonviolators, as long as the proportional decrease in expected sanctions is greater for the nonviolators. Suppose the damage award imposed after a finding of medical malpractice is fixed at $\$ 100,000$. Suppose further that unadvised coinpetent surgeons have a $10 \%$ chance of hability, which can be reduced to $2.5 \%$ with advice. Unadvised incompetent surgeons have a $20 \%$ chance of hability, which can be reduced to $10 \%$ with advice. The expected sanctions for coinpetent surgeons have thus decreased from $\$ 10,000$ to $\$ 2500$, or by $\$ 7500$. The expected sanctions for incoinpetent surgeons have decreased from $\$ 20,000$ to $\$ 10,000$, or by $\$ 10,000$, a greater amount. Advice to defendants could, however, be coupled with an adjustment that makes the standard of proof twice as easy for plaintiffs to ineet. In that case, the resulting expected sanctions would be $\$ 5000$ for competent surgeons ( 2 tines $2.5 \%$ times $\$ 100,000$ ) and $\$ 20,000$ for incompetent surgeons ( 2 times $10 \%$ times $\$ 100,000$ ). The net result would be a decrease in expected sanctions for the coinpetent without a decrease in expected sanctions for the incompetent. Making the standard of proof four times as easy for plaintiffs would increase expected sanctions for the incompetent without increasing thein for the coinpetent. ${ }^{178}$

The second strategy for benefiting from the differential change in expected sanctions involves adjusting actual sanctions. Where the advice causes a differential decrease in the expected sanctions of defendants, actual sanctions can be increased just enough to offset the decrease in expected sanctions for violators without offsetting the decrease for nonviolators. This combination of advice and sanction adjustment leaves the world better off by decreasing deterrence of desirable activity without

178. However, if advice benefits only defendants and, because of diminishing marginal returns, decreases the magnitude and proportion of expected sanctions for violators more than for the nonviolators, then no adjustment can eliminate the harmful effect of advice on deterring violations without increasing the expected sanctions of nonviolators. A similar problem results if advice has these sorts of diminishing marginal returns and benefits only accusers. 
lessening deterrence of undesirable activity. Alternatively, actual sanctions might be increased enough to offset fully the decrease in expected sanctions for nonviolators, leaving the world better off by increasing deterrence of undesirable activity at no cost to desirable activity. Similarly, where the advice aids just accusers, actual sanctions could be decreased just enough to offset the miproveinent in outcoines for unjust accusers (increasing deterrence of undesirable activity at no cost to desirable activity) or decreased enough to offset fully the improveinent in expected outcomes for just accusers (decreasing deterrence of desirable activity without lessening deterrence of undesirable activity). Or, for either form of advice, sanctions could be adjusted to achieve any result in between: mcreasing deterrence somewhat for undesirable acts and decreasing it soinewhat for desirable acts. Although different strategies might be optimal in different circumstances, all result in a social state that is preferable to the social states possible without the differential change in expected sanctions made possible by litigation advice that mcreases information and skew. ${ }^{179}$ As with adjustimg the standard of proof, a strategy of adjustimg actual sanctions inay be feasible even with diminishing inarginal returns as long as the proportional decrease in the expected sanctions is greater for the nonviolators than the violators.

A strategy of adjusting hability standards or actual sanctions to offset the adverse skewing effects of hitigation advice does, however, face other obstacles. Risk-aversion may be a problem. If, for example, those who commit desirable acts associated with a risk of sanctions are systematically inore risk-averse (with legal advice) than those who commit undesirable acts associated with a risk of sanctions, then increasing actual sanctions will mcrease deterrence inore for desirable actors than for undesirable actors. ${ }^{180}$ This will tend to offset the differential change in deterrence levels resulting from advice that reduces expected sanctions more for desirable acts than for undesirable acts. Society can, however, still benefit by coupling a differential change in expected sanctions with

179. Efforts to adjust sanctious might be complicated by two factors considered in Part III. First, advice can improve effective expected sanctions not only by improving the information presented, but also by improving the party's bargaining for the distribution of the settlement surplus. See supra notes 126-27 and accompanying text. But since this affects all advised parties, it does not alter the tendency of advice to aid nonviolators and just accusers more than violators and unjust accusers. Sccond, advice can improve expected sanctions by improving the mix of false or prejudicial information presented. See supra Section III(D). This is more troubling because one might well expect violators and unjust accusers to be more likely to present false or prejudicial information. But we doubt that this will have an impact substantial enough to alter the overall differential change in expected sanctions that we predict.

180. Cf. Polinsky \& Shavell, supra note 135, at 880 (discussing the effects of risk-aversion). Similarly, if desirable actors are systematically less risk-averse than undesirable actors, then decreasing actual sanctions will decrease deterrence more for undesirable actors than for desirable ones. 
an increase in actual sanctions, even if undesirable actors are systemically less risk-averse than desirable actors, as long as the systemic difference in risk-bearing costs is not substantial enough to outweigh the differential change in sanctions. ${ }^{181}$

Another problem is that adjustments in actual sanctions or standards of proof may have a feedback effect on the level of effort parties exert to identify and present information. Decreasing actual sanctions may, for example, decrease the trial efforts of defendants by making them less valuable. ${ }^{182}$ Because the trial efforts of nonviolators should be more effective than those of violators, this reduction in effort should dampen the improvement in the tribunal's ability to distinguish violators from nonviolators and thus reduce the effective differential change in expected sanctions. We doubt, however, that this feedback effect from adjusting sanctions will be sufficient to offset the differential change in expected sanctions that provoked the sanction adjustment. Moreover, where the adjustments call for increased sanctions, trial effort should increase and thus enhance the differential change in expected sanctions. This will tend to offset the adverse effect increasing sanctions has on risk-bearing costs where nonviolators are systematically more risk-averse than violators.

Special problems may attend strategies that depend on ad hoc adjustinents of sanctions to take account of differences in the quality of the parties' legal advice. Tribunals may not be able to recognize the appropriate level of adjustment in every case. ${ }^{183}$ In addition, ad hoc adjustments may conflict with the ideal of a neutral tribunal. ${ }^{184}$ But

181. In those circumstances, actual sanctions can simply be increased to achieve both (1) the same deterrence level for violators (taking into account both changes in expected sanctions and the increased risk-bearing costs caused by increasing actual sanctions) as would exist if hitigation advice did not cause the differential reduction in expected sanctions, and (2) a lower deterrence level for nonviolators. $C f$. id. (noting that the "possibility of risk aversion does not imply that individuals cannot be induced to make the same decision about engaging in the activity as they would" under a risk neutral inodel of expected sanctions). Adjusting sanctions to coinpensate for unilateral advice aiding defendants will be even more feasible if undesirable actors are more risk-averse than desirable actors or do not have systeimically lower levels of risk-aversion. But where the risk-aversion of desirable actors is systematically higher than that of undesirable actors, and the difference in riskbearing costs is sufficiently large, then imcreasing actual sanctions will not be a feasible strategy for offsetting the effect of litigation advice on expected sanctions.

182. See Rubinfeld \& Sappington, Efficient awards and standards of proof in judicial proceedings, 18 RAND J. ECON. 308, 313 (1987).

183. Tribunals may have considerable difficulty in determining how much of a disconnt to apply to evidence presented by a party who has the only lawyer in the case, or, more commouly, who has the "better" lawyer. Jurors, who typically have limited experience in observing lawyers and litigation, may find it particularly difficult to apply such a discount, or indeed, to determine which of two lawyers is "better." An example of two successful lawyers each atteinpting to appear less effective than the other appears in a recent account of the famous trial in which Pennzoil obtained a \$10 billion jury verdict against Texaco. See S. COLL, THE TAKING OF GeTTY Oll 422-23 (1987). Who won the "game within a game" is indicated not only by the final outcome but by one juror's strong praise for Texaco's trial attorney as a "terrific lawyer." Id. at 469.

184. Sometimes the process of discounting the claims of the party with better advice or 
adjustment of standards of hability and sanctions prompted by the effects of advice need be no inore ad hoc in character than any restrictions on advice that might be proinpted by those effects. In general, restrictions wonld be desirable only if advice systematically benefited one side in a definable class of hitigation. Where that is so the standard of hability or actual sanctions can, as the examples above illustrate, be adjusted across the class of litigation without inaking case-by-case adjustinents.

The problem of individual variation would remain. ${ }^{185}$ Parties vary in, ainong other things, the degree to which they benefit from litigation advice, their perceptions of expected sanctions, and their aversion to risk. These variations make it impossible to offset precisely the changes in the probability of liability or the level of deterrence each person experiences beeause of legal advice. Adjustinents to the rule of decision or actual sanctions will instead have to generalize about these varying characteristics, missing fine detail. Generalization and miprecision, however, are necessary features of every legal regime. Unless there is some reason to beheve that the pattern of miprecision that would exist without hitigation advice has some special virtues that the pattern of variation in an adjusted regime witl advice would not share, the risk of imprecision cannot support an argument against coinbining legal advice and adjusted sanctions to achieve a baseline level of deterrence that is generally higher for undesirable acts and lower for desirable acts.

A final problem where advice benefits defendants is that sometimes actual sanctions cannot be imcreased sufficiently to offset the effect of advice without other untoward consequences. There may be physical, constitutional, moral, or practical limits on increasmg actual sanctions to offset the effects of advice. Of these, moral and practical constraints seem inost likely to be significant. ${ }^{186}$ (None of these constraints operates

enhancing the claims of the party with worse advice might be seen as covert advocacy against the stronger party and in favor of the weaker party. In effeet, the tribunal must supply from its experience and imagination the information and inferences that the party with inferior advice would have presented had she been more able. Arguably, this process undermimes the neutral passivity that some accounts stress is critical to the functioning of adversary adjudication, cf. Fuller, The Forms and Limits of Adjudication, 92 HARv. L. REv. 353, 385 (1979) (a judge should not "interfere voluntarily in ... cases which are presented to him"), and others argue is important to the appearance of fairness, see Resnik, supra note 23, at 427 (a judge's personal involvement renders subsequent judgment unfair). These objections may seem less severe, however, when the adjustment consists of, say, the judge's decision to cross-examine a witness after a lawyer has done an exceptionally poor job at that task or to comment unfavorably on the evidence presented by the party with the better lawyer.

185. This is the obstaele stressed by Kaplow \& Shavell, supra note 17, at 590-93.

186. We doubt that the fact that physical punishments are ultimately limited to death often poses a significant barrier to increasing sanctions. Nor do we think that the constitutional limitations on cruel and unusual (or disproportionate) punishinent, as interpreted by the Supreme Court, will impose significant constraints on increasing actual sanctions within any range that a contemporary legislature would regard as morally permissible. $C f$. id. at 591 \& n.63 (concluding that recent Court decisions cast doubt on the effectiveness of that clause as a constraint). 
when the needed adjustment calls for decreasing actual sanctions to offet the effect of advice benefitimg accusers.). Society may be unwilling on moral grounds to countenance even an informal adjustment in the standard of hability like that described above or to impose actual sanctions at a level sufficient to deter the conduct im issue. For other offenses, society may be unwilling to pay the high cost of extended incarceration.

It is important, however, not to overstate the need for or difficulty of adjustments to offset the harmful or ambiguous effects of hitigation advice. In some classes of hitigation where sanctions cannot be adjusted, the net behavioral effects of reducing expected sanctions more for desirable acts than for undesirable acts may still be socially desirable. In other classes of hitigation, sanctions may already have been set to take account of the effects of hitigation advice. In most civil hitigation, for example, sanctions may be set on the assumption that the parties have roughly comparable litigation advice of a specified quality. If a unilateral mcrease in one party's advice simply brings the advicc available to the parties into that rough balance, no adjustment in sanctions is required. Similarly, those who beheve that sanctions in criminal cases are already sufficiently severe and should not be further increased to offset the effects of advice should note that those sanctions operate in a system in which all felony defendants already receive some advice. Hence criminal sanctions may already be set on the assumption that both parties will have comparable levels of hitigation advice. The question is thus not so much whether present sanctions should go higher, but whether they should be lowered if defendants' access to advice is limited. As a practical matter, then, the problems of adjustimg sanctions may exist primarily where conditions of relative equality are not met: criminal cases where the defendant has an exceptionally good lawyer ${ }^{187}$ or civil cases where there is an imbalance of representation.

\section{Advice That Decreases Information and Increases Skew}

Our analysis in Part III suggests that sometimes advice may decrease information and increase skew. For example, in a criminal case where a sanction-optimizing defendant faces a truth-telling prosecutor, the defendant has acted wrongly, and there is a substantial amount of suppressible infornnation unfavorable to the defendant, unilateral legal advice for the defendant might well have such effects. Such advice reduces the tribunal's ability to assess the desirability of defendants' conduct and has undesirable behavioral consequences that adjusting sanc-

187. To the extent that this category includes those cases where defendants can retain exceptionally talented counsel with the alleged proceeds of their crimes, the rules permitting the use of forfeiture statutes to prevent that result may therefore have socially desirable effects on trial outcomes that could not be achieved by adjusting sanctions. See infra text accompanying note 203. 
tions cannot fully offset. ${ }^{188}$ This has implications if, for example, one believes that an identifiable class of parties (such as social welfare agencies or prosecutors) are generally thorougli truth-tellers and that their opponents are generally sanction-optimizers who can withhold or suppress a disproportionate share of the relevant information. One who holds that behef should find some possibility of improving overall outcomes through a combination of reducing legal advice to all opponents and adjusting rules of decision or sanctions to inake tliem more favorable to opponents. We return to this disturbing class of advice im Section $\mathrm{V}(\mathrm{A})$.

\section{B. Nondeterrence Theories}

\section{Advice That Increases Information Without Increasing Skew}

The informational effects of advice that, like bilateral advice in our basic account, increases information without increasing skew should also be desirable from perspectives other than pure deterrence. In theories of civil or criminal justice tliat emphasize preventing liarm, accurate judgments about the cliaracter of the act sought to be enjoined or tlie defendant who faces incapacitation are obviously important. ${ }^{189}$ Accuracy is also important if the goal of adjudication is to ensure fair compensation for liarm suffered or just retribution for liarm done. In all these regimes, the improved accuracy made possible by bilateral advice appears socially desirable.

Such advice also seems likely to have a positive impact on tlie dispute resolution function of the tribunal. First, bilateral advice increases the ability of both parties to participate effectively in determining the outcome of adjudication by reducing effort wasted on gatliering and presenting irrelevant information and by increasing the amount of relevant information that each party is able to present. Second, many parties undoubtedly beheve that outcomes are fairer the more closely they correspond to what actually happened or will liappen. To the extent that more effective participation and improved accuracy enliance the likelihood that the parties will accept and abide by the tribunal's resolution of

188. Where such advice aids defendants, it decreases expected sanctions morc for violators than for nonviolators. Increasing sanctions to offset the decrease in expected sanctions for violators will result in a net increase in expected sanctions for nonviolators as well. Similarly, where this type of advice aids accusers, sanctions cannot be decreased enough to ofiset the increase in expected recovery for unjust aceusers (and thus an increase in expected sanctions for nonviolators) without resulting in a net reduction in expected recovery for just accusers (and thus a decrease in expected sanctious for violators).

189. Theories of adjudication based on incapacitation differ in one important way from theories that emphasize deterrence: for incapacitation theories, the increased accuracy of adjudication resulting from advice need not be communicated to prospective actors in order to have socially desirable effects. 
the dispute, the bilateral informational effects of legal advice should also increase party satisfaction with outcoines.

\section{Advice That Increases Information and Skew}

The effects of advice that increases information and skew, such as unilateral advice in our basic account, should also generally be desirable in accounts of adjudication that stress harm prevention, fair coinpensation, just punishment, or dispute resolution. For example, unilateral advice to defendants will, leaving aside diminishing inarginal returns, benefit harmless or deserving actors inore than it will benefit dangerous and undeserving actors. Uuless it is not possible to adjust the tribunal's rule of decision or actual sanctions to take advantage of that difference, the combination of advice and appropriate adjustments ought to produce outcomes more closely matched to the character of the parties and their conduct than those outcomes resulting without advice. ${ }^{190}$ Even when it is not possible to make such adjustınents, it may be sufficient to justify the advice in that it prevents maecurate conclusions that prejudice deserving actors inore often than it causes inaccurate conclusions that benefit the undeserving. This is especially true for advice to criminal defendants, because of the traditional judginent that "it is far worse to convict an innocent man than to let a guilty man go free." 191

\section{Advice That Decreases Information and Increases Skew}

Finally, we come to advice that decreases information and increases skew. Such advice seems clearly undesirable under theories of justice that stress enjoining wrongdoing, incapacitatimg criminals, compensating injuries, or exacting retribution. By making adjudication less accurate, such advice makes it harder to prevent harm or distribute rewards and pumishments justly.

Soine might argue, however, that fairness requires providing such advice notwithstanding its potential ill effects if the party's opponent has or can obtain comparable advice. Consider, for example, the stated obligation to tell "the truth, the whole truth, and nothing but the truth." On

190. For example, suppose the purpose of adjudication is to compensate those who suffer a specified harm, whom we will call "deserving claimants." To offset the inflationary effect of evidentiary advice upon claims of harm, the threshold for proof of harm can be raised. If the rise in the threshold offsets the improved showing inade by undeserving claimants, then more deserving claimants will receive compensation (because their presentations improve more with evidentiary advice than do the presentatious of the undeserving) without increasing the number of the undeserving claimants who receive compensation. If the threshold is raised sufficiently to offset the improved showing made by the deserving, fewer undeserving clainants will receive compensation (because their presentations improve less with evidentiary advice than those of the deserving) without reducing the number of deserving claimants who receive compensation. Either outcoine is preferable to that which would prevail in the absence of legal advice.

191. In re Winship, 397 U.S. 358, 372 (1970) (Harlan, J., concurring). 
its face, this oath creates an enforceable legal obligation to volunteer information. In fact, failure to volunteer information not asked for, although a plain violation of the oath, is not sanctionable. A party who acts on the assumption that failure to comply with the oath by volunteering information would be detected and heavily sanctioned, while her opponent understands and acts upon the real rules, will often be victimized by the opponent. ${ }^{192}$ One might think that if society cannot or will not deter the wrongful conduct of those who are already knowledgeable, the fairest way to achieve a rough balance of advantage is to allow botll parties to learn and act upon the real rules of the gaine.

Often these claims extend beyond fairness. Conduct that is normally undesirable in itself may be a desirable response to conduct by the other side. Say, for exainple, that two sellers get advice that lowers their expected antitrust sanctions for an anticompetitive merger that will give them monopoly power and allow them to raise prices. A group of buyers might then assert that "fairness" entitles them to advice that lowers their expected antitrust sanctions for forming an illegal anticompetitive buying cartel that will give them countervailing market power. This claim would extend beyond fairness if they claim that forming the buying association is allegedly a "second-best" solution that will lead to prices and outputs that are more efficient (and socially desirable) than those that would result if ouly the sellers had monopoly power. ${ }^{193}$ All this establishes, however, is that if an opponent is known to be engaging in undesirable conduct, advice that lowers sanctions for conduct that would ordinarily be considered undesirable (such as cartels) may become desirable. In these circumstances, the argument for advice that lowers sanctions for the illegal conduct in question is not an individual fairness claim in tension with social welfare: the advice is desirable to the extent that the illegal (and ostensibly undesirable) conduct is, im this special setting, socially desirable. ${ }^{194}$

Much more troubling is the claim that fairness or respect for party autonomy requires that advice be provided even in cases where it has undesirable effects that admittedly impair the tribunal's ability to distinguish the desirable acts from the undesirable. Some argue that furthering party autonomy or dignity is an mtrinsic good that may justify even

192. The case for advice will be even stronger if the tribunal (1) has already adjusted sanctions to reflect the general understanding among litigants that information should not bc volunteered, but (2) has not adjusted sanctions to compensate for the fact that one of the litigants does not have legal advice. In such cases, the sanction adjustment effectively assumes that the witness is not voluntecring information, even if she in fact is being forthcoming.

193. See generally P. AREEDA \& L. KAPLOW, ANTTTRUST ANALYSIS 40-42, 195 \& n.24, 223 n.46 (1988) (discussing countervailing power and second-best theory).

194. Cf. Sinon, supra note 12, at 1090 (arguing that professional norms should authorize deceptive conduct in litigation when necessary to prevent unjust results). 
advice that makes litigation less accurate. ${ }^{195}$ Others argue that advice which decreases the information reaching the tribunal may serve to legitimate litigation outcomes. In particular, the argument runs, the apparent fairness of the proceeding to the losing party may depend on the party's sense that slie has been an informed participant and that the best possible case has been made on her belialf. ${ }^{196}$

If, however, litigation advice decreases the accuracy of adjudication, furthering fairness, autonomy, or party satisfaction for the advised party has a necessary cost: denying fairness, autonomy, and party satisfaction to those injured by inaccurate adjudication. Some might be injured directly because they are improperly deprived of a remedy or improperly sanctioned. Some imight be injured indirectly because the resulting failure to deter undesirable activity or overdeterrence of desirable activity infringes their freedom. For example, the autonomy of women is infringed if they do not feel free to walk alone at might because rape is underdeterred. And erroneous findings of malpractice might overdeter obstetrics and make the costs of malpractice liability prohibitive, restricting the autonomy of doctors to become obstetricians and of individuals to further their reproductive goals. Whether imjured directly or indirectly, those injured by maccurate adjudication would seem to have claims to fairness, autonomy, and party satisfaction that are far stronger than those claiming an entitlement to advice that decreases the accuracy of adjudication.

\section{Conclusion}

The informational effects of advice that, like bilateral advice in our basic account, increases information witlout increasing skew are socially desirable whether one measures its social value by its contribution to optimal deterrence, to other goals of adjudication, or to some combination of the two. Under the analysis in Part III, this provides strong support for bilateral advice unless certain special conditions are present. The overall informational effects of advice that mcreases information but also increases skew, such as unilateral advice and bilateral advice where informational access is skewed, also seem generally desirable. The desirability of this latter form of advice may, lowever, depend in part on

195. See M. FreEdMAN, supra note 9, at 4. The general proposition that client autonomy justifies lawyer conduct that would otherwise be viewed as socially undesirable is developed in Fried, The Lawyer as Friend: The Moral Foundations of the Lawyer-Client Relation, 85 YALE L.J. 1060, 1073 (1976).

196. See Professional Responsibility: Report of the Joint Conference, 44 A.B.A. J. 1159, 1216 (1958) (legal advice legitimates outcomes by easing the "fear . . . that perliaps more might lrave been said for the losing side"); Curtis, supra note 50, at 12 (Defending legal advice on the ground that "the law ... must give the losing party . . . as much satisfaction as any loser can expect. At least the most has been said for lim."). 
whether advice has diminishing marginal returns and on the legal regime's ability to adjust the tribunal's rule of decision and actual sanctions. Fimally, where advice decreases information and increases skew, it seems undesirable. In the classes of hitigation identified in Part III where advice is likely to give rise to such harmful effects, restrictions appear warranted.

\section{$\mathrm{V}$}

\section{Regulating the Provision of Litigation Advice}

Many rules regulate access to hitigation advice. In this Part, we first discuss the informational effects of measures designed to increase or decrease access to counsel. We then apply our analysis to inore narrowly targeted proposals that would limit attorney-chent confidentiahty or restrict the advice a party receives about responding to investigation or questioning. Our account clarifies the compromises inherent in those rules and the possible justifications for the contours of present doctrine.

\section{A. Measures That Encourage or Discourage the Use of Lawyers}

To our knowledge, no legal doctrine establishes an outright ban on consulting with a lawyer in comection with a legal dispute. A handful of rules, however, impose relatively broad restrictions on advice. Some states, for example, forbid lawyers from participating in sunall claims court hearings. ${ }^{197}$ If it is likely that both parties would obtain advice without this ban, then we can evaluate the ban under our bilateral account of advice. On the classic assumption that "sinall" claims are simple enough for laypersons to handle (so that lawyer participation would normally produce no informational benefit), such a ban inight be justified as a form of paternalism to protect parties froin wasting their money. ${ }^{198}$ Our account suggests, however, that if a substantial number of "small" claims are in fact complex, ${ }^{199}$ such bilateral restrictions could significantly reduce the information reaching the tribunal.

Small claims restrictions also illustrate the difficulty of deterinining whether nominally bilateral restrictions on advice have bilateral or unilateral effects. If only one party would retain legal advice without a ban, then a nominally bilateral ban may in fact hinit only that party's advice. Such a restriction might be an important safegnard agamst presentations skewed to the advantage of a party willing and able to pay for legal counsel. On the other hand, suppose mstead that one of the parties is a repeat

197. See, e.g., Cal. Civ. Proc. Code \$ 117.4 (West Supp. 1990). See generally Yngvesson \& Hennessey, Small Claims, Complex Disputes: A Review of the Small Claims Literature, 9 LAw \& SOC'Y REV. 219, 223 n.4 (1975) (listing states barring attorneys froin sinall claims court).

198. See Yngvesson \& Hennessey, supra note 197, at 223, 225.

199. Id. at 258-59. 
litigant, like a bank or finance company, who has become familiar with the small claims process through repeat exposures while the other is a one-shot player, like a consumer debtor. In such cases, the ban will prevent the one-shot player from obtaining advice that would enable her to match the presentation of the repeat player, thus locking in place the disadvantage imposed by the party's inexperience.

More common than outright restrictions are legal rules that encourage or discourage advice, typically through the use of financial subsidies or disincentives. Often in these cases, the relevant rules clearly have unilateral effects because they burden or benefit identifiable classes of litigants. We have already shown how rules awarding attorney's fees to prevailing private attorneys general will tend to increase the information reaching the tribunal, particularly when the party benefited by the rule opposes a sanction-optimizing party who is also represented by counsel. ${ }^{200}$

Whether sixth amendinent subsidies for criminal defense counsel will mcrease the information reaching tribunals depends in part on the extent to which police and prosecutors are thorough and truth-telling. ${ }^{201}$ Lack of thoroughness may result from incompetence, laziness, or scarcity of resources. Such lack of thoroughness will reduce the governinent's identification and presentation of information favorable to the defendant. The government's desire to optimize sanctions (rather than simply tell the truth) will reduce its willingness to identify and present such information. Surprismgly, judicial opinions upholding the right to counsel seldoin focus directly on these issues. Distrust of the government's thoroughness and inotives is, however, clearly an important empirical predicate of both the sixth amendinent and the Bill of Rights. ${ }^{202}$

200. See supra Section II(D). In some private attomey general cases the benefits flowing from advice may be attenuated due to agency problems resulting from how attorney fees are calculated and the plaintiff's inability to monitor her lawyer. These difficulties inay be especially acute in class actions. See generally Coffee, The Unfaithful Champion: The Plaintiff as Monitor in Shareholder Litigation, 48 LAW \& CONTEMP. ProBs. 5 (Summer 1985).

201. Prosecutors (and some other government hitigants) may differ from the parties assumed in our basic account because they have a duty to pursue the truth over victory and do not have the same consistent personal interest in optimizing expected sanctions that inost private hitigants do. To the extent this public interest duty is enforced by evidentiary rules, such as the rule requiring that a conviction be vacated or reversed wlien prosecutors have withheld inaterial exculpatory information from the defendant, see, e.g., Umited States v. Bagley, 473 U.S. 667, 674-75 (1985), our sanctionoptimizing account addresses it when we discuss evidentiary sanctions. To the extent, however, that public interest motivations are internalized by governmental litigants, such litigants are less likely to seek solely to maximize the sanctions imposed on their opponents. A prosecutor inay, for example, turn over exculpatory evidence even though, given the low probability that withholding would be detected, withholding that evidence would on balance increase the sanetions imposed on the defendant.

202. Nonetheless, some undoubtedly believe tliat prosecutors are inherently truth-telling or lawabiding. To the extent this belief is correct, advice for criminal defendants is less desirable. Those 
Conversely, the positive informational effects of subsidized advice in criminal cases will be weakened to the extent that defendants are sanction-optimizers who control or can suppress most of the information unfavorable to their cause. Undeniably, many accused wrongdoers face horrific sanctions that any reasonable person would strongly wish to minimize. In addition, the fourth and fifth amendnients afford criminal defendants opportunities not available to civil litigants to withhold or suppress unfavorable information. Both factors create uncertainty about whether the net informational effects of subsidized advice for criminal defendants are as positive as those im civil cases.

If one can identify a definable class of advice to criminal defendants that seems likely to have negative effects, it niay even seem desirable to implenent laws creating financial obstacles to acquiring that advice. For exainple, in upholding a drug forfeiture statute, the Supreine Court treated as legitimate the statutory purpose of preventing organized crime and drug enterprises from using drug proceeds to hire high-priced legal counsel, despite recognizing that this would adversely affect the quality of legal representation. ${ }^{203}$ Within our account, the statute's informational effects flow from the unilateral decrease in legal advice resulting from the difference between the high-priced counsel that defendants could afford without forfeiture and the appointed legal counsel that defendants would get with forfeiture. Our model suggests these informational effects are likely to be desirable for known drug dealers. The more difficult question, however, is whether these effects are desirable for the whole class of cases covered by the forfeiture provisions of the Continuing Criminal Enterprise (CCE) and Racketeer Influenced and Corrupt Organizations (RICO) statutes. Given the notorious vagueness of the latter in particular, ${ }^{204}$ one imight well have doubts that the statutes rehiably define a class of undesirable advice meriting restriction.

Just as distrust of the government supports providing advice to criminal defendants, a showing that the government is thorough and benignly motivated may sometimes support rules that restrict or discourage legal advice to the government's opponents in civil cases. In Walters

who behieve prosecutors are law-abiding or truth-telling would, however, do well to ask themselves to what extent their understanding of prosecutorial behavior is based on their observation of prosecutors who anticipate that the defendant will have legal advice (and who calculate the expected value of withholding, suppression, and prosecution accordingly) or who have strong moral and prudential constraints against picking the wrong defendant. The documented performance of prosecutors who imagine that their opponents will not have effective advice or who do not labor under such moral and prudential constraints is often disturbing. See, e.g., D. CARTER, ScotTsboro: A Tragedy of THE American South (2d ed. 1979); R. Frost, The Mooney CASE (1968); E. Morris, The Thin Blue Line (Miranax Films 1988) (film).

203. See Caplin \& Drysdale v. United States, 109 S. Ct. 2646, 2654-55 (1989).

204. See generally H.J., Inc. v. Northwestern Bell Tel. Co., 109 S. Ct. 2893, 2897-909 (1989) (struggling with the problen of defining a "pattern of racketeering activity"). 
v. National Association of Radiation Survivors, ${ }^{205}$ the Supreme Court held that the due process clause was not violated by a statute that prohibited claimants from paymg more than $\$ 10 \mathrm{~m}$ legal fees when seeking benefits from the Veterans Administration. The Court agreed that the statute restricted claimants' access to advice, but found the restriction justified. In part, the Court relied on statistical evidence that claimants wlio used lawyers obtained results similar to those achieved by claimants wlio used lay agents and on the Court's own judgment that most claims were relatively simple and did not require a lawyer. ${ }^{206}$ Had the Court limited itself to those arguments, the case could be seen as reflecting a rationale similar to that used in denying advice to litigants in small claims court: where legal advice makes no difference, no harm is done by restricting its availability.

Other portions of the Walters opimion, liowever, suggest that the critical factor was the Court's view of the thoroughness and motivation of the Veterans Administration. The Court repeatedly stressed that Veterans Administration proceedings were not adversarial. ${ }^{207}$ The agency was required to " assist the claimant in developing the facts pertiment to his claim" "208 and to operate with "a high degree of . . . solicitude for the claimant."209 The Court emphasized that the agency decisionmakers possessed legal, medical, and occupational expertise, as well as the resources to conduct their own investigations. ${ }^{210}$ Further, the agency's rule of decision strongly favored the claimant. ${ }^{211}$ Fimally, although the Court minimized the differences in relevant knowledge and skill between attorneys and otlier agents, it concluded that the attorney's distinctive ethical orientation miglit sometimes require her to prevent unfavorable information from reaching the tribunal. ${ }^{212}$

Our account of advice provides a framework for understanding tle Court's opimion. The Court apparently believed that the Veterans

205. 473 U.S. 305 (1985).

206. Id. at $330-31$.

207. Id. at 309, 323, 324; see id. at $324 \mathrm{n} .11$ (rejecting as unfounded the district court's finding that the process was adversarial).

208. Id. at 310 (citing 38 C.F.R. § 3.103(a) (1984)).

209. Id. at $311 ;$ cf. id. at 314 n.6 (rejecting the district court's suggestion that the Veterans Administratiou might have a conflict of interest between its solicitude for veterans and its desire to protect the public fisc).

210. Id. at 309-10.

211. Id. at 310 (citing 38 C.F.R. $\S 3.102$ (1984)) (Administration must resolve all reasonable doubts in favor of the clainant); id. at 311 (Administration must read any submission in the light most favorable to the clainant).

212. The Court cited Judge Henry Friendly for the proposition that " 'under our adversary system the role of counsel is not to make sure the truth is ascertained but to advance his client's cause by any ethical means. Within the limits of professional propriety, causing delay and sowing confusion not ouly are his right but nay be his duty.' " Id. at 325 (quoting Friendly, Some Kind of Hearing, 123 U. PA. L. REv. 1267, 1287-90 (1975)). 
Administration was a thorough truth-teller, both capable of bringing out all favorable and unfavorable inforination about the claimant's alleged injury or illness and motivated to do so. Given the Court's further assumption about the professional obhigations of lawyers, allowing claimants access to legal advice would reduce the information reaching the tribunal. It would enhance the claimant's ability to withhold and suppress unfavorable information that the agency would otherwise obtain and present, and skew the mix of information in favor of the claimant. ${ }^{213}$

As shown in Section IV(A)(3), this effect would generally benefit undeserving claimants more than it would benefit deserving claimants, because undeserving claimants normally have more unfavorable information. Moreover, the two responses available to the Veterans Adinimistration could well be harmful to deserving claimants. The Administration might adjust its own behavior to become less truth-telling. ${ }^{214}$ In that case, more claimants with valid claims would need lawyers to prevail. Alternatively, the Administration could adjust its claimant-favoring rules of decision to reduce the success rate of undeserving claimants. But because the change in information presented on account of advice would generally benefit the undeserving more than the deserving, the results with the adjustment would tend to deny deserving clainants benefits more often than undeserving claimants.

Although the Court's optimistic view of the Veterans Adininistration may have been incorrect, ${ }^{215}$ the case illustrates the possibility of a general class of cases where the government's thoroughness and benign motivation might make restricting advice to the government's opponents desirable. ${ }^{216}$ As our analysis also suggests, such restrictions on advice

213. This general phenomenon is discussed in supra Section III(B)(2).

214. The Court hinted at this fear by citing a case where a potential change in the government's presumptively benign attitude toward its adversary justified denying the right to counsel. Walters, 473 U.S. at 324 (citing Gagnon v. Scarpelli, 411 U.S. 778 (1973)). In Gagnon, the issue was whether a parolee was entitled to counsel in a revocation proceeding. The Court stressed that parole was rehabilitative rather than pumitive, and that introducing lawyers into the proceeding might cause the parole board to become "less attuned to the rehabilitative needs of the individual." See Gagnon, 411 U.S. at 787-88.

215. Withont citing any contrary evidence, the Court reversed several district court findings suggesting that the agency was neither conipetent nor benign. See supra notes 207 \& 209. Moreover, after the Court's decision, the agency was found to have destroyed or hidden documents relevant to claims against it. See National Ass'n of Radiation Survivors v. Turnage, 115 F.R.D. 543, 546 (N.D. Cal. 1987).

216. See supra Section IV(A)(3). Professor William Simon's analysis of the role of counsel in welfare hearings reaches a similar conclusion. See Simon, Legal Informality and Redistributive Politics, 19 ClEARINGHouse REv. 384, 386 (1985) (stressing the benign orientation of the welfare bureancracy and the likelihood that the presence of lawyers inay lead to rule adjustinents that disadvantage deserving claimants); see also id. at 390-91 (stating that formal welfare hearings refiected elite professional distrust of the motives and competence of working-class lower-level bureaucrats). 
will often be coupled with rules of decision favorable to the party denied advice. The relevance of government motivation may explain why restrictions on legal advice are niore tolerable as part of a prograin of government benefits. As the proponents of the "new property" have long noted, the denial of government benefits can have consequences as severe or more severe than the demal of other forms of property. ${ }^{217}$ It may, however, seem particularly likely that the government will be benignly motivated in benefits cases. This could make advice to beneficiaries undesirable despite the severity of denying benefits. Indeed, the severity of denials would only heighten the undesirability of advice because such advice makes it harder to channel scarce benefits to deserving beneficiaries.

\section{B. Attorney-Client Confidentiality}

A variety of rules protect the confidentiality of the attorney-client relationship. The attorney-client privilege generally bars compelled disclosure of the contents of communications between lawyer and client made in confidence for the purpose of getting or giving legal advice. ${ }^{218}$ The ethical obligation of confidentiality generally bars attorneys from voluntarily disclosing information harmful to their chents, no matter what its source, uuless the client insists on committing or lias committed fraud on the tribunal in order to withhold the information. ${ }^{219}$ Work product immunity provides qualified protection from discovery of documents and tangible things reflecting the results of investigation ("ordinary work product") and absolute or near absolute protection for the lawyer's professional judgments ("opinion work product"), even if those judgments are not embodied in advice communcated in confidence to the client. 220

The privilege is intended to encourage parties to conımunicate harmful information to lawyers by reducing the risk that lawyers will subsequently disclose that information to the tribunal. 221 The general obligations of confidentiality and work product immunity similarly

217. See Goldberg v. Kelly, 397 U.S. 254, 264 (1970); Reich, The New Property, 73 YaLe L.J. 733, 769 (1964).

218. UNIF. R. Evid. § 502, 13A U.L.A. 256 (1986); MCCoRMICK ON EVIDENCE $\S 87$ (E. Cleary 3d ed. 1984).

219. Model Rules, supra note 1, Rule 3.3; ABA Standing Comm. on Ethics and Professional Responsibility, Formal Op. 87-353 (1987).

220. See Special Project, The Work Product Doctrine, 68 CoRnell L. Rev. 760, 773-80 (1983) (authored by Jeff A. Anderson, Gena E. Cadieux, George E. Hays, Michael B. Hingerty \& Richard J. Kaplan); Note, The Work Product Doctrine in Subsequent Litigation, 83 Colum. L. REv. 412, 413-20 (1983) (authored by Caroline T. Mitchell). We discuss the work product doctrine more fully at infra notes 247-59 and accompanying text.

221. E.g., 8 J. Wigmore, Evidence in Trials AT Common LAW $\S 2291$, at 545 (J. McNaughton rev. ed. 1961). 
encourage parties to involve lawyers in conducting investigations and evaluating the fruits of those investigations. We will describe both decisions to communicate information directly to a lawyer and decisions to allow the attorney to learn information froin other sources as decisions to "share" information.

It is often suggested that narrowing confidentiality rules, with a concomitant expansion of the attorney's obhigation to disclose information to the tribunal or the opponent, would increase the amount of information reaching the tribunal. ${ }^{22}$ Our account assists in understanding what is at stake in this claim, because it illuminates the informational effects of the information sharing encouraged by confidentiality, the informational costs of confidentiahty where it does not affect information sharing, and the factors influencing the causal connection between confidentiality rules and information sharing. ${ }^{223}$

For clarity, we contrast two simplified regimes. The regine of absolute confidentiality neither requires nor permits attorneys to disclose information harmful to their chents' interests and requires attorneys to provide hitigation advice no inatter what their clients intend to do with it. The regime of absolute disclosure requires attorneys to disclose to the tribunal all relevant information and all information that inight lead to the identification and presentation of relevant information.224 We initially assunie that the attoruey's obligations under either regime are perfectly enforced. Thus, under the regime of absolute confidentiality, a chent's decision to share information with a lawyer never increases the likelihood that unfavorable information will reach the opponent or the tribunal. Under the regime of absolute disclosure, harmful information shared with an attorney is always disclosed. We also imitially assume that decisions to share information reflect a full understanding of the applicable rule of confidentiality or disclosure. Later, we discuss the implications of inperfect enforceinent of attorneys' obligations and imperfect client information concerning the risk that the attorney will disclose shared information.

A regime of attorney disclosure will deter a party from sharing information with her lawyer only ${ }^{225}$ where tlie party fears such sharing

222. See Frankel, The Search for Truth: An Umpireal View, 123 U. PA. L. REV. 1031, 1055-57 (1975) (evaluating this approach).

223. We limit our discussion in this Section to the informational effects of advice. To the extent that confidentiality in litigation would also promote socially desirable withholding of information, foster advice about settlement or related primary conduct, or allow the sharing of information about party preferences that would permit more satisfactory outcomes, the case for the social desirability of confidentiality would evidently be stronger.

224. This is, in essence, Judge Frankel's proposal. See Frankel, supra note 222, at 1057-58.

225. A party may also be deterred from communicating information to her lawyer by the risk that favorable information will be disclosed, if disclosure would be harmful or embarrassing independent of its effect on the merits. To the extent the communication of favorable information 
will cause unfavorable information to reach the tribunal that otherwise would not have. ${ }^{226}$ Confidentiality thus encourages a party to share information that she fears may be unfavorable or may lead to unfavorable information. ${ }^{27}$ In addition, confidentiality encourages the attorney to investigate for information that the party would dismiss as irrelevant, and thus not affirmatively share, despite the risk that such investigation may produce unfavorable information.

The information-sharing caused by confidentiality miproves the attorney's ability to give advice. ${ }^{228}$ When the party is correct that disclosing the shared information would be harmful, a lawyer operating under a regime of confidentiality will often advise her chent to withhold the shared information. But this consequence cannot be considered a cost of confidentiality nor of the advice that it facilitates, because neither the attorney nor the tribunal would have received that information in the absence of confidentiality. Without confidentiality, the lawyer would not have learned the information and would thus have had nothing to disclose to the tribunal. And if a chent would not allow her lawyer to learn information because she feared the lawyer would disclose it, she certainly would not herself disclose it directly to the opponent or the tribunal. ${ }^{229}$

The lawyer may instead advise that the information communicated is favorable, rather than unfavorable or irrelevant, and should be presented. Or she may advise that, although the shared information is unfavorable or may lead to unfavorable information, the party should produce it because either the evidentiary sanctions are higher or the degree of unfavorability is lower than the party beheved. These types of advice will increase the information reaching the tribunal. ${ }^{230}$ An

would be deterred, it strengthens the case for confidentiality, but to clarify the exposition we do not discuss it further.

226. Although our account assumes the fear of unfavorable information reaching the tribunal is necessary to deter information-sharing, we do not assume it is sufficient, even when the fear is correct. See infra note 231 and accompanying text.

227. If parties are truth-tellers rather than sanction-optimizers, they will present all information even if it is unfavorable. Thus, confidentiality does not result in more information being shared by truth-tellers. For law-abiders, however, confidentiality is important because, without it, sharing information with an attorney may result in the attorney disclosing information that the party was not lierself legally obliged to produce.

228. It may sometimes be possible for a party to receive advice about iuformation without actually sharing it. The party may, for example, ask her attorney hypothetical questions without revealing the actual facts. Our analysis assumes only that the attorney's ability to use or give advice about the information is at least somewhat impaired by the lack of actual sharing.

229. Indeed, unless the information is the type about which chents can testify, clients are unlikely even to have any opportumity to present the information directly to the tribunal.

230. A recent article justifies the attorney-chent privilege based on one specific form of beneficial advice: advice that apprises clients of a "contingent claim" that may make apparently unfavorable or irrelevant information favorable. See Allen, Grady, Polsby \& Yashko, A Positive Theory of the Attorney-Client Privilege and the Work Product Doctrine, 19 J. Legal STuD. 359, 363-69 (1990). It seems plain to us, however, that advice about contingent claims is but one subset of advice that 
information increase should also result where confidentiality facilitates attorney investigation by causing the party either to communicate information that aids the attorney's investigation or to delegate the execution of investigations to that attorney. To be sure, sharing information may also allow the identification of additional suppressible information. But soine of this suppressible information will be unfavorable (and thus suppressed) and soine favorable (and thus saved from suppression by the opponent), with ambiguous effects on the amount of information reaching the tribunal. On balance, then, advice resulting from the sharing of information caused by confidentiality should increase the information reaching the tribunal.

The information lost to the tribunal because of confidentiality will be a portion of the unfavorable information the party would share with her lawyer whether or not she was guaranteed confidentiality. Even under a regime of absolute disclosure, there are several reasons why a party might share information with her attorney notwithstanding the risk that doing so will cause unfavorable information to reach the tribunal. She may believe the information being shared is inore likely to be favorable than unfavorable, or that, given perceived evidentiary sanctions, she will have to produce the shared information anyway. Or she may beheve that the benefits of hitigation advice obtainable only by sharing information (such as the skilled execution of investigations) outweigh the risk that sharing will cause unfavorable information to reach the tribunal. ${ }^{231}$ Once the party shares the information, advice may correct the party's misperceptions that the information is favorable, overestimations of evidentiary sanctions, or underestimations of the degree of unfavorability. ${ }^{232}$ In any of these circuinstances, a regime of confidentiality will, coinpared to a regime of disclosure, result in less information reaching the tribunal. ${ }^{233}$

The net informational effects of confidentiality thus depend on

might correct party misperceptions that information is unfavorable or irrelevant. Such advice is in turn, as our textual analysis reveals, but one subset of the types of advice that can increase the information reaching the tribunal. We thus do not share the conclusion of Allen, Grady, Polsby, and Yashko that where "legal claims are not contingent ... there would be no reason to have thc privilege." Id. at 367 .

231. Cf. supra Section $\mathrm{I}(\mathrm{C})(1)$ (explaining how identifying even unfavorable information the opponent will not obtain can be helpful, and how even investigations with perceived or actual positive expected value can collect harmful unfavorable information).

232. One inportant determinant of the degree of unfavorability is the likelihood that the opponent will independently obtain and present the functional equivalent of the information. Where the attorney advises the party that this likehhood is low, the party should be more likely to withhold the information despite the threat of evidentiary sanctions.

233. Where the opponent would present the information independently, or where the unadvised party would correctly determine that information is favorable or should be produced despite its unfavorable nature, the information will reach the tribunal whether or not there is a confidentiality rule and does not contribute to the social value of compelled disclosure. 
whether the increase in information resulting from confidentialityinduced information sharing is greater than the unfavorable information lost because it would have been shared (and thus disclosed) with or without confidentiality. That tradeoff in turn depends on the extent to which confidentiality causes information sharing. If confidentiahty has no effect on information sharing, then it causes the loss of much information without offsetting informational benefits. If relatively bttle information sharing would occur without confidentiality, then relatively hittle unfavorable information is lost (because attorneys would not have much to disclose without it) but more favorable (and perhaps some unfavorable) information is gained as a result of greater information sharing.

Imperfect enforcenent of attorneys' obligations under a regime of disclosure or confidentiality may alter the extent of our conclusions but not their qualitative nature. The attractiveness of imposing disclosure obligations on attorneys is not that those obligations can be perfectly enforced, but rather that attorneys are often more susceptible to sanctions than their chents. ${ }^{234}$ As long as attorneys respond to sanctions by disclosing information more often under a regime of disclosure than a regime of confidentiality, and in some cases disclose information that the party would not, then the risk that sharing information will cause unfavorable information to reach the tribunal (and thus the disincentive to share information) will be greater under a regime of disclosure, even if enforcement is imperfect. To be sure, imperfect enforcement will decrease the extent to which disclosure obhigations discourage information sharmg. But it will also decrease the extent to which disclosure obhgations cause disclosures. It is thus anbiguous, without einpirical evidence, whether imperfect enforceinent will make a rule of disclosure more or less attractive.

Imperfect knowledge about the apphicable rules of disclosure or confidentiality (and thus about the extent of the risk that sharing information will cause unfavorable information to reach the tribunal) inakes the informational effects of confidentiality less desirable because it weakens the causal connection between the existence of confidentiality and the level of information sharing. But though the maguitude of the effects will be influenced by imperfect knowledge, the nature of the effects we describe will still hold so long as there is not complete ignorance, that is, so long as there is some positive correlation between the level of information sharing and the degree of confidentiabity.

Insofar as the causal connection depends on this awareness of the applicable rule of confidentiality, there is good reason to believe it will be stronger for attorney-chent confidentiality in litigation than for attorney-

234. See supra Section $\mathrm{II}(\mathrm{C})(2)$. 
client confidentiality in nonlitigation settings or for confidentiality rules involving other professions. A litigation lawyer under an enforceable obligation to disclose will likely recognize a larger and inore immediate risk to the client froin information sharing, will be able to calculate that risk more accurately (and where necessary communicate it more clearly to the client), and will be more concerned with the professional and personal consequences of having to make disclosures liarmful to the chient. $^{235}$

Knowledge about the risks of disclosure is, however, ouly one determimant of the causal connection between confidentiality and sharing of information. Anotler is the private value of sliaring information despite the absence of confidentiality. Thus, even if hitigants' decisions to share information are inore likely to reflect awareness of the applicable rules of confidentiality than the decisions of clients in other relations, the causal connection may still be weaker if the private value to litigants of sharing information is unusually high.

The private value of sharing information may vary for different kinds of hitigation advice. In particular, the inultiple contributions of advice to the execution of investigation or to the im-court presentation of

235. These considerations are not refuted by reports that under present confidentiality rules many clients are not advised about the details of confidentiality. See, e.g., Zacliarias, Rethinking Confidentiality, 74 Iowa L. REv. 351, 377, 379 (1989). Apart from the fact that those reports do not focus on advice im hitigation, their findings do not support an inference either that present rules do not affect information sharing or that changes im those rules would not do so. Parties may often have a general awareness of the apphicable rule of confidentiality without having been specifically advised about it. Indeed, Zacliarias' own study suggests that most clients have a general notion of lawyer-chent confidentiality, although few learned about it from their lawyers and most overestimated or underestimated its scope. Id. at 383.

A lawyer may also not bother to advise a chient about confidentiality when correcting a client's misconceptions does not seem likely to help the chent, given the benefits and risks of sharing information. Furthermore, if a client's misconceptions will cause a liarmful failure to share information, advice that confidentiality is absolute, although technically inaccurate and arguably paternalistic, may be more efficient, more likely to inducc helpful sharing of information, and, under present rules, substantively correct for most chents most of the time. If a client's misconceptions will cause harmful sharing, the attorney may find it inore efficient and tactful simply not to inquire into a particular subject or to halt information sharing about that subject, witlout explaining the law of confidentiality. The imprecision of chents' understanding and of lawyers' advice about confidentiality therefore may demonstrate only that, under existing rules, few serious issues arise, or that when such issues arise lawyers are able to advance their clients' interest in sharing or not sharing information without fully explaining those rules.

In fact, the only study of which we are aware that has observed lawyer-client interaction in litigation suggests that sanctioning attorneys for withholding information has a significant impact on information sharing. Professor Mann's study of white-collar criminal defense attorneys showed that they sometimes avoided inquiry into subjects when they believed the client was likely to share unfavorable information. See K. MaNN, supra note 30, at 103-11. Althougl these attorneys operated under the strong confidentiality rules of the New York Code of Professional Responsibility, their fear that prosecutors might detect and sanction misstatements made in plea bargaining negotiations sometimes caused thein to remain intentionally ignorant of their client's information so that they could avoid disclosure of unfavorable information in those negotiations. Id. at 83 . 
information from nonparties normally cannot fully be realized unless the party delegates the conduct of those activities to her lawyer and shares with her the information required to make that delegation effective. Because this increases the likelihood that such information sharing wonld take place without confidentiality, reduced protection may be appropriate. This inay explain why the law provides less protection for information an attorney learns from persons other than the chent, which is exempt only from voluntary disclosure by the attorney, while information an attorney learns from chient communications is exempt even from compelled disclosure. ${ }^{236}$

This analysis does not pretend to demonstrate the desirability of a rule of absolute confidentiality, let alone of the present confidentiality rules. Such a demonstration would, at a minimum, require better empirical evidence about the causal counection between confidentiality and information sharing. Our aim is rather to frame the inquiry more accurately. In particular, the analysis deinonstrates the error of confiating the issue of the effects and desirability of litigation advice generally with the issue of the effects and desirability of attorney-client confidentiality in litigation. In our account, the informational effects of litigation advice are, on balance, socially desirable, but the informational effects of confidentiality are uncertain because of empirical questions about the effect of confidentiality on the willingness of parties to share information with their lawyers.

But even if it were true that, on balance, litigation advice has ambiguous informational effects, it would not follow, as Professors Kaplow and Shavell have argued, that the case for attorney-client confidentiality in litigation is a priori the "weakest" of any privilege. ${ }^{237}$ Even in Kaplow and Shavell's simplified model of advice, which considers ouly the effect of advice about categorization upon the production of information that is effectively party-controlled, confidentiality should encourage the party to share with her lawyer some information the party fears is unfavorable. Where the party's fears are correct, the advised party will not present unfavorable information. But that cannot be deemed a cost of confidentiahty since the party would not present information to the tribunal that she would not disclose to her attorney solely because of the risk the attorney would disclose it to the tribunal. Where, however, the shared information is actually favorable, the lawyer will advise that it should be presented. The sharing of information induced by confidentiality should, under Kaplow and Shavell's model, thus increase the presentation of favorable information without reducing that of unfavorable

236. See supra note 45; supra text accompanying notes 218-20; infra note 249 and accompanying text.

237. Kaplow \& Shavell, supra note 17 , at $600 \mathrm{n} .84$. 
information. ${ }^{238}$ Confidentiality should, on the other hand, prevent the lawyer from disclosing some unfavorable information that the party would have shared even without confidentiality.

Thus, as in our account, the effects and desirability of confidentiality in Kaplow and Shavell's model depend critically on the extent to which parties would share information with their lawyers $m$ the absence of confidentiality. If the causal connection between confidentiality and information sharing is strong, then the privilege will cause a strong increase in favorable information presented, with hittle loss of unfavorable information. This is normally desirable under any theory of adjudication, at least if both parties have lawyers. ${ }^{239}$ While it is true that their model-like ours-provides no a priori reason to think that the favorable information gained because of attorney-chent confidentiality is worth the unfavorable information lost, that a priori ambiguity exists for all privileges: we can

238. Kaplow and Shavell reach their conclusion that litigation advice presents the weakest case for protected confidentiality because they argue that the social value of some advice, like medical advice, is clear, whereas the social value of hitigation advice is ambiguous. See id. at 600 . Accordingly, they secm to reason that, while other privileges at least generate some clear social benefit to offset against the information lost because of confidentiality, privileging litigation advice may generate no benefit to weigh against the information lost. See id. at 600 \& n.84, 610 \& n.116.

This is wrong on two scores. First, it erroneously conflates the effects of advice encouraged by confidentiality with the effects of advice generally. Even if the Kaplow/Shavell model aceurately captured the real world, and litigation advice ambiguously increased favorable information and decreased unfavorable information, the analysis in text demonstrates that the effects of the litigation advice encouraged by confidentiality would be an imcrease in favorable information without any decrease in unfavorable information. Such an increase in favorable information standing alone is ordinarily desirable for the reasons articulated in Part IV. To be sure, this social gain from the communications encouraged by hitigation advice must be weighed against the loss of information from the communications that would have occurred even without confidentiality. But that is no different from weighing the social gain of the doctor-patient communications encouraged by confidentiality against the loss of information from doctor-patient commumications that would have occurred even without confidentiality.

Second, the social desirability of encouraging medical advice is not always so clear-cut. Medical eare is often wasteful or excessively costly and can cause injury. See I. ILliCh, Medical Nemesis (1976) (arguing that the medieal system creates more illness than it relieves). Medical care can also restore the health of bad people who go on to commit bad acts. Finally, medieal advice can be abused for purposes that have nothing to do with good health: for example, fraud rings use medical advice to trump up personal imjury claims. Indeed, such dubious uses of medical advice may seem particularly likely when patients would not confide in doctors without assurances that their communications would be kept from a tribunal.

239. Perhaps Kaplow and Shavell would go further, and contend that even a bilateral increase in information presented to the tribunal is socially ambiguous, based on their assumption that parties are unaware of any increases in the accuracy of adjudication resulting from legal advice at the time parties engage in primary conduct. See Kaplow \& Shavell, supra note 17, at 588.90, 610. We have already argued that the assumption that parties are, at the time they act, generally ignorant of court outcomes is implausible, and that, even if the assumption were accurate, increased accuracy would still be desirable under theories of adjudication that stress corrective justice, prevention of harm, or fairness. See supra Part IV. More importantly here, if informational increases have ambiguous social value, then that ambiguity attaches both to the benefits and the costs of confidentiality. Thus, it offers no grounds for concluding that the attorney-client relation in litigation presents the weakest case for confidentiality. 
never know whether the benefits resulting froin facilitated communications are worth the costs of the information lost without knowing the extent to which confidentiality facilitates communications. ${ }^{240}$

Although our account of confidentiality cannot justify the precise contours of present doctrine, it, does generate some rough predictions about those contours. First, our account predicts that there should be no confidentiality protection for information that clients will normally disclose to lawyers witl or without confidentiality. This prediction is clearly consistent with the requirement that to receive protection under the privilege, client communications seeking legal advice must be made "in confidence." 241 It may also help explain why the attorney-chent privilege generally does not protect a chent's identity. ${ }^{242}$ Presumably most chents would commumicate their identity to the lawyer with or without a guarantee of confidentiality in order to secure representation: in such cases, the privilege would deprive the tribunal of information without increasing the flow of legal advice to the chent. It is also consistent with our analysis that the general rule about chent identity has an exception where the chent's identity is the "last link" in proving a crime. ${ }^{243}$ The "last link" exception appears to identify a relatively narrow set of circumstances in which it is highly likely that lack of confidentiality would deter a client froin seeking advice: when lier identity is all the government needs to impose criminal sanctions.

Second, our account suggests that confidentiality sliould be restricted when the additional advice facilitated by information sharing is highly hikely to lead to the presentation of false evidence or the withholding or suppression of truthful information. Evidently this is consistent with the exception to the privilege in cases where the chent sought advice in aid of conduct that he knew or reasonably should have known was criminal or fraudulent ${ }^{244}$ and with the exceptions to some general confidentiahty rules requiring lawyer disclosure of unfavorable information to prevent or remedy the use of the lawyer's services in offering known false evidence. $^{245}$ It may also help explain the otlierwise anomalous rule

240. See generally Developments in the Law-Privileged Communications, 98 HaRv. L. REv. $1450,1471-500$ (1985) (explaining why the a priori desirability of any privilege cannot be determined under a variety of utilitarian and nonutilitarian theories).

241. See, e.g., $8 \mathrm{~J}$. WIGMORE, supra note 221 , $\$ 2311$.

242. In re Michaelson, 511 F.2d 882, 889 (9th Cir.), cert. denied, 421 U.S. 978 (1975); 8 J. WIGMORE, supra note $221, \S 2313$.

243. United States v. Hodge \& Zweig, 548 F.2d 1347, 1353 (9th Cir. 1977).

244. See UNIF. R. EVID. § 502(d)(1), 13A U.L.A. 257 (1986); 8 J. WIGMORE, supra note 221, $\S 2298$.

245. See MODEL RuLES, supra note 1, Rule 3.3. The disclosure obligations in Rule 3.3 are express exceptions to the general confidentiality obligations establislied in Model Rule 1.6. Id. Rule 3.3(d). The Model Code of Professional Responsibility does not permit attorneys to present or assist in presenting known false evidence. MoDEL CODE, supra note 2, DR 7-102(A)(4), (6), (7). But in 
requiring criminal defense attorneys in possession of physical evidence of a crime to turn it over to the prosecutor. ${ }^{246}$ The apparent effect of that rule is to reduce the extent to which lawyers examine, nove, or analyze apparently incriminating physical evidence. This effect may be socially desirable if the attorney advice in such cases would normally result in suppression of evidence. Because the consequences flowing froin the prosecution's discovery of incriminating physical evidence will often be severe, because physical evidence may often be relatively easy to suppress, and because the fifth amendment inay well reduce evidentiary sanctions for client suppression, the thesis that such advice is hikely to lead to suppression is relatively plausible. If, however, nuch physical information that appears incriminating actually proves on investigation to be exculpatory, then the rule may also deter advice that would increase the presentation of truthful information. The apparent wide acceptance of the rule may reflect "hindsight bias" resulting froin the fact that challenges to the rule occurred in cases where defendants were found guilty and where the relevant physical information was clearly inculpatory.

Our account also provides a clearer understanding of the justification for work product immunity. A recent rational actor account justifies the work product immunity on the ground that it increases the production of information to the tribunal by encouraging investigations that risk uncoverimg botll favorable and unfavorable information. ${ }^{247}$ Without an immunity, the account argues, hitigants may have an insufficient incentive to investigate in such cases of "joint production."248 As apphed to fact investigation, there appears to be a serious doctrinal objection to this theory: if work product immunity is intended to encourage parties to risk uncovering unfavorable factual information, then it should protect that information froin discovery. But the Supreine Court's statement of the doctrine and later cases interpreting amended Rule 26 of the Federal Rules of Civil Procedure both expressly state that the immunity does not protect information identified in investigation froin discovery. ${ }^{249}$

A inore plausible theory of the relation between work product

the name of confidentiality, it sharply restricts the lawyer's ability to correct known false evidence that the client lias already presented in the course of the representation. Id. DR 7-102(B)(1).

246. See supra note 90 (citing cases following this rule).

247. Allen, Grady, Polsby \& Yashko, supra note 230, at 385-87.

248. Id. at $385-86$.

249. The Court in Hickman v. Taylor, 329 U.S. 495 (1947), stated that interrogatories drawn with sufficient breadth can oblige a party to disclose "all pertinent information gleaned by [the party's lawyer] through his interviews with the witnesses," id. at 508-09, and that "searcling interrogatories" serve to reveal the "facts" in the lawyer's possession, id. at 513. The same result apparently follows under Federal Rule of Civil Procedure 26(b)(3). See 8 C. WRIGHT \& A. MILLER, Federal Practice and Procedure § 2023, at 194 \& nn.16 \& 17 (1970 \& Supp. 1990) (citing cases); 4 MOORE's Federal. Practice đI 26.64[1], at 26-348 (3d ed. 1989) (citing cases). 
immunity and the production of information would begin with a clearer understanding of what the immunity protects. Clearly the rule protects "docunients and tangible things" prepared in anticipation of litigation by a party or her agents, including lier lawyer. ${ }^{250}$ It also accords absolute or near-absolute protection to docuinents or tangible things that reflect the "mental impressions, conclusions, opinions and legal theories" of the party's lawyer. ${ }^{251}$ Finally, in the view of some, the rule also protects-or at least ought to protect-the mental impressions and opinions of the party's lawyer even when they are not recorded or reflected in a document or tangible thing. ${ }^{252}$ As it applies to factual imvestigation, then, the central thrust of the doctrine is to lower the risks associated with recording, manipulating, and analyzing information, ratler than the risks of learning that information in investigation. Moreover, the absolute or near-absolute protection afforded to the opimions and mental inipressions of attorneys reflects special concern with encouraging parties to use attorneys to manipulate and evaluate information in situations where the privilege would not apply.

The general effect of the conduct encouraged by the immunity is thus to enhance party preparation, and in particular to enhance the effects of legal advice across the full range of preparatory activities that influence the information reaching the tribunal. On balance, our account predicts that the additional preparation encouraged by the immunitywhether or not perforined by a lawyer ${ }^{253}$-ought to increase the amount of information presented, althougli the overall positive effect should be most pronounced where the rule causes additional lawyer involvement. In our account, however, that overall increase in inforination presented will reflect a mix of conflicting effects of advice, rather than a simple increase in investigation. Moreover, to the extent that the immunity increases imvestigation, it will do so not by protectimg inforination discovered in investigation from disclosure, but by decreasing the costs of party efforts to identify and execute appropriate investigative strategies and to evaluate and manipulate the fruits of those investigations.

Finally, it is iniportant to recall that the social value of work prod-

250. Fed. R. Crv. P. 26(b)(3).

251. Id.; Upjohn Corp. v. United States, 449 U.S. 383, 400-02 (1981) (recognizing that such materials are entitled to "special protection" but declining to decide whether they are absolutely protected).

252. Shapiro, supra note 45 , at 1071.

253. Nonlawyers often have legal knowledge that can improve the presentation of a party's case. Even when they do not, their ability to record the resnlts of their investigations without fear that doing so will ease the opponent's task should enhance the ability of those who are legally trained to make effective use of their work. The suggestion by Allen, Grady, Polsby, and Yashko that the extension of imınunity to the product of nonlawyer investigators is difficult to explain except in terms of their "joint production" theory, is thus inaccurate. Allen, Grady, Polsby \& Yashko, supra note 230 , at 391 . 
uct immunity is not established simply by showing that the conduct caused by granting immunity increases the information reaching the tribunal. One must also ask how nuuch of that preparation would take place in the absence of the immunity. If the niarginal effects are slight, then they inay not be worth the cost of the information lost on account of the immunity. In this connection it is relevant both that parties have very strong incentives to prepare their cases even in the absence of an immunity $^{254}$ and that an ill-judged statenient in an internal memorandum or draft can be capitalized upon by a conpetent opponent with devastating effects. In Hickman v. Taylor, the Suprenie Court appears to have adopted the view that the latter threat was sufficiently strong that it would significantly change preparation practices. ${ }^{255}$ To the extent that this view is correct, the work product doctrine appears to have substantial social value.

Like our general account of confidentiality, our account of work product predicts that work product protection will be denied where it will not significantly increase the net private benefits of recording, nianipulating, and analyzimg information. The limitation of the imnumity to materials prepared "in anticipation of higation" is consistent with this prediction. The deterrent effect of discovery requests fron the opponent is evidently heightened when the recording and analysis of infornation take place in the shadow of a ripening controversy with a specific opponent. ${ }^{256}$ Our account also predicts that work product protection will be denied when there is no prospect that the additional preparation facilitated by protection will nicrease the flow of information to the tribunal. The rule allowing for contention interrogatories ${ }^{257}$ and court decisions allowing for discovery of trial exhibits ${ }^{258}$ may be consistent with this prediction. A party's theory of the case and her trial exhib-

254. See Waits, Work Product Protection for Witness Statements: Time for Abolition, 1985 Wis. L. REV. 305, 331-35 (parties have sufficient incentives to prepare without work product immunity); Easterbrook, Insider Trading, Secret Agents, Evidentiary Privileges and the Production of Information, 1981 Sup. CT. REV. 309, 362 (same).

255. See Hickman, 329 U.S. at 511 (Without immunity "much of what is now put down in writing would remain unwritten" and "[i]nefficicncy, unfaimess and sharp practices would inevitably develop in the giving of legal advice and in the preparation of cases for trial.").

256. Accord Allen, Grady, Polsby \& Yashko, supra note 230, at 392. Those authors are, however, mistaken in suggesting that the limitation to documents and things "prepared in anticipation of hitigation ... is one of the most inportant pieces of evidence in support of the joint production theory." Id. The same linitation (or something very much like it) should apply in any account of work product which assumes (1) that the activities encouraged by granting inmunity generally are socially desirable, and (2) that allowing a litigation opponent to discover the results of those activities significantly reduces their private value.

257. FED. R. CIV. P. 33(b) (allowing interrogatories that call for "an opinion or contention that relates to fact or the application of law to fact"). Significantly, such interrogatories are normally disfavored if propounded too early in the trial preparation process. In re Convergent Tech. Sec. Litigation, 108 F.R.D. 328, 333-38 (N.D. Cal. 1985).

258. Ziminerman v. Superior Court, 402 P.2d 212 (Ariz. 1965). 
its both reflect the party's preparatory efforts and the lawyer's expertise in inanipulating and evaluating information. When a party has had full discovery and a fair opportunity to prepare her case, however, preparatory activity will inevitably reach a point of diminishing returns. To protect the party's case beyond that point serves only to allow the party to surprise her opponent. The working assumption of the Federal Rules of Civil Procedure appears to be that surprise normally reduces the flow of truthful information to the tribunal and increases the flow of false inforination. ${ }^{259}$ On that assuinption, to extend the protection of a party's contentions and trial exhibits past the point of diminishing returns to preparation would reduce rather than increase the information reaching the tribunal.

\section{Restrictions on Advice About Responding to Investigation}

Soine advice about responding to investigation (or other questioning) reduces the information reaching the tribunal. One might therefore think that it would be desirable to ban or restrict only such advice, while allowing other litigation advice with more desirable effects. ${ }^{260}$ It turns out, however, that it is difficult to prohibit advice about responding to investigation without encompassing or deterring other advice that has socially desirable informational or behavioral effects. We employ our account to explore these issues for both civil and criminal cases.

Advice about responding to investigation (or questioning) can reduce the unfavorable information reaching the tribunal in three ways. First, advice about whether information is favorable or unfavorable will cause the party to withhold more unfavorable information that is unrequested or party-controlled. Second, advice can lower the party's expected sanctions for withholding information, thus increasing the amount of information she controls and withholds. Third, advice about the level of expected evidentiary sanctions can reduce the amount of unfavorable information the party discloses if parties overestimate those sanctions.

One might atteinpt to prevent advice likely to lead to such untoward

259. See, e.g., 8 C. WRIGHT \& A. MilleR, supra note 249 , $\$ 2001$, at 17 \& n.16. The conclusion that reducing surprise will improve the quality or quantity of information reaching the tribunal is not obvious. Surprise reduces the amount of time available for an opponent to investigate the facts underlying the party's presentation and to prepare a response. It therefore makes it more likely that the tribunal will receive only the information favorable to the party who benefits from surprise. For the same reason, surprise reduces the party's expected sanctions for presenting favorable false information. But rules permitting surprise may also increase the information reaching the tribunal by increasing the opponent's incentive to prepare its own ease or by enabling a party to catch an opponent's witness in a he.

260. Kaplow and Shavell, for example, put forth (without advocating) the possibihity of deposing parties before allowing them to consult an attoruey. Kaplow \& Shavell, supra note 17, at 613 . 
results by formulating restrictions on the provision of advice that can be enforced without inquiring into the content of attorney-client communications. ${ }^{261}$ Complete restrictions on advice about responding to investigation may, however, also deter other desirable advice. Parties receive a great deal of advice about whether information is favorable or unfavorable in connection with advice about the conduct of their own investigations. This advice should increase the amount of information reaching the tribunal. Parties also receive advice about how to categorize information that is integral to desirable advice about settleinent and related primary conduct. To the extent that a ban on harmful advice about responding to investigation will encompass or deter such desirable advice, restrictions may liave to be limited to special situations where they can be narrowly targeted and easily enforced. This, as we will show, is what the law in fact does.

Even if restrictions can be narrowly targeted to advice about responding to investigation, they may result in several adverse informational and behavioral effects. First, denying advice to the responding party will reduce the opponent's expected sanctions for suppressing information, and thus increase the opponent's suppression of information favorable to the party denied advice. Second, the unadvised party will recognize, categorize, and present less favorable information divulged in investigation by the opponent. Third, the lack of advice will increase the party's mistaken failure to produce favorable information. Although the party may later be advised that the omitted information is favorable, subsequent presentation may be infeasible or disconnted by the tribunal, particularly if the party withheld the information by lymg. Fourth, if parties without advice systematically nnderestinnate evidentiary sanctions, depriving the party of litigation advice will decrease the favorable and unfavorable information reaching the tribunal. ${ }^{262}$

The rules regulating the provision of litigation advice reflect an awareness of these considerations. The easiest place to enforce restrictions on advice is at trial. When a witness is actually on the stand, advice must be provided in public and in the tribunal's presence. Moreover, restrictions on advising witnesses can easily be monitored, provided that they are limited in tinne. Accordingly, rules governing the exannination of witnesses at trial sharply restrict advice to a testifying witness. Law-

261. Such an approach is ex ante in the sense that it attempts to prevent the legal advice from ever being provided. Another approach would be ex post in that it would allow legal advice to be provided but would only punish legal advice on how to reduce the information presented. Such an ex post approach would require observing attorney-client conferences or relying on reports of what occurred in them. This would raise issues discussed in supra Section V(B).

262. In addition to these informational effects, the party denied advice will experience an increase in expected sanctions for desirable withholding and for desirable production that resembles undesirable withholding. 
yers may not ask leading questions of a friendly witness on direct examination: this effectively forbids advice during direct examination about whether information is favorable or unfavorable. More important, when witnesses are responding to cross-examination, lawyers cannot make "leading" objections that suggest whether particular information is favorable or unfavorable. In some cases, sequestration orders may bar lawyers froin speaking with a witness on any topic between the time that the witness takes the oath and the time she is excused.

Restrictions on leading questions avoid inany of the adverse informational effects of more general bans on responding to investigation. Because the opponent is not conducting the investigation, denying advice will not increase opponent suppression or reduce recognition of information divulged by the opponent. Although the party or witness may mistakenly omit favorable information, that effect will be amehorated by the attorney's ability to ask additional nonleading questions. Nor does the restriction threaten advice about investigation, settleinent, or primary conduct.

Restrictions on advice about responding to cross-examination also seem likely to generate substantial additional information while avoiding most adverse effects. Once a witness has testified on direct for the party who called her, she is likely to have produced almost all the information favorable to that party. Accordingly, information she has not presented is likely to be unfavorable. Denying advice about potential testimony on cross-examination should thus increase the amount of unfavorable information reaching the tribunal. The costs of this increase are probably small. Because cross-examination takes place before the party's lawyer and the tribunal, it should be possible to detect and sanction opponent suppression, to recognize unfavorable information divulged by the opponent, and to facilitate socially desirable withholding by objecting to questions that call for privileged information or are unduly coercive. Again, the reduction will not encoinpass advice to a party witness about investigation, settlement, or primary conduct.

So long as rules restricting advice to witnesses apply only when the witness is on the stand, they can be closely tailored to target only advice with doubtful informational effects. When rules about advice to witnesses extend beyond the time when the witness is on the stand, however, they pose difficult probleins of enforceability and scope, particularly for party witnesses.

The problein is illustrated by Perry v. Leeke, ${ }^{263}$ where the Supreme Court held that a criminal defendant's sixth ainendinent right to counsel was not violated by a court order that barred the defendant from consult-

263. 488 U.S. 272 (1989). 
ing with his lawyer during a fifteen-minute break between the end of his testimony on direct examination and the commencement of crossexamination. In upholding the order, the Court expressly rejected the notion that the validity of the order required a showing that the lawyer was likely to engage in "unethical" conduct. ${ }^{264}$ Rather it was "simply an empirical predicate" of the adversary system that cross-examination of an uncounseled witness is more likely to lead to the discovery of truth. ${ }^{265}$ It was therefore sufficient to justify the order that legal advice would enable the party "to regroup and regain a poise and sense of strategy that the unaided witness would not possess."266 The Court distinguished its earher decision in Geders v. United States, ${ }^{267}$ which had mvahidated an order barring all consultation during an eighteen-hour overnight recess, reasoning that consultation during a longer break would "encompass matters that go beyond the content of the defendant's own testimony ... such as the availability of other witnesses, trial tactics, or even the possibility of negotiatimg a plea bargain."268 In contrast, during a fifteenminute break, "it is appropriate to presume that nothing but the testimony will be discussed."269

The reasoning in Perry, and its distinction between fifteen-minute and eighteen-hour recesses, is consistent with the analysis offered here. Because a party who has completed her direct examination has already presented her favorable inforination, the predominant effect of advice about whether information is favorable or unfavorable or advice about how to shape her testimony to lower evidentiary sanctions will be a reduction in unfavorable inforination reaching the tribunal. This effect occurs whether or not the advice given to her is technically "unethical" in the sense that it amounts to "knowing" assistance in perjury. Moreover, on the Court's assumption that during a fifteen-minute break between direct and cross-examination the defendant's testimony would be the only topic of conversation, the order upheld in Perry posed no risk of deterring desirable advice about investigation or settlement. In the case of an overnight eighteen-hour ban on advice, however, the risk of preventing desirable advice may be mcreased sufficiently to justify the holding of unconstitutionahty, notwithstanding the risk (which the Court expressly recognized) that advice given during an overinght consultation would reduce the amount of information reaching the tribunal just as effectively as advice given during a fifteen-minute break in testimony. ${ }^{270}$

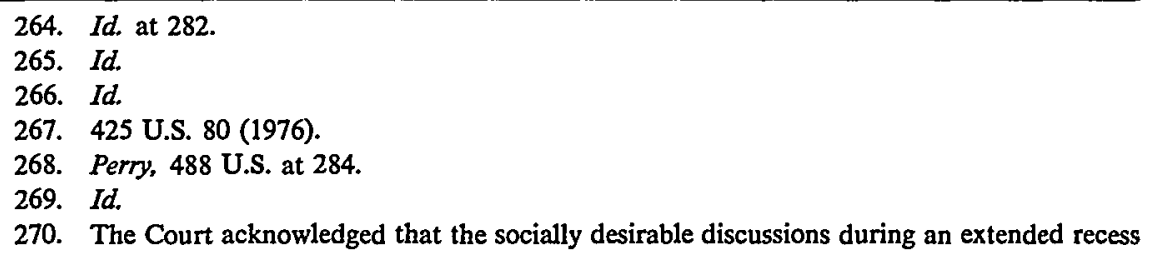


As Perry suggests, outside the courtroom it is extremely difficult to craft enforceable restrictions on advice about responding to investigations without deterring desirable advice. Again the problem is most acute for party witnesses. Once investigation moves outside the presence of the tribunal, the opponent's opportunity and incentive to suppress favorable information presented by the party increase. The informational costs of denying advice to the responding party increase accordingly. It also becomes more difficult to prevent parties from obtaining hitigation advice without barring desirable consultations about related primary conduct, settlement, or the party's own investigations. This is particularly true in civil litigation, because parties normally consult lawyers about whether to abandon, settle, or litigate their claim before an action is filed. Thus each party will already have received a good deal of advice before the tribunal is involved in any way. Since inany disputes in which lawyers are consulted settle before filing, the task of momitoring this advice would be enormous. Once a case has commenced, most parties receive additional advice about settlement and investigation, and many receive advice about related primary conduct.

Since narrowly targeted restrictions on out-of-court advice would likely be ineffective and unenforceable and because broader restrictions would bar too much desirable advice, it makes sense that outside the courtroom parties are normally free to obtain advice about responding to investigation-subject only to the normal prohibition agamst advice that amounts to knowing assistance in crime or fraud. It is also consistent with this analysis, however, that the law severely restricts giving such non-courtroom litigation advice to persons other than the client. It is often a disciplinary offense and sometimes a crime for a lawyer to provide accurate advice to a nonparty with the intention of causing the nonparty to withhold or destroy relevant evidence, even where such withholding or destruction is lawful. ${ }^{271}$ In such cases, the fact that the advice about responding to investigation is directed to a nonparty makes it easier to determine the likelihood that it will reduce the amount of information reaching the tribunal and also ensures that prohibiting the advice will not reduce the flow of desirable advice to the lawyer's chient. Moreover, in most cases the prohibition of advice to the nonparty will not prevent her froin obtaining advice from another, more disinterested source.

So far as we know, the foregoimg exainples represent the only cases in which hitigation advice is expressly prohibited due to its informational

"will inevitably include some consideration of the defendant's ongoing testimony," but concluded that this "does not compromise" the defendant's right to unrestricted access to her lawyer during a longer recess. Id.

271. See supra note 39. 
effects. Our account, however, should also assist in evaluating nuinerous other legal rules that encourage or limit advice about responding to investigation. In civil cases, these include the rule that prohibits a lawyer from knowingly commumcating with a represented party concerning the subject of the representation without the consent of the party's lawyer. ${ }^{272}$ In criminal cases, they include fifth and sixth amendment rules that govern the existence, invocation, and waiver of the criminal defendant's right to counsel before and after indictınent. ${ }^{273}$

Depending on the inotivations and knowledge of the parties and the amount of information that is party-controlled or suppressible, such rules inay have important informational effects. For example, if inost criminal defendants routinely overestimate how favorable their information is ${ }^{274}$ or overestimate the sanctions for keeping silent in the face of custodial interrogation, ${ }^{275}$ rules that inake it easy to waive the pre-indictment right to counsel under the fifth amendment will increase the party-controlled unfavorable information reaching the tribunal. ${ }^{276}$ This should generally hurt the innocent less than the guilty. On the other hand, if police officials conducting a custodial investigation are willing and able to suppress information favorable to the defendant and a substantial amount of the information likely to be uncovered in a custodial investigation is suppressible, ${ }^{277}$ a relaxed waiver rule inay reduce the governinent's expected

272. See Model RulES, supra note 1, Rule 4.2; MODEL CoDE, supra note 2, DR 7-104(A)(1).

273. Under the fifth amendment, a party in custodial interrogation must be advised of her right to counsel, Miranda v. Arizona, 384 U.S. 436, 467 (1966), and cannot be interrogated if she invokes that right, Edwards v. Arizona, 451 U.S. 477,484 (1981). Under the sixth amendment, a defendant has a right to counsel during any post-indictment imterrogation, Massiah v. United States, 377 U.S. 201, 206 (1964), or post-imdictment lineup, United States v. Wade, 388 U.S. 218, 237 (1967).

274. Indeed, even if party errors are unbiased, advice given in connection with investigation that corrects the suspect's mistakes about whether information is favorable or unfavorable nay reduce the unfavorable information presented. If the party under investigation mistakenly believes that her information is, on balance, unfavorable, so that she claims the privilege, advice about responding to investigation would cause her to change her decision. Unless later presentation of the information will be infeasible or discounted, however, this will affect only the timing of her decision to produce, since the lawyer appointed for her later in the case will also counsel her to disclose the information. Ill-advised decisions to present unfavorable information, however, may well be more difficult to reverse. Accordingly, unless favorable information that is withheld during an initial interview will be discounted, denying advice about whether information is favorable or unfavorable will increase the flow of information to the tribunal.

275. Under the line of cases following Griffin v. Califormia, 380 U.S. 609 (1965), and Doyle v. Ohio, 426 U.S. 610 (1976), the government's right to make use of silence following Miranda warnings, even for impeachment purposes, is extremely limited. Thus silence, at least for the period required to consult a lawyer, is essentially costless. It therefore seeins quite likely that overestimating the costs is inore cominon than underestinuation, and that allowing easy waivers of counsel will have the positive effects described in text.

276. See generally Stuntz, Waiving Rights in Criminal Procedure, 75 VA. L. REv. 761 (1989) (discussing the effeets of waiver).

277. Concern with the government's opportunity and notive to suppress information favorable to the defendant has sonetimes figured in the Court's decisions concerning the right to counsel in pretrial investigation. For example, in United States v. Ash, 413 U.S. 300 (1973), the Supreme 
sanctions for suppressing that information. That effect would reduce the amount of favorable information reaching the tribunal, harming the innocent more than the guilty. While thc outcome of these calculations cannot by itself determine the social desirability of the waiver rule chosen, its relevance is clear.

\section{CONCLUSION}

In a hiberal society, it is widely beheved that it is desirable, indeed essential, for citizens to know the law. ${ }^{278}$ We have attempted to determine the conditions under which that behef might be justified for legal advice about the hitigation of factual disputes in an adversary systen. While the inatter ultimately turns on difficult empirical questions, our overall conclusion is positive. Much litigation advice appears to have desirable informational and behavioral effects, and advice with undesirable or ambiguous effects is often difficult to regulate without deterring desirable advice. Our positive general conclusion is striking because it is derived despite the adoption of the cynical premise that hitigants and lawyers recognize no duty to obey the law, and indeed suppress or withhold information whenever it furthers their own interests. If parties are generally more law-abiding or truthful than our basic account assuines, then the effects of advice may be even more desirable.

Our conclusions, however, are richer and more refined than this general statement suggests. Indeed, a principal lesson of our analysis is that one cannot make responsible judgments about the desirability of legal advice or its regulation without attention to multiple and mixed effects. The complexity of our account stands as a rebuke to both simphistic defenders and simplistic critics of advice who reach sweeping judgments about its general desirability based on partial descriptions of its effects. In many cases, our account suggests hitherto unrecognized weaknesses and complications in arguments that have classically played a central role in the debate about the adversary system.

Defenders of advice, for example, frequently point to the value of

Court held that the sixth amendment did not entitle defense counsel to attend post-indictment sessions where a witness sought to identify the defendant from an array of photographs. In distinguishing such sessions from post-indictunent lineups (where the right to counsel does apply) the Court argued that the defense counsel's opportunity to cross-examine the persons involved in the photo session at trial could "serve as a substitnte for counsel at the pretrial confrontation." Id. at 316; see also id. at 324 (Stewart, J., concurring) (arguing that improper influence from use of photographs can be "readily reconstructed at trial"). This arguably reflects the judgment either that information cannot be effectively suppressed in a photographic lineup, or that expected sanctions for suppression were already sufficiently high to deter suppression without the presence of counsel. The majority also stressed that the "ethical responsibility of the prosecutor" would tend to mimimize exploitation of opportunities to suppress. Id. at 320.

278. See L. Fuller, The Morality of Law $49-51$ (1964). 
competition im improving the presentation of information to the tribunal. ${ }^{279}$ Our account suggests that legally advised competition between the parties will often have that effect, especially in the case of nonsuppressible information available to both parties. But competition can sometimes result in a reduction of information reaching the tribunal. Whether advice increases or decreases the coinpetitive presentation of information turns out to depend on empirical questions about whether information is suppressible, who has access to it, and the misconceptions entertained by unadvised parties. Defenders of advice would do well to look more closely at those questions.

Critics of the system, on the other hand, frequently stress the harmful or doubtful effects of advice that is not balanced between the parties. ${ }^{280}$ Our account confirms that when both parties have comparable advice, the positive effects of advice are more robust. ${ }^{281}$ It also confirms that imbalances may have harmful or doubtful effects, particularly because they increase the ability of the nore knowledgeable party to present false or prejudicial information and to impose costs on her opponent. But we also show that even unbalanced advice has a strong general tendency to benefit those who have acted desirably more than it benefits those who have acted undesirably. This will inost clearly be socially desirable if the tribunal can make appropriate adjustments to its rules of decision. In a substantial range of cases, imbalances of representation may therefore produce results superior to those that would be possible if both parties were demied advice.

Beyond providimg a more sophisticated understanding of general claims about the effects of advice, our account also explains many of the problems that arise in regulating it. It points to some siguificant classes of cases where broad restrictions on advice may be socially desirable. It also identifies several narrowly limited classes of advice, including advice to testifying witnesses and advice to nonchent witnesses, which are so likely to be harmful and so easily targeted that rules barring such advice inay well be socially desirable. We also provide a clear framework for assessing rules of attorney-client confidentiahty, which accurately identifies the nature of the tradeoffs required by such rules and the empirical questions that determine whether those tradeoffs will be worthwhile.

279. E.g., R. POSNER, supra note 15, at 491-93.

280. See, e.g., sources cited supra notes 10-13.

281. See supra Section II(D). 